\title{
FACE-TO-FACE, ONLINE, AND HYBRID DESIGNS \\ FOR MENTORING
}

A Dissertation
presented to
the Faculty of the Graduate School
at the University of Missouri-Columbia
In Partial Fulfillment
of the Requirements for the Degree
Doctor of Philosophy
YA-WEN CHENG
Dr. Mark J. Volkmann, Dissertation Supervisor

DECEMBER 2013 
The undersigned, appointed by the dean of the Graduate School, have examined the dissertation entitled

FACE-TO-FACE, ONLINE, AND HYBRID DESIGNS

FOR MENTORING

Presented by Ya-Wen Cheng,

A candidate for the degree of Doctor of Philosophy,

And hereby certify that, in their opinion, it is worthy of acceptance.

Professor Mark J. Volkmann, Dissertation Supervisor

Professor Deborah L. Hanuscin

Professor Sarah Bush

Professor James M. Laffey 
(C) Copyright by Ya-Wen Cheng 2013

All Rights Reserved 
This work is dedicated to

my aunty, Hsu-Shiou Kao, who loved me unconditionally;

Dr. Sandra K. Abell, who had faith in me and inspired me to be a researcher;

and to my best friend, Ming-Yi Chao, without whose caring support, it would not have been possible. 


\section{ACKNOWLEDGEMENTS}

I would like to thank my advisor, professors, friends and family for providing me with the support needed to find the inspiration to achieve my goal. Without their love and support, I wouldn't be here today!

My sincere thanks are given to Dr. Mark J. Volkmann, my dissertation advisor, for his patient advice and guidance throughout my period of study. I especially appreciated your constructive criticism and prompt responses to my queries. He was always there for me when I needed advice, and he challenged me to be a better researcher and better person. He is truly an inspiration to me.

I also would like to thank all my committee members for their support, patience, encouragement, and thoughtful suggestions. Dr. Deborah L. Hanuscin, I am so grateful for your constructive criticism, generosity, guidance, and continuous support. You were always there for me whenever I needed advice. Thank you so much for being an amazing mentor. Dr. Sarah Bush, you are one of the most brilliant scientists that I have ever met. Your passion and enthusiasm on teaching and learning is exemplary. You inspire me to be passionate about my works. Dr. Jim Laffey challenged me and helped me grow in ways I never thought I would in my field of study.

I want to give my special thanks to my friends for supporting and cheering me on from the beginning. My dear friend, Yu-Ju Lee, my life is much more colorful with you in it. You mean a lot to me. Dr. Dominike Merle-Johnson, I will always remember the time I shared with you. Thank you for your friendship and supports. Dr. Deanna Lankford, thanks for listening when I needed to bounce ideas around and for providing 
excellent advice. Dr. Bina Vanmali, thank you for keep encouraging me throughout the process. Sonmnath Sinha, thanks for your encouragement and being a good friend to me. I would also like to thank my family for the continuous support they have given me throughout my time in graduate school; I could not have done it without them. I want to thank my parents, Ming-Fen Cheng and Chin-Chi Kao, for always supporting me and pushing me to do my best. 


\section{TABLE OF CONTENTS}

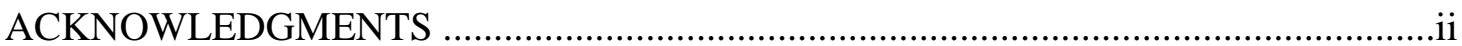

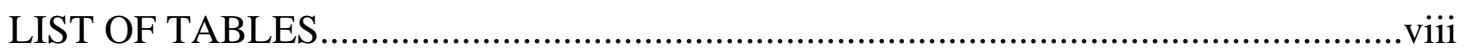

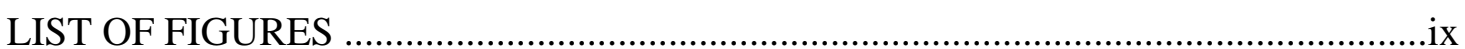

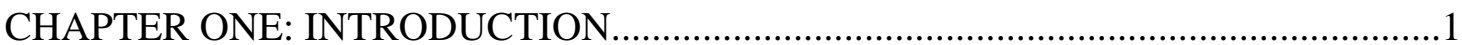

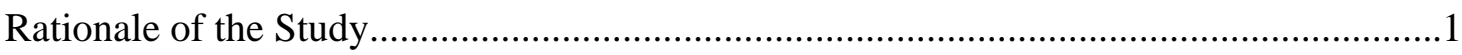

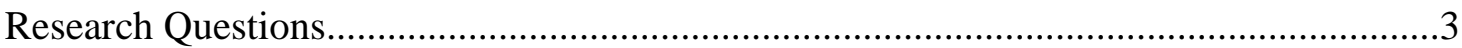

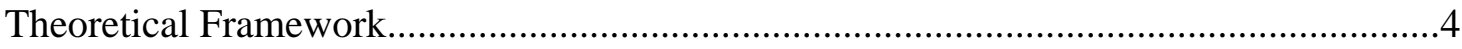

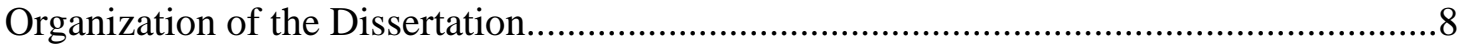

CHAPTER TWO: LITERATURE REVIEW................................................................10

Principle of Effective Professional Development...........................................................10

Emphasize Effective Classroom Learning and Teaching ...................................12

Provide Support for Sustainability....................................................................13

Promote Self-directed Learning............................................................................13

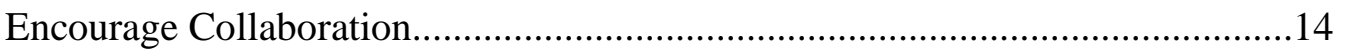

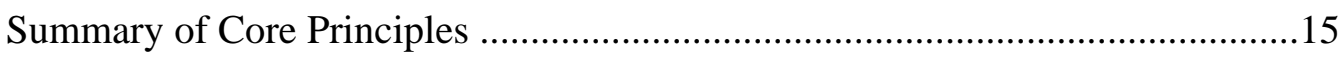

Network Technology Supported Teacher Professional Development................................16

Provides On-going Support, Reduces Isolation, and Enhances Interaction.........17

Provides more Opportunities to Reflect on Teaching and Learning.......................19

Increase Technology Integration in Learning and Teaching...........................20

Promote Self-directed Learning..........................................22

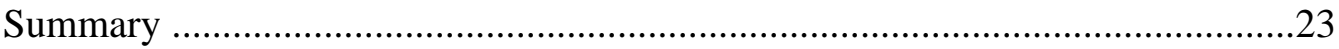

Hybrid Professional Development Opportunities.............................................................24 
Gaps in the Literature.

Significance of the Study......................................................27

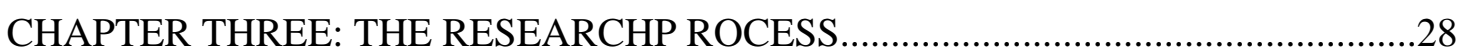

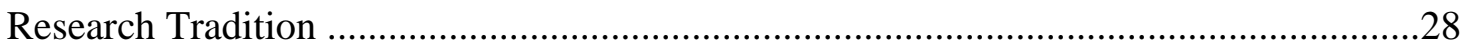

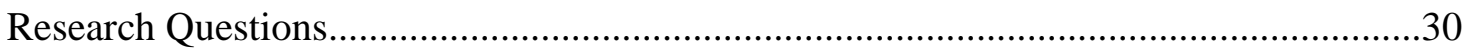

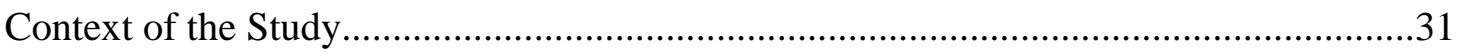

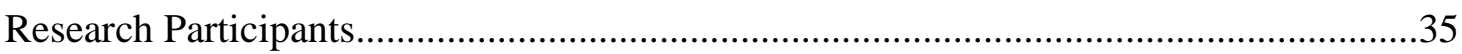

Institutional Review Board and Data Storage..................................................................36

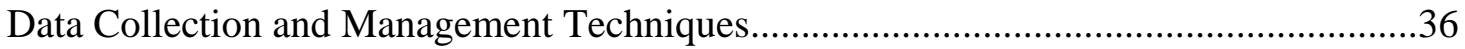

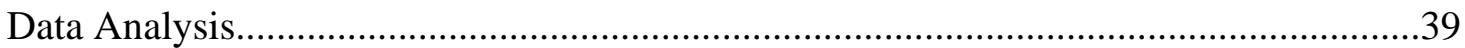

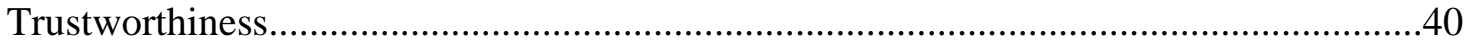

Role of the Researcher........................................................42

Limitations of the Study......................................................... 42

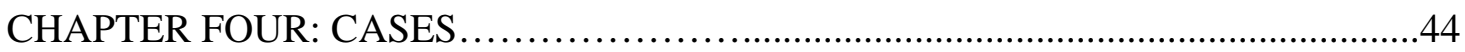

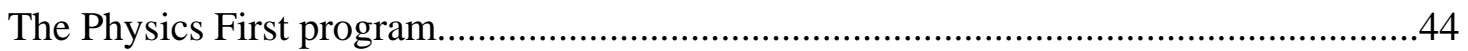

Cohort 1 Coaching sessions and PLC meetings...........................................................45

Cohort 2 Mentoring sessions and PLC meetings.......................................................47

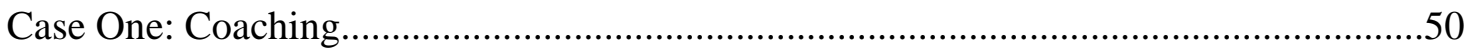

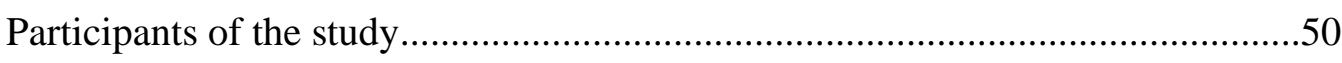

Face-to-face Coaching process and Expectation.................................................54

Professional learning community (PLC) Meeting...........................60

Problems of the Coaching Design..........................................63

Solutions of the Problems....................................................66 
Limitation of the Solutions

Summary of Case One: Coaching ......................................69

Case Two: Online Mentoring..................................................... 71

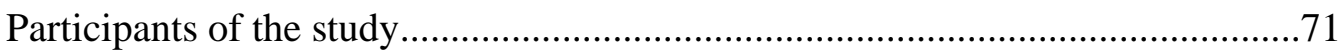

Online Mentoring Process and Expectation.........................................................74

Professional learning community (PLC) Meeting...........................82

Problems of the Mentoring design........................................85

Solutions of the Problems.................................................89

Limitation of the Solutions.............................................99

Summary of Case two: Mentoring......................................92

CHAPTER FIVE: ASSERTIONS, IMPLICATIONS AND CONCLUSIONS................94

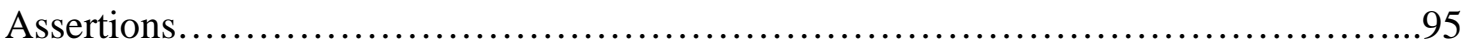

Assertion \#1: The types of questions that were asked in face-to-face and online post-observation discussion were very similar. The quality of those discussions is influenced by the venue and the context........................................95

Assertion \#2: Classroom observation is an essential component for coaching and mentoring designs.

Assertion \#3: Effective coaching or mentoring includes time for meaningful post-observation discussions.............................................106

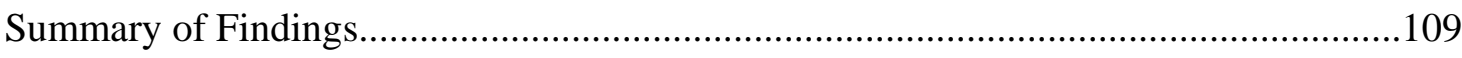

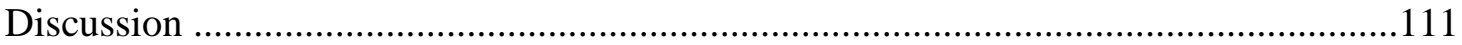

Hybrid design and social constructivism.......................................................112

Hybrid Design supports effective mentoring...................................................113

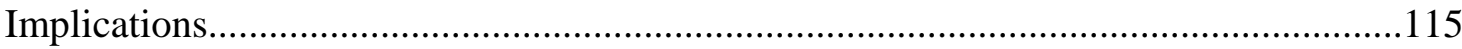

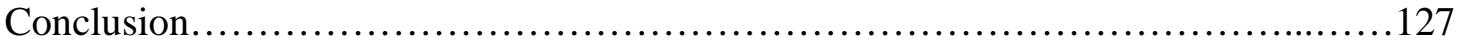




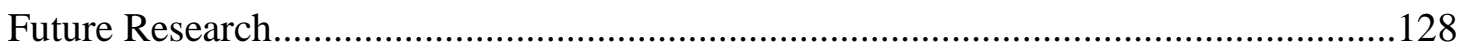

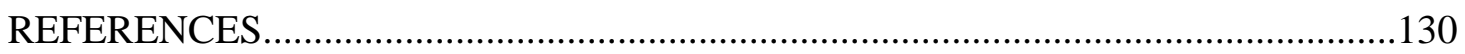

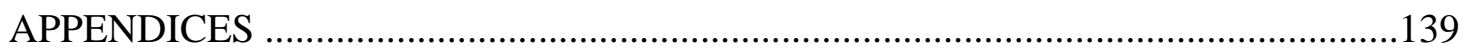

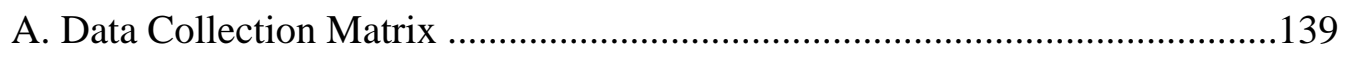

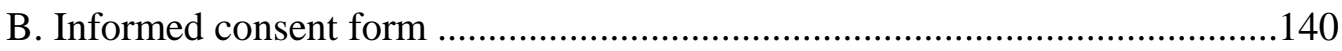

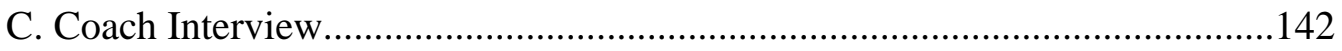

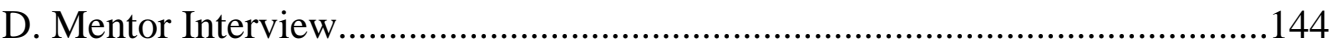

E. Teacher Interview (Cohort 1) .....................................................................145

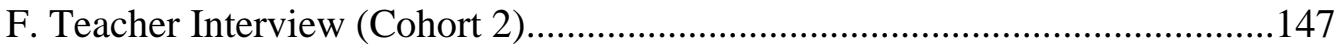

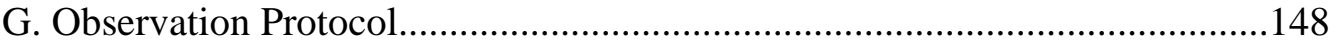

H. Classroom Observation Form...................................................................149

I. Mentee Self Reflection Form....................................................................151

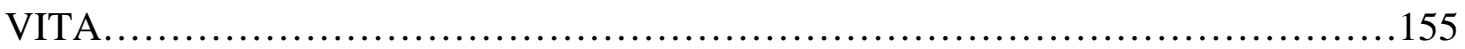




\section{LIST OF TABLES}

Table

1. The characteristic of social constructivism................................6

2. Core Principles of Effective Professional Development ......................................11

3. Demographic data of C1teachers........................................51

4. Summary of the types of questions asked by $\mathrm{C} 1$ teachers in the F2F coaching sessions.

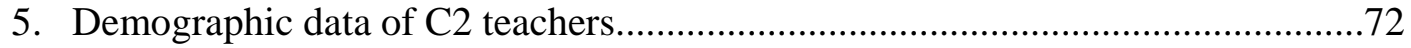

6. Summary of the types of questions asked by C2 Participants in the online mentoring sessions.

7. Summary of the types of questions asked by C1 and C2 Participants...................96

8. Summary of the types of questions asked by $\mathrm{C} 1$ teachers in the F2F coaching sessions

9. Summary of the types of questions asked by C2 Participants in the online mentoring sessions. 


\section{LIST OF FIGURES}

Figure $\quad$ Page

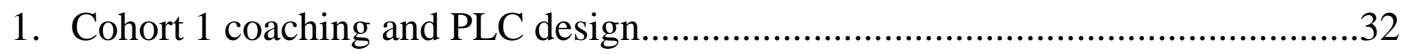

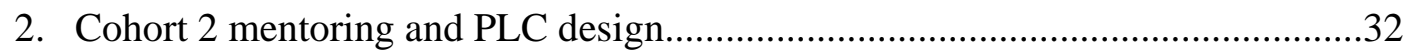

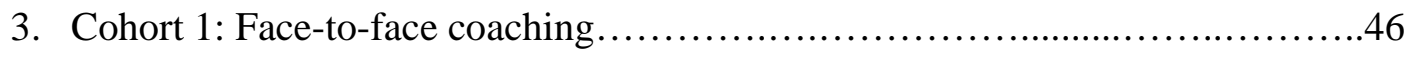

4. Cohort 1: Face-to-face PLC meeting.....................................47

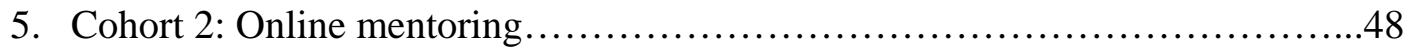

6. Cohort 2: Online PLC meeting..........................................49

7. Hybrid mentoring design for statewide PD projects........................117

8. Hybrid PLC design ....................................................... 


\section{CHAPTER ONE: INTRODUCTION}

\section{Rationale of the Study}

Teacher Professional Development (PD) is an important subject of education reform. According to the National Research Council (1996), "reforming science education requires substantive changes in how science is taught, which requires equally substantive change in professional development practices at all levels” (p. 5). Undoubtedly, PD is essential if teachers are to develop content knowledge, pedagogical content knowledge, and skills they need to succeed in their classroom as well as build or strengthen their learning community (Loucks-Horsley, Stiles \& Hewson, 1996; Vrasidas \& Zembylas, 2004). Furthermore, NSTA (2006) suggests that a "high-quality science teacher workforce requires meaningful, ongoing professional development” (p.1). However, in many cases, PD is only providing one-time learning opportunities with limited impact on teaching and learning (Loucks-Horsley et al., 1996).

In a typical face-to-face (F2F) professional development, teachers usually attend one-week summer workshop and meet two or three times in the remaining academic year. This design often fails to provide an on-going collaborative opportunity for participants. After a short period of time in F2F professional development, teachers return to the classroom with limited support. In addition, teachers work in an isolated environment with a very busy schedule and seldom have a chance to discuss their teaching practice with peers. Therefore, online teacher PD may offer more opportunities for teachers to share, interact, and learn from others because information and resource are accessible without any limitations.

Network technology has developed rapidly in the past decade and now has a variety of applications. Synchronous (e.g. instant message, video conferencing) and 
asynchronous communication (e.g. email, discussion forum) are widely used in communication. Unlike F2F environments, where individuals have a short time to think, reflect, interact and share with others, on-line environments provide more time to reflect and share, and more time to interact with others. In a recent study on impact of online professional development, peer interaction and collaboration have a valuable impact on learning (Liu, Carr \& Strobel, 2009). However, online communication may lose social cues (Habanek, 2006), lack personal contact (Kirk \& Olinger, 2003) and cause time gaps between posting and responding (Habanek, 2006).

In teacher education, mentoring as a supportive mechanism is broadly used to assist pre-service and in-service teachers to gain content knowledge and pedagogical skills (Gutke \& Albion, 2008; Schneider, 2008). Mentoring is a process to sustain effective teacher professional development. Mentors are "experienced teachers with more content knowledge or experience in using particular program or teaching practice” (Loucks-Horsley, Love, Stiles, Mundry, and Hewson, 2003, p. 219). Particularly, studies focus on mentoring to support pre-service and induction year teachers (Gutke \& Albion, 2008; Israel, 2008; Schneider, 2008; Brady \& Schuck, 2005).

Mentoring provides mentees on-going learning opportunities, as well as opportunities to learn from experienced others. In addition, studies argue that not only do mentees benefit but mentors, as well (Huling \& Resta, 2001). However, both F2F and online mentoring have limitations. For instance, F2F mentoring is time consuming because mentor and mentee need to find time to meet (Kirk \& Olinger, 2003) and time to travel to and from the meeting location. Online mentoring, on the other hand, has some 
limitations, too. For example, it is difficult to establish close relationships between mentor and mentee through online communication (DuBois \& Karcher, 2005).

A hybrid model is an integration of online and F2F which delivers a more flexible learning environment. In the discussion above, time and location may cause the failure of F2F mentoring, and the lack of personal contact may decrease the benefits of online mentoring. Hybrid can address both of these concerns. Personal connection is supported by a few f2f meetings and more frequent online meetings can provide efficient ways to meet. In the hybrid environment, learners have the flexibility to meet virtually, without the constraints posed by time and location (Single\& Muller, 1999). Osguthorpe and Graham (2003) listed six goals of hybrid learning: pedagogical richness, access to knowledge, social interaction, personal agency, cost effectiveness, and ease of revision. With different levels of F2F and technology integration, hybrid design can support teaching and learning in a more effective way.

However, research of hybrid mentoring in teacher education is limited. Most of the studies focus on e-mentoring in induction year teacher and in-service teacher professional development. There is a lack of research on what pedagogical challenges are best addressed through hybrid mentoring; what obstacles impede successful F2F or online mentoring; and how mentor and mentee construct knowledge through hybrid mentoring.

\section{Research Questions}

The Physics First program is designed for $9^{\text {th }}$ grade teachers that enabled them to interact with coaches and mentors to support their learning of physics concepts and implementation of a year-long course in freshman physics. Two cohorts of teachers 
( Cohort 1 and 2) were provided different opportunities to interact with coaches and mentors through F2F or online venues.

The purpose of this qualitative case study is to understand how F2F coaching and online mentoring influence teacher PD and learning. The overarching question guiding this study is: What affordances do F2F and online venues provide to a PD project in terms of mentoring? This question is supported by the following sub-questions.

1. How do the types of questions asked face-to-face by teachers compare to the types of questions asked online by teachers?

a. What types of questions are asked in face-to-face meetings by teachers?

b. What types of questions are asked in online meetings by teachers?

2. How do coaches, mentors, and participants utilize different venues to support their responsibilities?

a. In what ways did C1 participants and coaches change the face-to-face design of their coaching sessions to better accommodate their needs?

b. In what ways did the C2 participants and mentors change the online design of their mentoring sessions to better accommodate their needs?

\section{Theoretical Framework}

The purpose of mentoring is to provide an on-going support for PD which could sustain learning. Mentoring is a learning process which occurs through social interaction between mentor and mentee. In this study, teacher-participants receive continuing learning supports from the Physics First project through mentoring. The project adopted Cognitive Coaching (Costa \& Garmston, 2002) to support teacher learning. The concept of Cognitive Coaching is to help the mentee understand and solve problems of practice. 
According to Costa and Garmston (2002), in the process of Cognitive Coaching, the coaches must remain non-judgmental throughout the process. Coaches are trained to help the mentee identify the problem, reflect on the problem, and solve the problem. The Coach refrains from solving the problem for the mentee, which is the traditional approach to mentoring. This purpose is addressed as the participants learn from the mentoring process through meaningful interaction with coaches and other participants.

Therefore, the lens I use to investigate hybrid mentoring is Social Constructivism. This theoretical framework makes sense because mentoring is a social interaction which provides opportunities for learning. In addition, learners achieve their learning goals when they gain new skills and knowledge through mentoring process.

\section{Social constructivism}

Learning is a social behavior and individuals learn through interaction with others. The motif of social constructivism focuses on how individuals constructed knowledge through meaningful social interactions, discourse, and negotiation. Vygotsky (1978) suggests that knowledge construction is not only a social process but also a cognitive process. From a social constructivist perspective, discourse and social interaction are the fundamental elements for cognitive development. Jaworski (1994) outlined the characteristic of social constructivism (see Table 1). 
Table 1

The characteristic of social constructivism (Jaworski ,1994)

- Active construction of knowledge based on experience with and previous knowledge of the physical and social worlds

- Emphasis on the need for the ZPD

- Emphasis on the influence of human culture and the sociocultural context

- Recognition of the social construction of knowledge through dialogue and negotiation

- Emphasis on the intersubjective construction of knowledge

- Multiple interpretations of knowledge

According to Woo \& Reeves (2007), social constructivism explains the processes of learning by addressing three key concepts. These three concepts are: Zone of Proximal Development (ZPD), intersubjectivity and enculturation. Each of these is described in greater detail below.

Zone of Proximal Development (ZPD). The ZPD is "the region of activity that learners can navigate with aid from a supporting context, including but not limited to people" (Vygotsky, 1986 cited in Brown et al., 1993, p. 5). Vygotsky suggested that "the distance between the actual developmental level as determined by independent problem solving and the level of potential development as determined through problem solving under adult guidance, or in collaboration with more capable peers “(Vygotsky, 1978, p. 86). The zone of proximal development is "constantly changing with the learner's increasing independent competence at each successive level” (Brown et al, 1993 p. 35). The more capable peers refer to anyone who has better skills, understanding or ability level than the learners. Mentoring is a good example to explain this concept. A mentor is a more experienced individual who helps guide the novice to become more skilled and knowledgeable. 
Intersubjectivity. Intersubjectivity refers to "shared understanding based on a common focus of attention and some shared presuppositions that form the ground for communication” (Rogoff, 1990). In other words, intersubjectivity is the mutual understanding that people share through meaningful interaction and communication (Gauvain, 2001; Woo \& Reeves, 2007). Mentoring “creates intersubjectivity among the participants, thus transmitting meaning, values, affect, motivation, and indeed the planes of consciousness of mentors and entire cultures” (Gallimore, John-Steiner \& Tharp, 1992).

Enculturation. Enculturation refers to individuals who learn culture by which he or she is surrounded and acquires values that are appropriate or necessary in that culture (Kottak, 2007). Through this process, an individual will be accepted by the community or culture. In addition, enculturation is a lifelong process, which shapes individuals learning, values, and beliefs as culture changes. Vygotsky (1978) suggested that "human learning presupposes a specific social nature and a process by which children grow into the intellectual life of those around them” (p. 88). From a social constructivism perspective, "learning occurs through the process of intersubjectivity in the enculturalized Zone of Proximal Development” (Woo \& Reeves, 2007, p. 19). In this study, I see Physics First project as a culture with values (goals) to 1) create a cadre of teacher-leaders who will become advocates for excellence in physics content and research-based pedagogy, 2) to strengthen high school freshman science teachers' and students’ understanding of physics, 3) to enhance teachers' knowledge and ability to utilize reform-based pedagogies in teaching freshman physics, 4) to promote institutional change among Core partner institutions, and 5) to increase students' science coursework. Participants acquire the 
project values that are necessary for them to be successful. Through meaningful discourses with mentors and coaches, participants reflect and solve their problems in order to achieve the project goals and become an expert in implementing physics first curriculum.

\section{Organization of the Dissertation}

This study is divided into five chapters. Chapter One provides an overview of the study including the rationale, research questions and theoretical framework. The theoretical framework includes sections on social constructivism, Zone of Proximal Development (ZPD), intersubjectivity and enculturation. Chapter Two focuses on a review of the literature in three areas: principle of Effective Professional Development, Network technology supported teacher professional development, and hybrid PD opportunities. This chapter also addresses the gaps in the literature and significance of the study. Chapter Three outlines the qualitative approaches used in this study. This includes a description of the research tradition, research methodology, and the design of the study. I included details of the context of the study including the Physics First project, design of the coaching and mentoring and the participants. I also describe data collection strategies and data analysis methods. The chapter concludes with a description of the trustworthiness of the design and implementation of the study. Chapter Four describes the findings of the study. I present two case profiles. The purpose of Chapter Four is to provide data and evidence for the assertions made in Chapter Five. Chapter Five is the final chapter and includes a summary of the findings in relation to the research questions and a discussion of the findings relative to the research literature. In this chapter, I provide a cross-case analysis and assertions that emerged from the data. Throughout this 
chapter I refer to the profiles presented in Chapter Four. This chapter also concludes with implications and recommendations for future research. 


\section{CHAPTER TWO: LITERATURE REVIEW}

In this chapter, I review three areas of literature that provide background information for understanding the significance of my research questions and the context of my study. The three areas include 1) core principles of effective professional development, 2) network technology supported teacher professional development, and 3) hybrid Professional Development Opportunities. The chapter also includes a description of the gaps found in the research literature that this study will help to address.

\section{Principle of Effective Professional Development}

Teacher professional development (PD) is an essential element for improving quality teaching and learning. In education reform, teacher education and professional development play key roles in enhancing quality teaching and learning. Teachers have direct impact on what and how students learn; therefore, preparing in-service and preservice teachers with in-depth content and pedagogical knowledge are necessary for best practice. In addition, “science has a rapidly changing knowledge base expanding relevance to societal issues, and teachers will need ongoing opportunities to build their understanding and ability” (National Research Council, 1996, p. 55-56).

So, what are the characteristics of effective teacher professional development programs? National Science Education Standards (National Research Council, 1996) provide its vision of professional development standard which is similar to LoucksHorsley, Hewson, Love and Stiles (1998) views on effective PD. I extracted the core principles of effective PD from both documents. Table 2 provides a brief summary of the core principles of effective PD. Each core principle will be discussed in greater detail in the following sections. 
Table 2

Core Principles of Effective Professional Development

\begin{tabular}{|c|c|}
\hline Core Principle & \\
\hline \multicolumn{2}{|c|}{ Emphasis on effective classroom learning and teaching } \\
\hline Content Knowledge & $\begin{array}{l}\text { - } \quad \text { in-depth understanding of science and math should build on } \\
\text { - } \quad \text { shouldicipants current understanding and expand it } \\
\text { - } \quad \text { will impact students' learning } \\
\text { - } \quad \text { participants should be able to apply the knowledge to the } \\
\text { - classroom practice } \\
\text { - } \quad \text { knphasis on inquiry-based learning } \\
\end{array}$ \\
\hline $\begin{array}{l}\text { Pedagogical Content } \\
\text { Knowledge }\end{array}$ & $\begin{array}{ll} & \text { comprehend of subject matter } \\
\text { - } & \text { understand how student learn and identify possible } \\
\text { - } & \text { adjusconceptions } \\
\text { - } & \text { knowledge of general pedagogy } \\
\end{array}$ \\
\hline \multicolumn{2}{|c|}{ Provide supports for sustainability } \\
\hline Support & $\begin{array}{ll}\text { - } & \text { Feedback form/to peers and experts } \\
\text { - } & \text { on-going support such as problem-solving, feedbacks } \\
\text { - } & \text { connecting to learning community } \\
\text { - } & \text { provide resources (media, literature, technology) } \\
\text { - } & \text { evaluation of learning progress, problems and effective of } \\
& \text { learning }\end{array}$ \\
\hline \multicolumn{2}{|c|}{ Promote self-directed learning and help participants to become a life-long learner } \\
\hline Self-Directed Learning & $\begin{array}{l}\text { - } \quad \text { opportunities to access various resources, tools and } \\
\text { - } \quad \text { evaluate his/her own learning } \\
\text { - } \quad \text { able to use and find resource for learning } \\
\text { - } \quad \text { opportunities to generate new knowledge about science } \\
\text { teaching and learning by using the skills of research which PD } \\
\text { provide }\end{array}$ \\
\hline \multicolumn{2}{|l|}{ Encourage collaboration } \\
\hline Leadership & $\begin{array}{l}\text { - Develop leadership skills } \\
\text { - participants can take leadership role to support other teachers }\end{array}$ \\
\hline Collaboration & $\begin{array}{l}\text { - Interaction with peers, experts, educators and learning } \\
\text { communities } \\
\text { - working with peers and construct knowledge } \\
\text { - with school or school district }\end{array}$ \\
\hline Reflection & $\begin{array}{l}\text { - } \text { participants have opportunities to reflect on teaching practice } \\
\text { - } \quad \text { on-going refection opportunity }\end{array}$ \\
\hline
\end{tabular}




\section{Emphasize Effective Classroom Learning and Teaching}

Effective PD should emphasize effective classroom learning and teaching (National Research Council, 1996; Loucks-Horsley et al, 1998). Content knowledge refers to "the amount and organization of knowledge per se in the mind of the teacher” (Shulman, 1986, p. 9). It is important to help teachers to have sound content knowledge because content knowledge is important for good teaching (Ball, Hill \& Bass, 2005). Furthermore, pedagogical content knowledge (PCK) is the knowledge that teachers need to know. PCK includes the 1) knowledge of subject matter, 2) knowledge of students and possible misconceptions, 3) knowledge of curricula, and 4) Knowledge of general pedagogy (Shulman, 1986). Shulman $(1986,1987)$ argued that teachers need to have content knowledge, general pedagogical knowledge, curriculum knowledge, knowledge of learner and their characteristics, knowledge of educational contexts and knowledge of educational ends, goals, purposes, values, philosophy, and history.

Effective classroom teaching and learning should adopt inquiry based learning (National Research Council, 1996). Through inquiry learning, students engage in the activities and thinking process which are similar to scientists (Olson \& Loucks-Horsley, 2000). Thus, inquiry method could promote in-depth science learning and achieve higher levels of scientific literacy.

The effective PD should focus on content knowledge, pedagogical content knowledge and inquiry-based learning. Teachers with sound pedagogical content knowledge understand how children learn and know how to adjust teaching and content to fit learner needs. The levels of teachers' understandings of subject matter have direct 
impact on student learning. Therefore, having sound content knowledge is the first step of promoting effective classroom teaching and learning.

\section{Provide Support for Sustainability}

Effective PD should provide support for sustainability (National Research Council, 1996; Loucks-Horsley et al, 1998). For professional development to be effective, it must take place over time and provide follow-up for participants to share what they have learned (Guskey, 1999). However, professional development is often seen as a onetime learning opportunity with limited opportunity to impact learning and teaching (Loucks-Horsley et al., 1996). Teachers often struggle to implement what they learned from the workshops into real classrooms. If PD can provide various supports and resources, teachers are given more opportunities to interact and reflect upon new knowledge and practice.

Effective PD project provides learning opportunities "through a set of goals, strategies, and support over time” (Loucks-Horsley et al., 1996, p. 2). Therefore, ongoing support, resources and connection to the learning community are essential to sustain learning and encourage implementation.

\section{Promote Self-directed Learning}

Effective PD should promote self-directed learning and help participants to become life-long learners (National Research Council, 1996; Loucks-Horsley et al, 1998). Self-directed learning refers to learners take responsibility and manage of their own learning and learning process (Knowles, 1975).

Attending a professional development project is one way to learn and improve teaching practice. However, teachers need to keep learning and learn inside and outside 
the classroom in order to bring the new knowledge and perspectives to their students. PD offers an environment for teachers to evaluate, improve, and reflect their learning. However, after attending PD, teachers have to keep learning to improve their teaching practice. Thus, helping teachers to become a self-directed learner can also enhance collaboration and reflection because teachers will have motivation to learn and a desire to improve their teaching.

Learning is like rowing upstream, not to advance is to drop back. Teachers have to take responsibility for their own learning, to evaluate their own learning, to use and find resources for learning, and to generate new knowledge about science (Knowles, 1975). According to Knowles (1975), learners who take initiative in learning learn more deeply and permanently. Therefore, effective PD should focus on fostering teachers to become self-directed learners.

\section{Encourage Collaboration}

Effective PD should encourage collaboration (National Research Council, 1996; Loucks-Horsley et al, 1998). Through collaboration, teachers can develop leadership skills, learn from peers and foster learning communities with people who have similar interests. Collaboration with peers, experts, schools, districts and learning communities can enhance professional growth. Teachers also need to collaborate with schools or districts. Teachers can take leadership roles and make difference in their schools if PD integrates " professional development activities into other initiatives of the school or district” (Loucks-Horsley et al., 1996, p. 3).

Teaching can be a very isolated job, which limits social interaction. Moreover, teachers with busy workloads do not have many opportunities to collaborate with their 
professional community. By attending PD, teachers are given opportunities to collaborate and share with other teachers.

\section{Summary of Core Principles}

Effective PD has the following characteristics 1) to extend teachers' content knowledge and pedagogical knowledge, 2) to provide supports for sustainability, 3) to promote self-directed learning, and 4) to encourage collaboration among participants. Under the core principles of effective PD, PD projects offer more opportunities to learn and improve teaching practice. But, it is not easy for a typical PD to provide continuous support and learning opportunities to participants. A typical F2F PD sometimes lacks collaborative opportunities for participants. Teachers leave with new knowledge and ideas of teaching after a short period of time in F2F professional development. In addition, teachers work in an isolated environment with very busy schedules and seldom have opportunities to discuss their teaching practice with peers. Without providing continuous supports or opportunities to share, learning cannot sustain. Therefore, online teacher professional development may offer more opportunities for teachers to share, interact, and learn from others.

The goals of Physics First project are 1) to create a cadre of teacher-leaders who will become advocates for excellence in physics content and research-based pedagogy, 2) to strengthen high school freshman science teachers' and students' understanding of physics, 3) to enhance teachers' knowledge and ability to utilize reform-based pedagogies in teaching freshman physics, 4) to promote institutional change among Core partner institutions, and 5) students will increase their science coursework. These goals are aligned with three core principles of effective PD. The three core principles are 1) 
emphasis on effective classroom learning and teaching, 2) Provide supports for sustainability, and 3) encourage collaboration. Thus, in this study, I will focus on the goals of Physics First that aligned with three core principles. Next section will discuss the impact of network technology on professional development.

\section{Network Technology Supported Teacher Professional Development}

Network technology has been used to support teacher professional development projects. In the past 15 years, research studies have focused on integrating different network technologies into teacher professional development projects. However, the focus of using network technologies varies because of different PD designs. A PD project may focus on providing supports or it may focus on delivering content knowledge. Therefore, I reviewed and summarized studies on network technologies for teacher professional development over the past 15 years. By doing so, I have a better understanding about the types of network technologies used in PD as well as the impact of these technologies on PD. Most importantly, through the literature review, I wanted to find out how networktechnologies support the core principles of effective PD. Advantages of using network technologies, in teacher professional development, include 1) provides on-going support, reduces isolation, and enhances interaction, 2) provides more opportunities to reflect on teaching and learning, 3) increases technology integration in learning and teaching, and 4) promotes self-directed learning. Each advantage will be discussed in greater detail in the following sections. 


\section{Provides On-going Support, Reduces Isolation, and Enhances Interaction}

In this section, I reviewed the studies which focus on using network technology as a tool to provide supports. I hope to know what kinds of technologies are used and how they have been used.

Teaching is a social of activity which can also be very isolating (National Academy of Sciences, 2007). On-going support is critical for effective PD. Lack of on-going support and opportunities to interact often result in the failure of teacher PD. Too often, when pre-service teachers intern in school, "they struggle to reconcile their perceptions of classroom reality as filtered through naive, unexamined experience, with theory-based recommendations for best practice” (Roddy, 1999, p.2).

Roddy (1999) used a mailing list similar to listserv to assist pre-service K-12 teachers in the field to reconnect the learning community (university professors and peers). Pre-service teachers, staffs, faculty members are able to participate in electronic discussion on different topics by subscribing to the mailing list. After studying four quarters in the university teacher development program, pre-service teachers had to do internships in schools for a quarter. Since they learned lots of knowledge and ideas of teaching from the teacher program, they had opportunities to practice and apply the knowledge in the real classroom. In order to offer continuous supports for student teachers, the program adapted a mailing list to support the learning community and connect all the participants. The author analyzed all emails and monitored interactions among participants. The result indicated that pre-service teachers were benefited from the mailing list. They were supported through sharing and by developing an understanding of practices in the real classroom. 
Levin and Waugh (1998) explored the way to support the extensions of the traditional F2F apprenticeships in teacher preparation by analyzing different teleapprenticeship frameworks. The framework includes question answering and asking, collaborations, student publishing, web-weaving, and project generation and coordination. The authors focused on how these frameworks support learning especially for pre-service teachers. As the result, participants were benefited because tele-apprenticeships allow learners to be supported by multiple mediators and serving as mediators themselves at the same time (Levin \& Waugh, 1998). In other words, tele-apprenticeships provide opportunities for participants to observe and learn from peers and from a remote site.

Additionally, Barnett et al., (2002) studied the Inquiry Learning Forum (ILF) for science and math teacher by utilizing video vignettes and discussion forums to support sharing and learning inquiry based instruction. Participants watched eight 5-minute video clips of inquiry lessons and discussed those videos on the discussion forum. Especially for pre-service teachers, watching video clips is an alternative option for gaining field experience. Moreover, sharing their views on discussion board gives teachers opportunities to practice and evaluate their understandings about inquiry based instruction. ILF creates meaningful interactions for in-service and pre-service teachers in sharing their knowledge and experience of implementing inquiry based teaching in the classroom.

Having access to the education community helps teachers in all levels overcome isolation (Fusco, Gehlbach \& Schlager, 2000). TAPPED IN is a large online professional development community where teachers with the same interests can establish their own learning community. The purpose of this study is to investigate how participants' 
experiences of using TAPPED IN affect their teaching and learning. The researchers conducted a large scale survey to uncover the barriers and benefits of using TAPPED IN system. The results showed that participant login to TAPPED IN system more often, the greater they do not feel isolation and had higher positive impact on teaching practice (Fusco, Gehlbach \& Schlager, 2000).

Based on the review of literature, we learned that network technology can provide on-going support, reduce isolation and enhance interaction in different ways. With different forms of network technologies like asynchronous tools, PD can offer more learning and collaboration opportunities for teachers.

\section{Provides more Opportunities to Reflect on Teaching and Learning}

I reviewed the studies which focus on providing reflection opportunities through technology. I hoped to understand how network technology supports reflection opportunities for reflection.

Treacy, Kleiman and Peterson (2002) reviewed their works on EdTech Leaders Online program and claimed that participants and facilitators were given more time online to prepare responses. Additionally, Hawkes and Romiszowski (2001) investigated the impact of computer-mediated asynchronous communication on teacher professional development program. Experienced in-service teachers participated in this technology supported problem-based learning (PBL) curriculum development project to develop their own PBL curriculum. Both face to face and online sessions were offered to participants but participants were not required to use computer mediated communication. In addition, no facilitators were online to foster the interactions. All the communications included F2F meetings and online discussion forums were analyzed for assessing the 
level of interaction and reflection. The quantitative result showed that computer mediated communication is more reflective than F2F communication because participants had more time to think (Hawkes \& Romiszowski, 2001). Thus, the authors suggest that “asynchronous computer networks are capable of facilitating reflective discourse at a level which encourages teachers to collaboratively examine their practice in light of instructional theory.” (Hawkes \& Romiszowski, 2001, p.298).

Based on the studies, the attributes of network technology can provide more opportunities to reflect on teaching and learning. Network technology provides 24/7 access to information and resources. Information, resources and discussion postings are always online and easy to retrieve. Therefore, teachers will have more times to think, to read, to write, to reflect and to reformulate their own understanding (Roddy, 1999).

\section{Increase Technology Integration in Learning and Teaching}

The knowledge and skills for using technology are critical in the $21^{\text {st }}$ century (Trilling \& Fadel, 2009). Teachers need to be prepared for technology in order to help their students to use technology (Fredrickson, 1999). In order to understand how network technology increases technology integration in learning and teaching, I reviewed the studies which focus on integrating technology into teaching and curriculum.

In the EdTech Leaders Online program, the authors shared their experience of building the successful local online professional development program. EdTech Learners Online program is designed to train participants to develop their online workshops for teachers or to facilitate online workshops in integrating technology into teaching and curriculum (Treacy, Kleiman and Peterson, 2002). The benefit of participating in EdTech Leaders Online programs is that participants have opportunities to use technology. It 
helps participants and educators "consider how they might use technology with their own students and to feel comfortable introducing it into their own classrooms” (Treacy, Kleiman and Peterson, 2002, p.46). In addition, teachers who have firsthand experience using technology, their future students will benefit from it because teachers will be likely to help students to use technology ( Sujo de Montes \& Gonzales, 2000).

Furthermore, a similar result was found in the research of the TeacherLine project. TeacherLine is sponsored by PBS which provides high quality online course and professional development opportunities for teachers and schools. In this study, a survey was given to K-12 participants to uncover teachers' attitude toward online and face- toface PD. Cole and Styron (2006) studied TeacherLine module and compare it to F2F PD. The result showed that teachers who participated in TeacherLine had positive perception in participating in another TeacherLine module. Moreover, teachers who participated in online PD were more likely to carry their experience back to their classrooms. In other words, teachers will "incorporate more technology within teaching methodologies and encourage greater student interactivity with technology” (Cole \& Styron, 2006, p.26).

Based on the studies, in order to prepare students to be tech-literate, technology should be integrated into curriculum to foster a positive attitude toward learning and using technology. In addition, "teachers who are supported are less likely to feel threatened and develop more positive attitudes toward technology, and teachers who are supported are more likely to become proficient users of technology in the classroom" (Diem, 2000, p. 495). 


\section{Promote Self-directed Learning}

Knowles (1975) explained the concept of self-directed learning as:

"Self-directed learning is a process in which individuals take the initiative, with or without the help of others, in diagnosing their learning needs, formulating learning goals, identifying human and material resources for learning, choosing and implementing appropriate learning strategies, and evaluating outcomes” (p.18). The Collaborative Teacher Education Program at Indiana University (CTEP) offered online course for rural area teachers to obtain teaching licenses and master's degree (Rodes, Knapczyk, Chapamn \& Chung, 2000). In the CTEP program, participants used web-based conferencing and email to collaborate with peers and instructors. The authors addressed the importance of web-based instruction for non-traditional learner, such as teachers and several techniques in designing collaborative PD. The authors suggested that Web-based PD could help teachers to be more active, more responsible and take ownership of their learning.

Furthermore, the Project is an online course delivery system, which was designed to provide professional development opportunities for teachers. The study focused on the motivations and needs for K-12 teachers as adult learners. The study compared two focus groups which had different technology experience and accessibilities to computer and Internet. The authors claimed that "the quality online learning takes a substantial investment of time for reading, following online and perhaps written resources, composing and posting thoughts and assignments, and responding to their colleagues' postings online” (King \& Dunham,2005, p.11). Thus, network technologies will nurture self-directed learning and assist teachers to become lifelong learners. 
On the other hand, one research discussed the failure of using online discussion to build a professional community for PD teachers (Stephens \& Hartmann, 2004). The teaching mathematics with technology project (TMTP) was designed to build a learning community among in-service math teachers by utilizing online discussion forum. The goals of TMTP were to help teachers use educational technology in teaching and build a professional community for teachers to share and support their professional development. The researchers analyzed two years of data and found the participants failed to use an online discussion forum to learn and interact with peers. The availability of technology and Internet was not the reasons for the failure; instead, failure resulted from the fact that participants had little sense of responsibility to participate in online activities.

Based on the studies, self-directed learning is a key factor for learning and network technology can help participants to become self-directed learners. Since online learning does not require regular meetings as traditional learning does, successful online learning requires learners to be highly self-motivated and to manage their learning progress. However, we still have limited knowledge about helping teachers to become self-directed learners through online PD.

\section{Summary}

Learning and knowledge transmissions are restricted in the traditional learning environment (McAllister and McAllister, 1996; Zang \& Nunamaker, 2003). In a typical F2F environment, because knowledge is delivered through books or schools, individuals only have very limited time to think, reflect, interact and share with others. Now, learning becomes more flexible and accessible due to technology (Lee, 2003). Network technology includes synchronous (instant message, video conferencing) and 
asynchronous communication (email, discussion forum). With network technology, knowledge can be accessed without physical or time limitations (Sun, Tsai, Finger, Chen \& Yeh, 2008). Individuals now have more time to reflect and share, as well as more time to interact with others. Technology can be a valuable resource for improving teacher education because it can foster stronger connections among teachers, mentors, and university faculty (Office of Technology Assessment, 1995).

A successful online learner needs to be a self-directed learner (King \& Dunham, 2005). Helping an adult learner to become a self-directed learner is critical to promote life-long learning. In the case of PD, unlike F2F professional development that has fixed schedule for meeting dates, online PD usually does not require participants to meet on specific time. Participants may need to manage their learning process and monitor learning progress. Therefore, self-directed learning is a critical factor influence learning and practice. However, a longitude study to investigating how teachers become a selfdirected learners and how technology meets teachers' learning needs in different stages of their career is needed.

\section{Hybrid Professional Development Opportunities}

Using hybrid model benefits leaners with options to freely use both settings (Ocker \& Yaverbaum, 1999). Bonk and Graham (2006) defined blended learning as combination of face to face instruction with computer-mediated instruction. Driscoll (2002) defined blended learning as combination of different instructional methods.

Different hybrid learning designs have been used in several studies. In this project I will define hybrid learning model similarly to Driscoll and Graham. My definition of hybrid learning is the combination of technology and F2F instructional strategies to improve 
learning. In the study of comparing traditional and hybrid-based instruction (Utts, Sommer, Acredolo, Maher \& Matthews 2003), F2F class time was used for giving quiz and overview of the reading material. A hybrid class only met once per week, whereas a traditional class met three times per week. The instruction and reading assignments were distributed in an online environment. In another study of comparing F2F and online discussion, the design of hybrid class is slightly different. The instruction was given in WebCT and students met once per week to discuss the learning materials (Campbell, Gibson, Hall, Richards \& Callery, 2008).

Teacher professional development has been recognized as an important element of educational reform. A "traditional” teacher professional development design is often considered as a one-time learning opportunity. To change this perception, educators are seeking ways to support teacher learning and provide quality PD. Furthermore, learners have diverse learning styles and personality. Thus, no one teaching strategy could fulfill all types of learners. Providing different learning tools, resource and flexible learning environments will help learners learn better. Technology, such as video conferencing and online discussion boards, are used to assist in teaching and learning in K-12 and higher education. In addition, technology in classrooms helps to engage students, to visualize abstract concepts and to interact with materials and peers. However, technology has its' disadvantages. Habanek (2006) argued that online teaching lacks social cues due to time gaps between posting and responding and less opportunity to interact with others.

Therefore, online education may not replace the traditional classroom. On the other hand, the features of F2F teaching include interactions with others, immediate responses and the capability to track students' learning progress in the class period. However, it is not 
easy to divide time equally for every student. Teachers have limited time to meet every student's needs in learning. Moreover, some learners may need more time to reflect on what they learn; therefore, they may not be able to participate in class discussion and feel uncomfortable doing so. Because neither of the learning contexts can fully support learning and teaching needs, hybrid model may be a solution to provide better learning and teaching experience.

\section{Gaps in the Literature}

This review reveals several gaps in the literature. First, we have a limited understanding about what types of content materials are appropriate to deliver online. Not many researches specifically address this issue as the way that they investigate technology for learning. Some researches only address the importance of using content and activities to motivate teachers. For instance, the ILF project provided video clips from real inquiry based instruction as well as instructional materials for PD teachers. Online learning is different from F2F learning. Teachers’ activities in a F2F learning environment may not be able to transform to an online environment. For example, it is hard to transform a lab experiment to an online environment.

Second, we have a limited understanding of how an online professional development project impacts on teacher learning and students' learning in the long term. In the literature, all the discussions have centered on the impact of technology on teachers' practice and learning shortly after their participation in an online professional development project. Moreover, we do not know how an online professional development project affects student. The ultimate goal of education reform should aim at both teacher and student learning. 
Third, we have a very limited understanding of hybrid professional development. For example, we do not understand how F2F and online support one another, we do not know what level of F2F and online combination can best support PD, we do not know what kinds of support teachers feel comfortable getting online, and we don't know whether that kind of support is possible to provide.

\section{Significance of the Study}

There is growing interest in and use of digital electronic communication tools and little is known about how these tools can be used to support PD. The significance of my study is to address some of these gaps in the research literature by 1) investigating how PD participants utilize F2F, online, and hybrid environments for learning, 2) understanding how a hybrid environment supports the core principles of effective PD, and 3) studying a hybrid mentoring design of a PD. Additionally, my study can provide PD developers who have interests in designing a hybrid PD to know what can and cannot be implemented in hybrid and online environment. 


\section{CHAPTER THREE: THE RESEARCH PROCESS}

\section{Research Tradition}

This research study was guided by a constructivist research tradition.

Constructivists are interested in how individuals construct the knowledge of reality (Hatch, 2002). ”Because human beings have evolved the capacity to interpret and construct reality, the world of human perception is not real in an absolute sense, as the sun is real, but is 'made up' and shaped by cultural and linguistic constructs” (Patton, 2002, p. 96). Thus, knowledge about reality is constructed, not reality itself is constructed. In addition, within the constructivism paradigm, central questions are: "How have the people in this setting constructed reality? What are their reported perceptions, 'truths,' explanations, beliefs, and worldview? What are the consequences of their constructions for their behaviors and for those with whom they interact?” (Patton, 2002, p. 132). I used Patton's questions to develop my research questions because the purpose of this study is to understand how participants learn in two venues and affordances of F2F and online venues in supporting coaching and mentoring in a professional development project. Therefore, Patton's questions help me to focus on interaction, communication and knowledge construction among teachers, mentors and coaches. One interview question: what are the things you and your coach did the most in F2F meetings? is an example that fits the criteria. “The constructivist paradigm assumes a relativist ontology (there are multiple realities), a subjectivist epistemology (knower and respondent co-create understanding), and a naturalistic ([set] in the natural world) methodological procedures” (Denzin \& Lincoln, 2000, p. 21). 


\section{Ontological Assumption}

Ontology concerns about "what do we believe about the nature of reality" (Patton, 2002, p.134). From an ontological perspective, “multiple realities exist that are inherently unique because they are constructed by individuals who experience the world from their own vantage point” (Hatch, 2002, pp.15). Because this study is to understand the affordance of two venues provide to teachers' learning. Thus, I assume that teachers will learn differently in different venues as they interact with coaches and mentors.

\section{Subjectivist Epistemology}

The subjectivist epistemological views of this study are aligned with its constructivist design that will give me opportunities to observe and interview participants throughout the study. Patton (2002) suggests researchers to continually "work back and forth between the evidence and his or her own perspective and understanding to make sense of the evidence” (p. 477). By doing so, I will be able to generate my understanding about the participants’ belief systems.

\section{Methodological Assumption}

This study is guided by naturalistic qualitative and constructivist paradigm. I plan to interview and observe the events in the natural setting to understand the reality and make sense of it (Hatch, 2002). According to Yin (2003), case studies are preferred when how and why questions are being posed, when the investigator has little control over events, and when the focus is on a contemporary phenomenon within a real life context. This study focuses on two unique designs of mentoring in a professional development project. These two designs are the cases of this study. In addition, my role as an investigator is not to intervene but to make sense how participant learns. Furthermore, this study will 
involve multiple data sources, which will provide rich and detailed information. Thus, a case study approach is appropriate to guide this study. Since two cohorts have different mentoring designs, therefore, I will treat each cohort as a separate case. The unit of analysis is the source of the information (Yin, 2008). Therefore, the unit of the analysis will be each coaching/mentoring episode. An episode could be a F2F meeting or an online meeting. The objective is to compare the kinds assistance participants ask for and the kind of assistance coaches/mentors give.

\section{Research Questions}

This research investigated how F2F coaching and online mentoring influence teacher professional development and learning. The overarching question guiding this study is: What affordances do F2F and online venues provide to a professional development project in terms of mentoring? This question is supported by the following sub-questions.

1. How do the types of questions asked F2F by teachers compare to the types of questions asked online by teachers?

a. What types of questions are asked in F2F meetings by teachers?

b. What types of questions are asked in online meetings by teachers?

2. How do coaches, mentors, and participants utilize different venues to support their responsibilities?

c. In what ways did C1 participants and coaches change the F2F design of their coaching sessions to better accommodate their needs?

d. In what ways did the C2 participants and mentors change the online design of their mentoring sessions to better accommodate their needs? 


\section{Context of the Study}

This study took place at a large mid-western University with a project titled: A TIME for Physics First. A TIME for Physics First (PF) is a 5-year National Science Foundation (NSF) funded project, which focuses on developing 9th grade science teachers to become teacher leaders and build physics content knowledge integrated with inquiry, modeling, and technology. The goals of the Physics First project are: (1) to create a cadre of teacher-leaders who will become advocates for excellence in physics content and research-based pedagogy, (2) to strengthen high school freshman science teachers' and students' understanding of physics, (3) to enhance teachers' knowledge and ability to utilize reform-based pedagogies in teaching freshman physics, (4) to promote institutional changes among partner institutions, and (5) to increase students’ interests to take more science courses. The PF is an ongoing project that has received 2 rounds of funding from NSF. Some of the teachers in the first round (2007-2010) continued into the second round (2010-2014) of funding.

The program has two cohorts, Cohort 1 began in Summer 2010 and Cohort 2 began in Summer 2011. Both cohorts attend Summer Academies, attend academic year follow-up sessions, enroll in a 1 credit graduate course on leadership, and participate in online discussions. Teacher-participants receive support from a coach (Cohort 1) or a mentor (Cohort 2) during the academic year. Cohort 1 received F2F coaching, whereas Cohort 2 received online mentoring (no F2F assistance was provided) (Figure 1 and 2). Coaches, mentors, and teacher-participants were assigned to different Professional Learning Communities (PLCs) and each PLC is moderated by a coach or a mentor. 


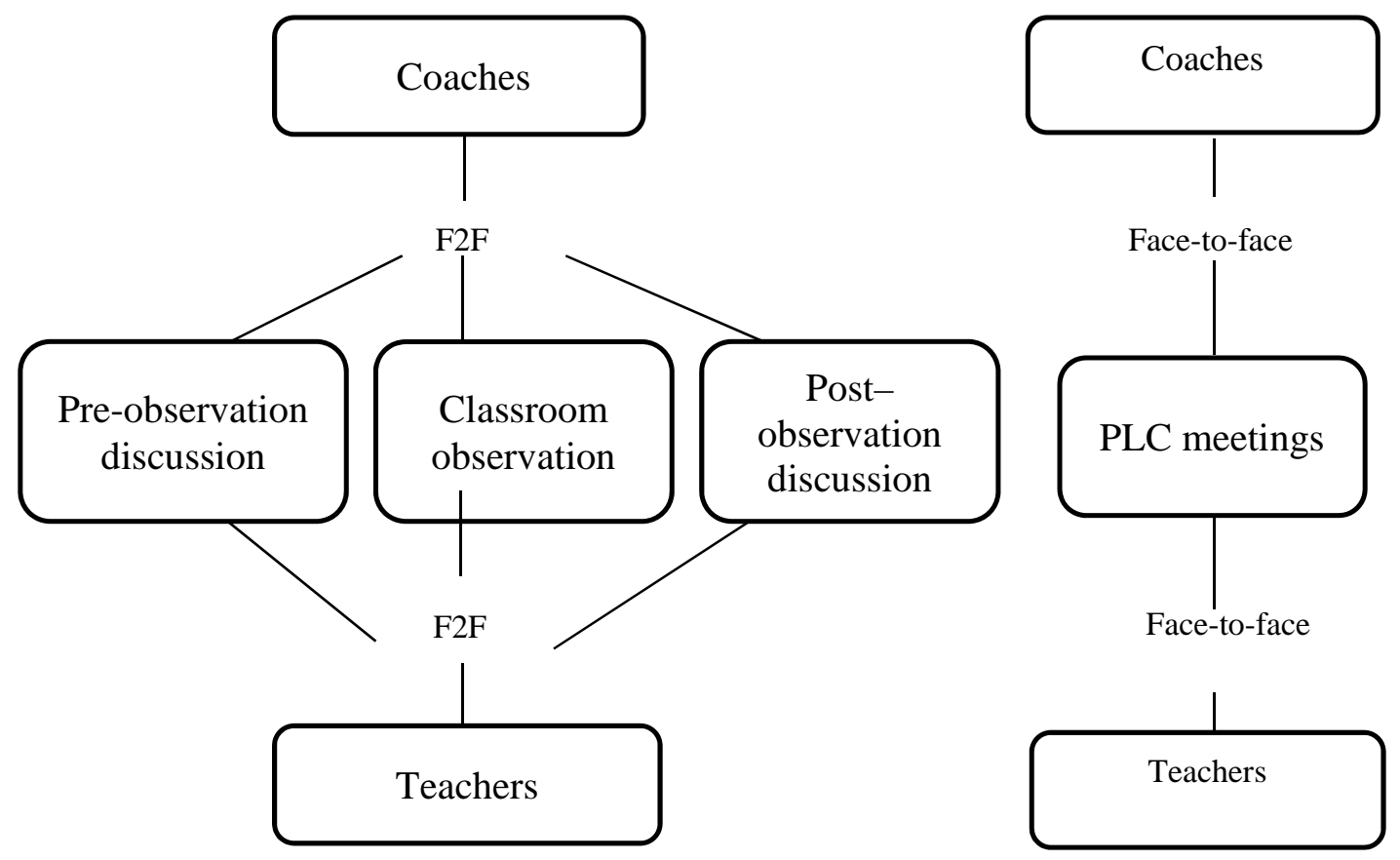

Figure 1. Cohort 1 coaching and PLC design

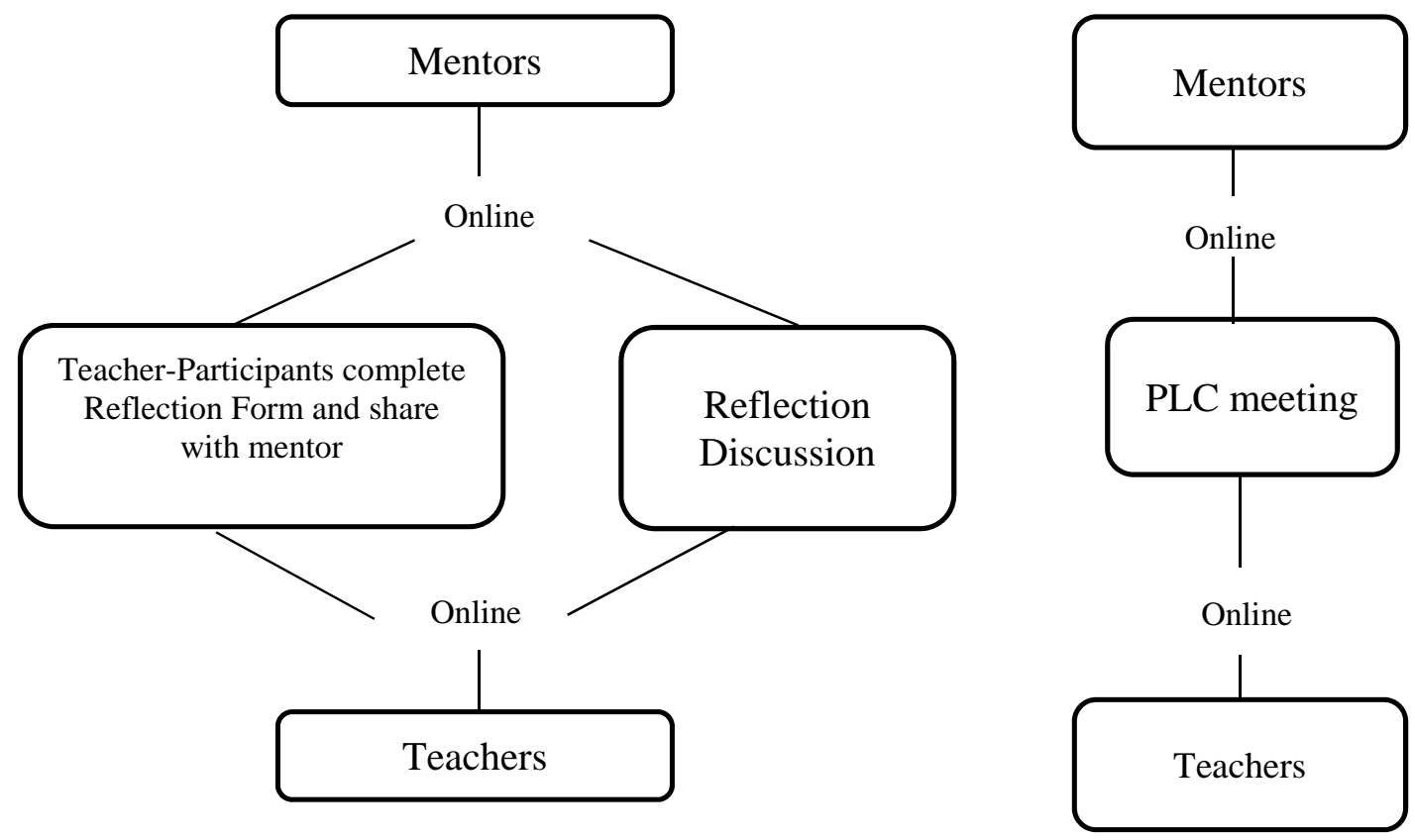

Figure 2. Cohort 2 mentoring and PLC design 
In the Summer Academy (SA), teachers learn physics content and receive leadership training. The PF Instructional Team, which includes university professors, consultants, and teachers develops and teaches content courses. The Physics Frist curriculum is based on inquiry and modeling pedagogies and leadership training. Physics topics include electricity, uniform and accelerated motion, forces, and Newton’s Laws. These topics are aligned with Missouri Course Level Expectations (CLEs) and National Science Education Standards (NSES). During the Summer Academy, teachers spend at least six hours each day on content-focused sessions. The Leadership Team, which includes a university professor and graduate student assistants, offers leadership training and instructional activities in the Summer Academy.

During the Summer Academy, coaches and mentors were placed with their PLC in physics content, leadership courses and follow-up sessions. In the academy year, teacher-participants attended three F2F follow-up sessions that focus on content, pedagogy and leadership. In addition, C1 participants received classroom observation from coaches and C2 participants received online mentoring from mentors once per month. Coaches and mentors assisted teacher-participants in teaching and applying PF curriculum.

Online coaching and mentoring took place with Sakai. Sakai online learning management system is similar to Blackboard, but provides more interactive functions for users. For example, Sakai users can see who is online now and can chat with others immediately. Users can post comments on their group discussion board and also can send private messages to other members. Although Sakai is an open-source collaborative learning interface, membership is setup by the administrators. In other words, it is a 
closed online community. The online mentoring uses a video-conferencing tool named Wimba. Wimba as a synchronous tool supports audio and video conferencing and also incorporate recording features.

Coaches and mentors were trained under a Cognitive Coaching (CC) framework (Costa \& Garmston, 2002). The approach of CC is to help the mentee identify problems of practice and to help the mentee decide the best way to solve those problems. Cognitive Coaching uses the planning conversation, reflecting conversation and the problem solving conversation in the process of coaching. Costa and Garmston (2002) explain the three conversations:

"The planning conversation occurs before a colleague conducts or participates in an event, resolves a challenge, or attempts a task. The reflecting conversation occurs after colleague conducts or participates in an event, resolves a challenge, or completes a task. The problem-solving conversation occurs when a colleague feels stuck, helpless, unclear, or lacking in resourcefulness; experiences a crisis; or requests external assistance from a mediator “(p. 34).

In each conversation, the coach uses specific strategies to plan the conversation. In the planning conversation, coaches engage the mentees' cognitive process by helping the mentees to: clarify goals, specify success indicators, anticipate approaches, strategies, decisions, identify personal learning focuses and reflect on the coaching process (Costa \& Garmston, 2002). In the reflecting conversation, coaches will engages mentee to: "summarize or recall supporting information, analyze causal factors; compare, analyze, infer, and determine cause-and-effect relationships, construct new learning and applications, commit to applications, and reflect on the coaching process and explore refinement” (Costa \& Garmston, 2002, p. 40). In the problem-solving conversation, coaches have to help mentee to: "honor existing state, frame desired state, locate and amplify resources, check for congruence, and reflect on coaching process” (Costa \& 
Garmston, 2002, p. 223). According to Costa and Garmston (2002), in the process of cognitive coaching, coaches must remain non-judgmental throughout process and use structured conversations to help the mentee plan, reflect, and solve problems.

\section{Research Participants}

Participants in this study included one coach, one mentor, one dual coach/mentor and nine teacher-participants from the PF project. The coaches and mentors are referred to by pseudonyms: John, Andy, and Ryan. The participants are referred to by pseudonyms: Henry, Bella, Jason, Lydia, Becky, Nancy, Sarah, Andria and Ted.

\section{Selection}

I purposefully selected one coach from cohort 1, one mentor from cohort 2, and one person who served as coach and mentor for cohort 1 and 2 to participate in the study. According to Patton (2002), purposeful sampling focuses on in-depth understanding of the case. Thus, the participants will be selected on the basis of their ability to provide “information rich and illuminative” (Patton, 2002, p.40). The coach/mentor selection criteria were based on frequency of interaction, quality of the relationship between coaches/mentors and mentees, and meeting minimum job expectations. The frequency of interaction included the number of times coach/mentor facilitated and participated PLC and online discussion. The quality of the relationship included the detail and richness of coach classroom visit reports and coach/mentor monthly log. The minimum job expectations include participation in required activities of the Physics First project. Required activities included attendance of SA and Follow-Up sessions, submission of monthly coach/mentor report, participation of classroom visits and online sessions. Teacher-participants were selected from the PLCs of each selected coach and mentor. 
There were a total of thirty-four teacher-participants from Cohort 1 and thirty-six teacher-participants from Cohort 2 in the PF project. Each coach and mentor has two PLCs and each PLC has 4 or 5 teacher-participants. I selected one PLC from each selected coach/mentor and from that PLC I selected the participants for this study. A total of nine teacher-participants were selected.

\section{Institutional Review Board and Data Storage}

This study was approved by University Campus Institutional Review Board (IRB) to conduct research. Since this study focused on coaching and mentoring design, I submitted an amendment to the PF IRB for approval. IRB approval was granted on January 31, 2012.

Under the guideline of the University Campus IRB, only participants who sign the consent form to participate are included as participants of the study. All participations were voluntary. Non-participation did not stop participants from receiving stipends or graduate credits. All the data is kept confidential and will be secured for four years (until the end of Physics First) when it will be properly disposed. Only I have rights to access the data.

\section{Data Collection and Management Techniques}

Qualitative research seeks to understand the world from the perspectives of those living in it (Hatch, 2002). Qualitative research seeks out the 'why' question and tries to gain insight into people’s behavior. This study investigates F2F coaching and online mentoring. I want to understand how the venue influences teacher professional development. Therefore, I choose case study as my research approach because I looked at two bounded system: coaching and mentoring. According to Yin (2003), “a case study is 
an empirical inquiry that investigates a contemporary phenomenon within its real-life context, especially when the boundaries between phenomenon and context are not clearly evident” (p. 13). Case study is most appropriate when the research is focused on a “specific, unique, bounded system” (Stake, 1998, p. 88). The multiple sources for data collection, including field observation, interview, Teacher Self-Reflection form, Classroom Observation Form, monthly blogs, and artifacts collected for study. These met Yin’s recommendations of six types of information: “documentation, archival records, interviews, direct observations, participant-observation, and physical artifacts” (Yin, 2003, p. 85-97). The primary data were interview and field observation. Secondary data included the Teacher Self-Reflection Form, the Classroom Observation Form, monthly blogs, and artifacts.

\section{Field Observation}

Hatch (2002) adapted some of Spradley’s (1980) suggestions to guide early observation, the suggestions include: 1) where do social interactions take place, 2) who were involved in social interaction, 3) what are the activities people engaged in, and 4) what are the emotions expressed. Field observation was collected from the first week of the spring semester (2013) to the end of that semester. First, because part of coaching and most of the mentoring occurred on Sakai, I observed the activities on Sakai discussion forum and PLC board. Second, I watched the Wimba sessions of the participants in the study. I asked mentors to record all of the mentoring sessions. I used the same observation protocol (Appendix G) (to guide my observation. Hatch (2002) suggested that the level of participation that an observer takes in the research setting is a key issue in doing qualitative observations. I did not interact with my participants during the 
observation period in order to remain neutral. This continuous observation increased the quality of my data and enlarged the meaningfulness of my analysis. Observation notes were also used to triangulate interview data.

\section{Classroom observation}

I asked coaches who participated in the study to record their conversations with my participants. By doing so, I was able to know what occurs during the observations and the nature of the conversation between coach and teachers. The conversations offered details of the types of support that participants sought. I also had permission from coaches to review classroom observation notes.

\section{Wimba Sessions}

I asked mentors who participated in the study to record the conversations they have with participants on Sakai. By doing so, I was able to know the nature of the conversation between mentor and participants. In addition, I had mentor and participants' permission to review mentors' notes and participants' self-reflection form. The conversations offered details of the types of supports that participants seek in the online environment.

\section{Interview}

The purpose of the interview was to reveal the kinds of support the physics teachers seek in the coaching/mentoring sessions and the kind of support coaches and mentors provide. The interview protocols were developed in terms of the research questions. In addition, questions led me to gain in-depth knowledge about two different venues. The semi-structured interview took about one hour for each participant. 
I interviewed mentors and coaches to gain their perspectives. Through one-hour semi-structured interviews, I was able to discover the similarities and differences between the way coaches and mentors utilize online and F2F conversations to assist teachers and to what extent those interactions are influenced by the venue of interaction (F2F or online). Participants, including teachers, coaches and mentors were interviewed once and some of the participants had follow-up interviews for clarification. (Appendix C, D, E and F).

\section{Artifacts}

The artifacts are lesson plans, blogs, and coach/ mentor monthly log which teacher-participants, coaches and mentors submit to the Physics First Academy. I retrieved all of the artifacts through Sakai. The artifacts provided insight of how coaches and mentors influence participants' professional development. For example, a lesson plan provides information about participant's learning trajectory through mentoring or coaching process.

\section{Data Analysis}

I used interview, classroom observation notes, self-reflection form and Wimba sessions as the primary data sources to obtain descriptions and interpretations from coaches, mentors, and teacher-participants in the coaching and mentoring context. My secondary data sources are field observations and artifacts. In data analysis stage, all the raw data, such as the field notes and interviews, were analyzed. Then, I looked at the pattern of these data to answer the research questions.

In terms of determining whether coaches/mentors did or did not accomplish the goals of the PF project, I focused on the following evidence in the data analysis process. 
The evidence includes: (1) how the coaches/mentors supported teacher-participants in online and F2F venues, (2) how the coaches/mentors used Cognitive Coaching in each venue, and (3) how teacher-participants used coach/mentor support to implement PF curriculum.

According to Yin (2003), five analytic techniques should be considered in case study method: pattern matching, explanation building, time-series analysis, logic model, and cross-case synthesis. In this study, I used pattern matching and cross-case synthesis to analyze data and build my cases from the data. This study was a descriptive case study which did not focus on comparing and finding the best case. Instead, this study was to inform the differences and similarities of the two cases. Two cases were constructed in this study: (1.) the case of F2F coaching and (2.) the case of online mentoring.

\section{Trustworthiness}

Lincoln and Guba (1985) proposed techniques of establishing trustworthiness. I used the following techniques as criteria to assess trustworthiness in this study.

\section{Credibility}

First, Lincoln and Guba (1985) suggest five activities to increase creditability: prolonged engagement, persistent observation, triangulation, peer debriefing and negative case study. I served as a research assistant for the PF project and observed both online and F2F activities for years. This prolong engagement helped me have profound knowledge about the structure of the PF coaching and mentoring design. Multiple data resources were used in this study. The data resources included observation notes, interview data and artifacts. I compared both observation notes and interview data to triangulate the data. 
I also used the peer debriefing method with my colleagues, "a process of exposing oneself to a disinterested peer in a manner paralleling an analytic session and for the purpose of exploring aspects of the inquiry that might otherwise remain only implicit within the inquirer's mind” (Lincoln \& Guba, 1985, p. 308). Peer debriefing helped me to modify my research question, share coding strategies and critique data analyzing techniques.

\section{Transferability}

Using the thick description, this study could provide valuable resources and recommendations for teacher professional development to curriculum designers who want to integrate technology with design. Therefore, it is transferable for other teacher professional development projects.

\section{Dependability}

Lincoln and Guba (1985), suggest that triangulation is one of the techniques used to establish dependability. Because I did triangulation in establishing creditability, therefore, I established dependability.

\section{Confirmability}

The criteria of confirmability are audit trail and audit process (Lincoln \& Guba, 1985). All the materials I collected were listed in Appendix A. Hard copies of observation notes, interview transcript, audio files and artifacts are saved in electric files at secured locations. All the electronic files are stored in different devices. All the data are kept confidential. I am the only person who has access to them. 


\section{Role of the Researcher}

My role as researcher was influenced by my experience of using educational technology and PD evaluator. I worked as a graduate research assistant (GRA) for a state funded professional development evaluation project for four years. While I was working with the evaluation team, I traveled around the state to observe and evaluate different PD projects. I saw many PD projects utilize online tools to provide on-going support for teachers without much success. Then, I worked as a GRA for the Physics First project that used F2F and online mentoring to support teachers. In the PF project, I found teachers were not resistant to using online tools to support learning and teaching. This was different than what I experienced before. Although in my role as a GRA, I had to interact with coaches, mentors and teachers. My interactions were limited to the leadership component of the PF program and to assist teachers to use online tools.

My role as a researcher was to (1) observe how teacher-participants interact and how they utilized the venues (2) investigate how coaches or mentors, in different venues, assist teacher-participants. In order to keep myself neutral, I did not join coaching and mentoring activities in either venue. I constructed my understanding of mentoring and coaching by observing and participating in Physics First activities.

\section{Limitations of the Study}

I was not able to be present in the classroom observation and PLC meeting due to schedule conflicts. This was a potential limitation of the study because I missed opportunities to observe the interactions and conversation between coaches and participants. Although I asked coaches to record the conversations, I was not able to record everything that may have been valuable for this study. 
The second potential limitation was that the Cohort 1 had already begun the Physics First project one year before Cohort 2. Thus, Cohort 1 had already developed relationships with coaches before my investigation began. This variable may confound differences and falsely attribute differences to the time rather than the venues. In response to this limitation, I focused on how participants construct the knowledge of Physics first curriculum through support from coaching and mentoring rather than focus on how they developed relationships with coaches and mentors. In addition, I reviewed the historical data to find out the topics discussed by teacher-participants and coach/mentor as well as difficulties participants faced during the coaching and mentoring process. Through the review of the historical data, I can determine whether it was time or venue that explains differences.

The third potential limitation is the generalizable of qualitative study. The affordance, in this study, depends on how the Physics First participants used the coaching and mentoring. In this study, affordance does not mean how technology itself can provide to users. Therefore, this study may be applied beyond the study if the study focuses on how users accomplish learning goals through the support of PD in F2F and online venues. 


\section{CHAPTER FOUR: CASES}

The following is a description of the F2F coaching and online mentoring design of the professional development portion of the Physics First project. Below I develop two cases that are distinguished by the venue of communication. Case one relies on a F2F venue for individual coaching and for Professional Learning Community (PLC) meetings. Case two relies on a venue of online communication for individual mentoring and for PLC meetings. Then, I provide in-depth information for each of the cases.

\section{The Physics First program}

In Summer 2010, a total of 34 Cohort 1 (C1) teachers participated in the first year of the Physics First (PF) program. In Summer 2011, 36 Cohort 2 (C2) teachers participated in the second year of the Physics First (PF) program for a total of 70 teachers. Participants were required to attend three consecutive years of Summer Academy (SA) as well as participate in online sessions such as blogging and leadership courses. In each SA, teachers spent four weeks at the university learning content, pedagogy, and leadership skills. The first two years of SA are four weeks long and year 3 is two weeks long. During the participation in the PF program, teachers were assigned to different professional learning communities (PLCs) based on their geographic location. Each PLC includes four to five teachers and one coach/mentor. Some of these PLC consisted of teachers in the same building while others consisted of teachers from different districts. Teachers worked collaboratively with other PLC members and with coach/mentors while attending the SA, as well as participating in online activities during the academic year.

After four weeks of SA, teachers continued to receive support from the project and coaches. The support consisted of quarterly follow-up meetings (where all teachers, 
coaches, and mentors met project leaders on the university campus), monthly coaching sessions (at the teacher's school) and monthly PLC meeting (a centrally located meeting place for the 4-5 teachers involved). Because this study focuses on the relationship between the coach/mentors and the teachers, data was gathered from the monthly coaching/mentoring sessions and monthly PLC meeting and not from the quarterly follow-up meetings.

\section{Cohort 1 Coaching sessions and PLC meetings}

The monthly coaching sessions began by teachers and coaches scheduling F2F coaching session for classroom observation. The purpose of the F2F coaching session is to support the teachers as they implement the PF curriculum. Most of the coaching sessions are scheduled through email or Sakai. In general, teachers did not pick a specific class for coaches to observe. Participants were fine with any dates as long as it was not an exam day or a school meeting day. The purpose of pre-observation discussion is to touch base, and help the coach to understand the progress of the class and to assist the teacher with the implementation of PF goals. The pre-observation discussion usually takes about 5 10 minutes, depending on the schedules of the coach and the teacher. Coaches and teachers often meet in the school building before classroom observation. During the observations, coaches are asked to complete a Classroom Observation Form which is provided by the PF project (Appendix J). The Classroom Observation Form includes 1) background information on the lessons being observed, 2) student engagement, 3) classroom learning environment, 4) instructional delivery method observed, 5) evidence of leadership, 6) script of class and, 7) summary of post observation discussion. The classroom observation usually takes about 50 to 90 minutes depending on the length of 
the class period. After the observation, coaches and teachers meet F2F to discuss the lesson. The post-observation discussion takes from 5 minutes to an hour, depending on the coach and the teacher, however, most Post-Observation Discussions were very brief. The purpose of post-observation discussion is to help the teacher reflect on teaching and the implementation of the PF curriculum. Teachers are encouraged to ask coaches questions to improve the implementation of the PF curriculum. The flowchart below represents the design of the coaching session (Figure 3).

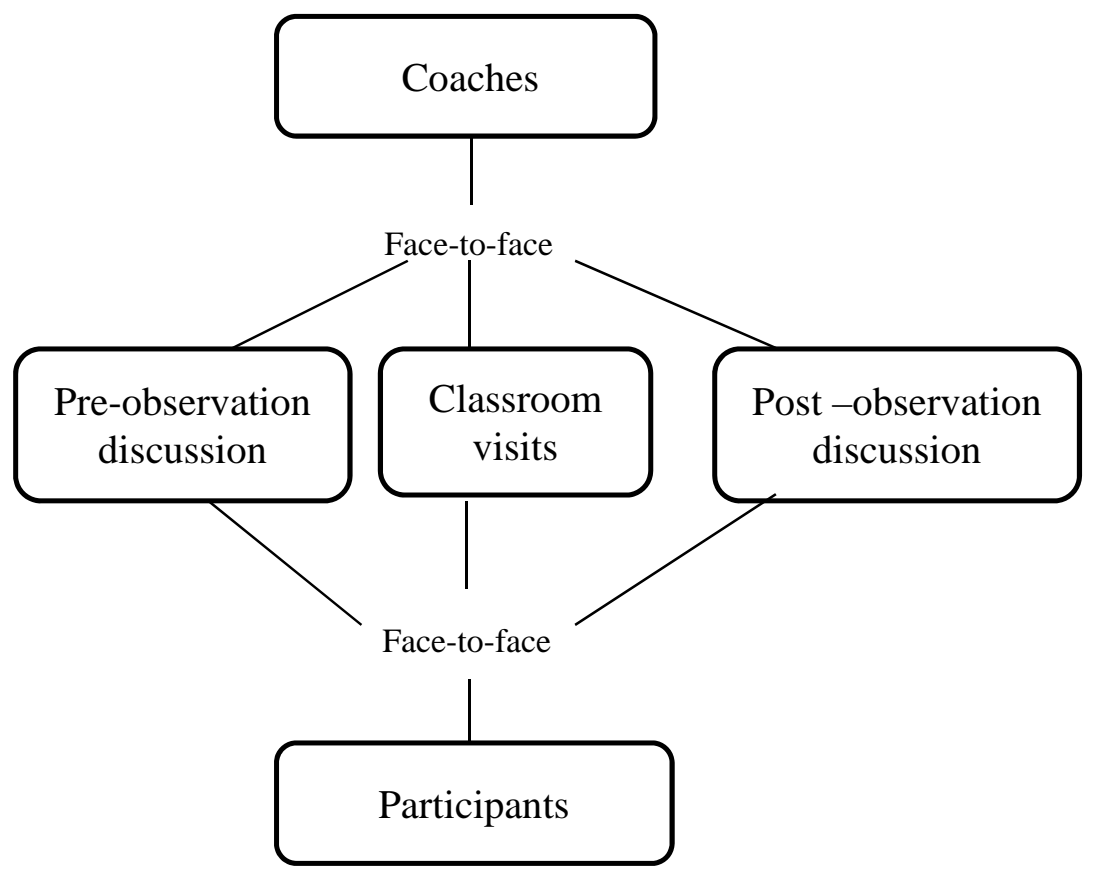

Figure 3. Cohort 1: Face-to-face coaching

In addition to F2F coaching, teachers and coaches meet F2F in their monthly PLC meeting, to share their success or challenges in implementing the PF curriculum. These meetings were scheduled after school in a centrally located school building. The PLC meeting usually takes about an hour depending on the coach and the teachers. In the PLC 
meetings, coaches served as facilitators, assisting teachers in identifying problems to improve teaching and learning, while one of the teachers served as leader of the group. The flowchart below represents the design of the PLC meeting (Figure 4).

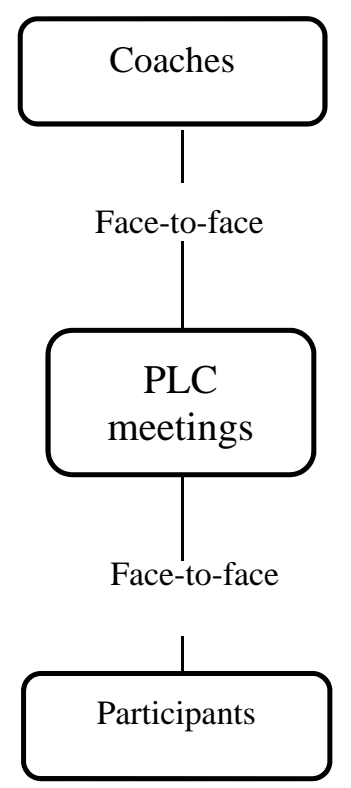

Figure 4. Cohort 1: Face-to-face PLC meeting

\section{Cohort 2 Mentoring sessions and PLC meetings}

Teachers and mentors schedule monthly online mentoring session to discuss the implementation of the PF curriculum. The purpose of the online mentoring session is to provide support for teachers to implement successfully the PF curriculum. Most of the online meetings are scheduled through email or Sakai. The online meeting schedule depends on the availability of mentors and teacher-participants. Teachers prepare for this online mentoring session by completing a Teacher Reflection Form which is provided by the PF project (Appendix I). The Teacher Reflection Form includes 1) details of a lesson s/he has implemented by responding to several self-evaluation questions and 2) additional 
comments about the lesson. The mentoring takes place in an online environment and uses Wimba, a video-conferencing tool. During the online meeting, mentors and teachers discuss the teacher reflection form and problems associated with the teaching of a lesson. Teachers are also encouraged to ask mentors questions to improve the implementation of the PF curriculum. The flowchart below represents the participants of the mentoring case and the design of the mentoring session (Figure 5).

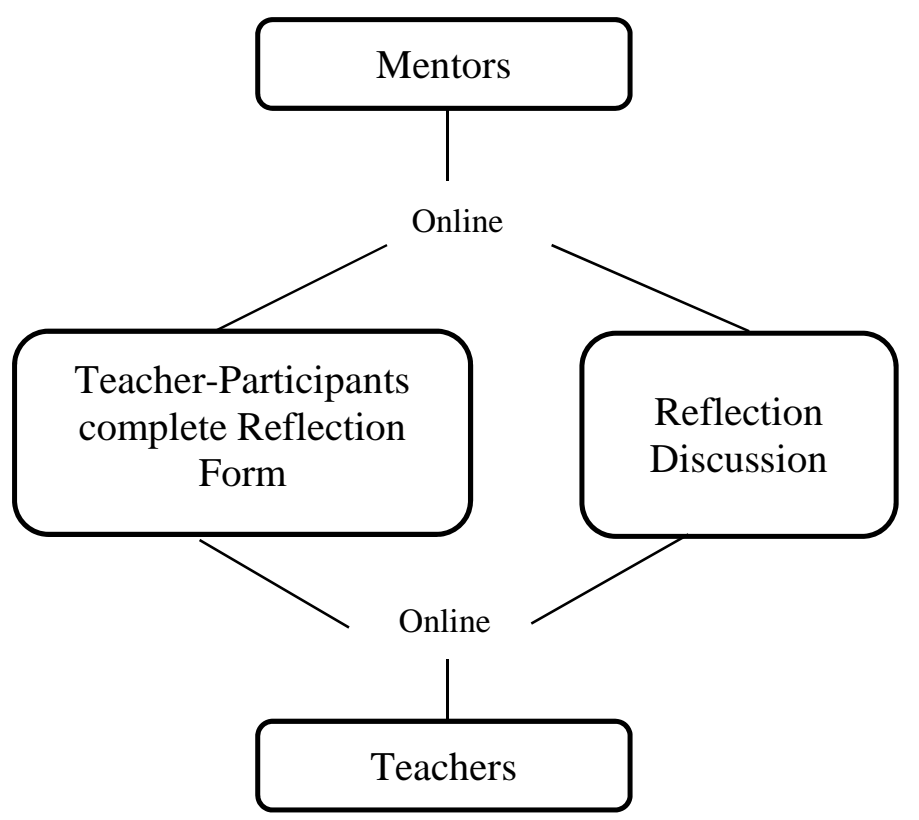

Figure 5. Cohort 2: Online mentoring

In addition to online mentoring, teachers and mentors meet online monthly, with their PLC, to share successes and challenges in implementing the PF curriculum. In the PLC meetings, mentors serve as facilitators, assisting teachers in identifying problems to improve teaching and learning. The PLC meeting is led by teachers and the mentor is more of an observer than a moderator or leader. 
The flowchart below represents the relationship among teachers and mentors (Figure 6).

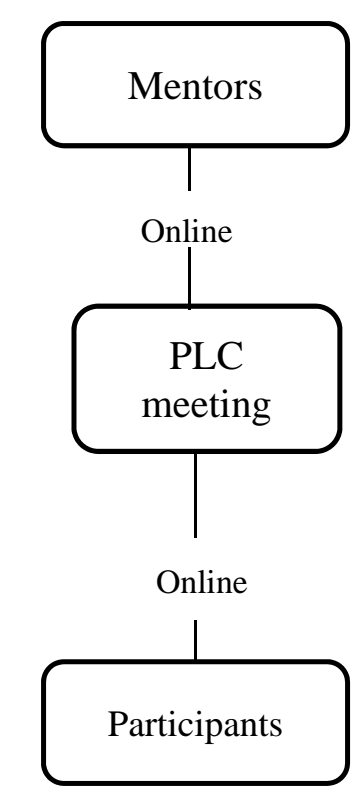

Figure 6. Cohort 2: Online PLC meeting 


\section{Case One: Coaching}

The case study includes four teachers and two coaches who utilized F2F coaching to support the implementation of the PF curriculum. First, I provide participants' demographic information. Second, I describe the F2F coaching process and expectation. This includes conversations between participants and coaches before and during the coaching and PLC meeting. Third, I discuss problems teachers encountered in the coaching and the solutions they implemented. Fourth, I discuss the limitations posed by these solutions.

\section{Participants of the study}

A total of four teachers - Henry, Bella, Jason and Lydia and two mentors - John and Andy, from two PLC groups, who participated in the study. Henry and Bella taught in the same school and shared the same mentor, John. Jason and Lydia shared the same coach, Andy. However, they taught in different school districts and were in different PLC groups. Jason attended another Physics First PD at Arizona State University prior to his participation in this program. In this case, only Jason had prior experience of teaching PF curriculum. The following table (Table 3) describes the teachers of the two C1 groups in case \#1. 
Table 3

Demographic data of C1teachers

\begin{tabular}{l|l|l|l|l|l}
\hline Coaches & $\begin{array}{l}\text { Teachers by } \\
\text { PLC }\end{array}$ & $\begin{array}{l}\text { Prior PF } \\
\text { experience }\end{array}$ & $\begin{array}{l}\text { School district } \\
\text { demographic }\end{array}$ & $\begin{array}{l}\text { Years of } \\
\text { Physics } \\
\text { teaching } \\
\text { experience }\end{array}$ & $\begin{array}{l}\text { years of teaching } \\
\text { experience }\end{array}$ \\
\hline \multirow{3}{*}{ John } & Henry & $\mathrm{N}$ & Urban & 1 & 17 \\
\hline \multirow{3}{*}{ Andy } & Bella & N & Urban & 1 & 10 \\
\cline { 2 - 6 } & Jason & Y & Urban & 3 & 9 \\
\hline
\end{tabular}

Note: Y means yes; $\mathrm{N}$ means no

The participants' prior experience with PF and their years of teaching experience provide support to the teachers' belief that they have a good understanding and experience of teaching the PF curriculum. Below, I provide demographic information, teaching experience, and goals for each of the four participants.

Henry has taught science subjects for nineteen years. He taught earth science four years before teaching physical science at the high school level. Thus, this was his first time to teach the PF curriculum. He teaches in an urban school that supports the PF curriculum. Henry, Bella and another PF participant teachers were the only teachers teach the PF curriculum. In his monthly blog and discussion posts in Sakai, Henry focused on developing assessment materials, improving his teaching practice and student success, pacing and collaborating with colleagues. He said:

We finished our first Physics First classes in December and are now on our second "go-round" starting with Electricity again. We found, as many of you probably have, that we got very bogged down in electricity first semester and trudged slowly through uniform motion, as well. We have spent some time (and continue to do so) deciding what we need to teach and what we can cut out in order to get through the material a little more quickly. And with some activities, we're not tossing them out altogether; we're just presenting them differently maybe a demonstration instead of a lab. 
Bella has ten years of teaching high school level science subjects with the exception of physics. In her monthly blog, she specific discussed her plan to improve student engagement and motivation and implementing the PF curriculum. Thus, she thought that joining the Physics First program had great impact on her student learning and her teaching, she explained:

I think the kids are less bored in the class. I think I was bored in class. So I think all that kind of in general, it just makes everything more fun. It's more open, that we can change it a lot more if needed than I first realized for stuff we could. So I think it allows a lot of flexibility. I think the kids are more interactive with each other and with me than ever before. The kids are less afraid being wrong. I think that was their biggest afraid before. They hated to be wrong. I try to make it -I don't care. The wrongs are all great; just fix them. I don't think I was that way before. So many different ways those things have been changed.

Jason is an experienced teacher who has taught Physics First curriculum for over three years. He first attended another Physics First PD in another state before he applied to this program. Thus, he believes he has experience and deep understanding of the PF curriculum. Moreover, his school also used the Physics first concept as their curriculum. Thus, he also received supports from his school. The PF project helped him to reflect and share his professional growth. He said Physics First “forces me to go out to look at other stuff and reflect on my teaching and why I teach and how I teach.”

Lydia has taught the physics part of physical science for sixteen years and had three years of experience teaching junior and senior physics. However, according to Lydia, her physics content knowledge is relatively weak. Therefore, she viewed herself as a novice to teaching physics and PF curriculum. As the only science teacher in her school teaching the PF curriculum, Lydia has no other person in her school to discuss her implementation of the PF curriculum. Thus, she valued having a coach visit her and discuss her implementation. Her goal to participate in the PF program was to help 
students understand the physics concepts. She was concerned about the pace of the curriculum and student learning.

Andy and John are the coaches in the study. Andy is a retired Physics teacher who also has experience teaching Physics First curriculum. John is a Physics professor in a Midwest University and is familiar with Physics First curriculum. Before he became a professor, he taught Physics in high school level for many years. He also serves as a school board member in the same school district as his teacher-participants. As mentors in the Physics First program, Andy and John were trained under Cognitive Coaching. (Costa \& Garmston, 2002). In cognitive coaching, mentors use questions to help mentees develop the ability to solve problems through planning, reflecting and problem solving strategies. John talked about his approach and strategy to help his mentees. He explained: Cognitive coaching mainly asks questions in the classroom, lead the discussion to the questions. It is fairly natural for me. That is the way you communicate with people and resonates with them. So it's critical to, any interactions you have within a dialogue whether is another teacher or the students in your classroom. I just try to question and ask why their actions are or what they are; try to point out things in a very friendly way, just matter of fact observation and let them see it themselves if I can. I think that is the part that I don't think they totally will see everything, as an outside observer, I see the things they don't. And a lot of times teachers that have these difficulties are because some teachers can see everything literately and goes on and know what is happening and others is so concentrate on their content and they lose track on what the kids are doing in all parts of the room. I think that is what the issue is.

John used cognitive coaching strategies to ask questions to help teachers to identify their problems. Particularly, as an observer, coaches can see things or problems that teachers do not.

In this case, teachers had varied teaching experiences and focused on different areas to successfully implementing the PF curriculum. Thus, the participants had 
different goals to improve their teaching practice. Through the coaching design, they asked for different types of support for improving their teaching and student learning.

\section{Face-to-face Coaching process and Expectation}

In this section, I first discuss the project expectation for coaches and teachers. Second, I present the coaching process by describing how coaches and teachers schedule the F2F meeting, what coach and teachers do before, during, and after the classroom observation, what they discuss, and what occurs during a typical PLC meeting. Third, I will discuss problems or issues they encountered as they used F2F coaching to conduct the coaching sessions. As the four participants had similar coaching experience, I focus on Henry’s experience, however, I also include other Participants' experience as part of the case. The reason I selected Henry is because he expressed a strong desire to improve his teaching practice and he thought deeply about ways to improve practice.

First, the PF project had requirements for both coaches and teachers. The coaches had two primary responsibilities: monthly coaching with each teacher and monthly PLC meetings with the group of teachers they coached. In the monthly coaching, coaches were to conduct a pre-observation discussion, the classroom observation and the postobservation discussion. The goal was to support teachers as they implemented the PF curriculum. The coaches were expected to conduct at least eight mentoring sessions throughout the academic year (one/month). The teachers had to collaborate with coaches to schedule classrooms. In the next section, I describe the F2F coaching below.

Henry and John scheduled the F2F coaching meetings via email or Sakai private messages at beginning of the month. All of the F2F meetings were based on the availability of coaches and teachers. Unless the potential observation date fell on an exam 
day, both were fine with any dates. Thus, John and Henry did not pick a specific Physics lesson or a class for the classroom observations. Usually, if possible, John would arrive early to conduct the pre-observation discussion with Henry regarding the lesson he was about to observe. They usually spent five to ten minutes briefly talking about: 1) what unit he was teaching and 2) what they are doing and the goals that day. The preobservation meeting was informal, its purpose was to touch base, and help the coach to understand the progress of the class.

During the observation, John just sat quietly in the back of the room taking notes. He observed the way Henry implemented Physics First curriculum and instructional strategies, and interactions between Henry and his students. While taking notes, John completed a classroom observation form (see Appendix H). Henry did what he normally did in his Physics class. He did not change his routine. Henry's students were used to having John in the classroom observing them; thus, they were not bothered by his presence. The observations normally took one block of class which was ninety minutes in Henry’s case. Henry described the classroom observation, he said:

We don't do any pre, not a formal, pre-observation. A lot of time, I will tell him what it is, what are we going to do that day or we are gonna be doing a lab or we are gonna be in this topic but nothing formal, written or anything like that usually. It's mainly just observation. it's pretty much he is in one area of the room observing class, I just kind of do my thing like I normally do, I don't really change anything. And my students are used to now people being in the classroom, so they just carry on as normal. So it is very unobtrusive as far as it's not really a change in our routine at all.

And I guess afterwards, it is kind of a short visit, very informal and it is not a formalize process at all. At the end of that block, we usually have some time to discuss things we are doing in the class or maybe the ideas for the next class coming up with my coach. 
After observations, Henry and John sometimes had about ten minutes to discuss the observation. They discussed what they had seen, how the lesson went, things Henry did, and questions. John also asked what Henry's goals were for the lesson and for the students. As a coach, John did not want Henry to feel like he is being judged. His role was to be there to support Henry. Using a Cognitive Coaching approach, John began the discussion by asking Henry what he would like to change, a better way to explain things, and how Henry would teach it the next time. Through the conversation with these types of questions, John helped Henry reflect on his teaching practice. John stated:

Usually it's probably another just 5 or 10 minutes sessions that we talk about the lesson, what they did, how things went, what their plans are, where they are going, what I can help them with, and ask them what they need. So, I just ask a couple of questions and see where they are at, what they need of me at that point because it's more that I am a resource for them and is there anything that I have suggestion about, I will come and ask them about why they did what they did and see if there is really something that I need to tell them that I think. But I try to do it through questioning more than anything.

Most of the questions that Henry asked were related to pedagogy, content and curriculum modification. Henry explained:

We usually have some time to discuss things we are doing in the class or maybe the ideas for the next class coming up with my coach.....We have a lot of success with the curriculum kind of as it outside of the box. We have changed the few things and I ask the coach about some ideas. And, occasionally I ask him about pedagogy, what would be the best way to approach this activity or another way that we might do this lab.

According to John, Henry had poor physics content knowledge. Thus, they spent time talking about physics content and answering content related questions.

I would say [I ask] content probably more than anything. Usually, some of them maybe I am really familiar with and a lot of times are my students who ask extend question about, go beyond what we actually teach in the classroom from which I am not familiar with the questions or the answers. 
As a coach, John led Henry to reflect on his teaching and identify problems through questions. Henry, as a novice PF teacher, focused on the physics content knowledge, pedagogy and curriculum modification.

Bella's coaching experience was similar to Henry’s with a few differences. Bella, focused on her special needs students, asked questions regarding curriculum, student learning, classroom management and instructional strategies. She described her conversation with John.

Most of the time, we kind of go over just systematic of what we were teaching, if we have a better way to explain these or is there a better way to do this; or if you think it is ok to flip flop these two worksheets; or take this lab out, because we do this one instead. With those kids [special ed.], I need millions of different ways practically to explain one concept to them. Because like I said, one way one kid will get it; but reworded slightly, another kid will get it; reworded another way, third kid will get it. So I have to [learn] from other people, other people that know what they are doing, like our coach, come up with other ways to work on explanations.

I ask him how to deal with the difficult kids because you get one in every class, how to deal with the kids that doesn't want to do anything. I know that he had taught the past outside the physics. Just for advice. So, just anything relates to teaching and curriculum.

The first time she taught the PF curriculum, Bella had problems of sequencing. John assisted her during the classroom observations, she said:

It was last year, first time I was teaching it. I remember I was doing something on the board, he was like, hey come here, he said: you flip it, you did it backwards. I am like: oh, gosh. And so, he corrects it.

John explained to her that her sequence of instruction was backward to the PF approach. With the special needs students, Bella needed someone who had teaching experience who could help her with things like lesson sequence and instructional strategies. She wanted to learn different ways to explain the physics concepts to these students. 
Jason worked in an urban school district that had been teaching freshmen physics through modeling for several years. The other physics teachers in Jason's school were not participants in the PF program, but their expertise was a great benefit to Jason's development. As an experienced PF teacher, Jason wanted his coach (Andy) to focus on his questioning skills. Jason, felt this was an area where he could improve with the help of an observer. He explained:

I do like to ask him to watch how I am asking questions. I want to make sure that I am focusing students, not doing call and response. Questioning strategy is short trip almost got no coaching at summer academy, people were not taught how to ask questions, I think it is better, I know other teachers can get better, and if you don't do it well, students don't learn as much, and if you do it in the white boarding session, you can actually hurt some people's feelings.

According to Jason, the questioning strategy was not taught in the SA, thus, he was eager to improve his questioning skills to improve his teaching.

Since Lydia was a novice teacher in teaching the PF curriculum, she was concerned about pacing with the PF materials, curriculum modification and student learning. Lydia asked questions related to her questioning skills and strategies to keep student focus. She stated:

I am mainly concerned about questioning because I think one of thing that is new to me for PF compare to just teaching the way I used to teach is a high level of questioning so you are not just asking closed questions or low level questions just kind of, level knowledge questions and so I, we talk about that. I also am concerned about keeping everybody focused on the class, not just me talking to one student while everybody else is doing something else. I want to make sure that everybody is listening to the conversation and is thinking about what the class discussion is even if I am not calling on them, and so I'm always wanting to see how he feels things are going.

In the coaching, the teachers asked various questions associated with the implementation of the PF curriculum. Data from teacher interview, coach interview and 
coach observation notes were used to construct the table. The summary of the questions asked by the teachers is presented in Table 4 below.

Table 4

Summary of the types of questions asked by C1 teachers in the F2F coaching sessions

\begin{tabular}{|c|c|c|c|c|}
\hline & Henry & Bella & Jason & Lydia \\
\hline $\begin{array}{l}\text { 1. Student learning - } \\
\text { difficulties, misconceptions, } \\
\text { progress }\end{array}$ & 1 & 1 & 1 & 1 \\
\hline 2. Instructional strategies & 1 & 3 & & 1 \\
\hline $\begin{array}{l}\text { 3. Curriculum/lesson } \\
\text { modification }\end{array}$ & & 2 & 1 & \\
\hline 4. Pedagogy & 1 & & & \\
\hline $\begin{array}{l}\text { 5. Classroom learning } \\
\text { environment }\end{array}$ & & & & \\
\hline 6. Content knowledge & 1 & & & \\
\hline 7. Pacing of material/lesson & 1 & & & \\
\hline 8. Student engagement & & 1 & & 1 \\
\hline 9. Classroom management & & 1 & & 1 \\
\hline 10. Instructional planning & 1 & 1 & & \\
\hline 11. Questioning Strategies & & & 1 & 1 \\
\hline 12. Sequencing & & 1 & & \\
\hline
\end{tabular}

According to the table, Jason asked fewer questions than other teachers and Bella asked the most. Jason is the most experienced teacher in the C1 group. Interestingly, he asked the fewest questions because he focused on his questioning strategies in an effort to improve student learning. Bella asked more questions than other participants because she focused on her special needs students, rather than the improvement of a specific teaching strategy. In the C1 case, all of the participants spent the most time discussing questions associated with student learning and instructional strategies. The fewest questions were asked about sequencing. Only one participant (Bella) asked that question. 


\section{Professional learning community (PLC) Meeting}

As mentioned in the previous section, Physics First designed a Professional Learning Community (PLC) as part of the coaching and mentoring design. The PLC design offers opportunities to develop a learning community and enhance collaboration among teachers. In the monthly PLC meeting, coaches attended the PLC meetings with their assigned teachers, but the role of the coach was as observer/supporter and not as leader. He listened to the discussion and provided suggestions to the PLC group.

Thus, each PLC has its own schedule to meet and collaborate to improve the implementation of the PF curriculum. Since Henry and Bella are in the same PLC and teach in the same school building, they were able to meet regularly. There were three other teachers in Henry's and Bella's PLC, two of them worked in the same school building and one worked in another school district. Therefore, it was easy to meet frequently with the teachers who were in the same school building, but not as easy to meet with the teacher who was not in his building. In the meeting, they usually worked on creating and modifying assessments, discussed classroom management, as well as how to pace the curriculum. In the discussion of assessment, the teachers talked about when to give assessment, how to write an assessment, and how to write a good test question. Henry described his PLC meeting:

It is very easy for three of us to meet. Our PLC meets twice a week, usually. Our schedule I will say 45 minutes twice a week. We have created assessments. And so either our whole group or part of our group meets during that time on the weekly basis. The only exception is when we have a teacher [works in another district] in our group; we haven't really met with her very often as a group.

We modify assessment to align with our objectives. We have talked about formative assessment strategies and different examples of formative assessment, to cooperative learning strategies, different examples of cooperative learning; we 
talk about classroom management, we have covered a lot of ground. Pacing, we have talked about pacing of the curriculum in each semester and it has been great.

Henry and his PLC team focused on developing and modifying assessment as well as the pacing of the PF material. The PLC meetings were productive for the teachers in Henry's building, but not for the teacher who did not work in that building.

Bella, in the same PLC and same school building with Henry, also talked about her PLC meetings and the role of coach in the meetings. For her, sharing ideas with other teachers and coaches is important. She said:

I will go watch him (a teacher in her PLC) a lot and see what I can take from him. It is nice to hear different ideas even from our coach about how maybe we can do this instead of said what we did and try this way the next time. So that is what I get the most from it- different ideas.

I think he is just a mediator. I think he knows what works, what don't work, and here is another idea. I know the last one we had, he is kind of let in and sense of this is what we are talking about, do you guys have any questions about this, this one is good. I feel like our PLC is working very nicely. We are growing all together. I don't think we have ever had, there are so many things that I feel we email things about, just things that we already covered when the time we get together, when we meet, we already handle it. He is kind there to bounce ideas off.

Bella and her PLC group shared ideas to use in teaching the PF curriculum.

Jason, in another PLC, did not have regular meetings with his PLC group. Instead, he met with the physics teachers in his school building (who were not participants in the PF program). These teachers were highly qualified teachers of physics at the freshmen level. Jason's school has its own PLC design. Jason meets with these teachers regularly. As an experienced teacher, Jason did not see the need to ask for help from his PF PLC.

His coach, Andy, explained his case. Andy stated:

As far as just getting together and talking about the material; because they both have really good command of the material, for them to get together as a PLC, they can do better things with their time. And they do better things with their time, they meet with their PLC in their school. 
Jason did not meet with PF program PLC group. Instead, he met with freshmen physics teachers in his own school.

Lydia’s PLC scheduled quarterly meetings. All of her PLC members are located far away from each other. Therefore, not everybody was able to travel to the PLC meetings. Therefore, Lydia thought the PLC meeting was the least effective part of coaching. She stated:

We do the PLC meeting supposedly once every quarter and because mainly of technology problems and I can't go to meet F2F. I think the PLCs are the least effective piece for me. We live like three hours from one another and so if I was going to meet with them, I would have to take off a day from school and drive over to town and that is really difficult for me.

Although the PLC design is to provide collaboration opportunity for teachers to share and work together, it was not an effective use of time for teachers to drive to the meeting especially when that trip takes several hours. In Lydia’s experience, since it was not easy to meet F2F, it limited the effectiveness of the F2F PLC design.

The PLC design provides opportunity for teachers to interact and communicate throughout the academic year. However, not all of the participants had the same experience of participating equally in the PLC meetings. For example, Henry and Bella met regularly and had productive meetings, but two other members of their PLC, who worked in another district, did not meet regularly with them. Lydia could not participate in the PLC meeting because of the distance she would need to travel. Jason, because he was more experienced than other members of his PLC and because he was active with his own school's PLC, did not see the need to join the PF program PLC meetings.

Summary. Teachers benefited from the coaching sessions and the PLC meetings. They felt that coaching supported their teaching and the implementation of the PF 
curriculum. Another benefit of coaching is that it supported teachers to reflect on their teaching. The classroom observation provided teachers and coaches an opportunity for indepth discussion. For instance, Jason asked his coach to focus on his questioning strategies while observing him teaching. Furthermore, the PLC design connected teachers and encouraged them to work together. However, due to time and location constraints, teachers received little feedback and were unable to meet with their PLC groups. These problems are described in greater detail in the next section.

\section{Problems of the Coaching Design}

In this section, I focus on the problems that participants (coaches and teachers) encountered in the coaching process. In the Physics First project, coaching was designed to provide teacher-participants ongoing support as they implemented the PF curriculum. Teachers and coaches communicated through F2F for coaching and the PLC meeting. However, coaches and teachers discussed three problems they encountered: 1. receiving too little feedback from coaches; 2, limited number of classroom observations, and 3. limited number of F2F meetings with PLC.

First, participants received little feedback from the coaches because of time constraints. All four teachers in this case had to teach other courses and/or had school duty after the observations. As mentioned earlier, coaches and teachers had five to ten minutes for the post observation discussions. The time was too short for teachers and coaches to exchange ideas and discuss problems at a deep level that were associated with the teaching. Also, John wrote brief observation notes (they did not contain any specific critique of the teaching of the lesson), he did not share these notes with his teachers. This concerned teachers because they valued the feedback from coaches to improve their 
teaching practice. For instance, Henry only received oral feedback with no specific critique of his teaching. He wanted more feedback, either verbal or written feedback, from John. Often times, he only received encouragement type of feedback such as "you are doing a good job” from John. He pointed out the importance of having feedback for improving his teaching. He stated:

I am always anxious to hear good and bad about my teaching and things that might change. I get a lot of feedback from my students because I do survey with them and ask them continually. It would be nice to have a little more feedback. And if maybe some kind of formalized feedback forms or online or email back. I have not received much feedback and like I said positive or negative would be nice. Just to get and he always verbally says - you are doing a great job, keep it up. Specific feedback would be nice.

Bella also wanted to see written observations from John. However, it was difficult for the participants and coaches to schedule other times for the post-observation discussion. Additionally, John did not share the notes with participants. The teachers felt these postobservation discussions were a missed opportunity for meaningful conversations about their teaching.

Second, participants wanted more observations each month. Henry mentioned the difficulties associated with having more frequent coaching and PLC meetings. He stated:

It is hard because the coaches have schedules too. And it is hard to be more frequent in the visits. And I don't know if the frequency will be an issue but maybe a chance for three of us or PLC sit with our coach and talk through some things that, you know, as a group collectively might have better questions than just one at the time. You know, a lot of time that would spark better conversations in your group. So, I would say maybe a, not frequent but a semesterly or quarterly visit which I guess we have at our follow-up meetings, we had time to sit with our coach and asked questions. So, we actually did that Saturday, so maybe doing that more often than just follow-up meetings. 
Jason, suggested a different design. He felt "the least effective is that only one visit for one day. Coaching should be done, like I said, several days in a row. Coach should see the lesson progress and changes.”

Third, F2F PLC meetings were difficult for teachers to attend who worked in different districts. Henry also mentioned his desire for more frequent PLC meetings. Since he and two of his PLC members were in the same school building, it was easy for them to have a productive meeting. But, one of his PLC members (not in this study) teaches in a different school district. Thus, it was not easy for them to meet with her regularly. He stated:

So either our whole group or part of our group meets during that time on the weekly basis. The only exception is when we have a teacher in other district in our group, we haven't really met with her very often as a group. Last year we did, she came four times in the school year last year, but we haven't had a lot of communications this year with her.

The expectation for teachers to meet as PLC was once a month. Since Henry and Bella were in the same school building, it was easy for them to meet frequently. However, one of their PLC teachers did not participate the PLC meeting because she worked in a different district and she had to drive for meetings. The distance resulted in a disconnect and the lack of full participation by all members in the PLC.

Lydia encountered the same problem. She would have to drive 3 hours to take part in the PLC meetings. Thus, she did not have the opportunity to work and share with her PLC.

Summary. In summary, the coaching design had problems that limited the effectiveness of the coaching and PLC meeting. The limitations included receiving little feedback during the post-observation discussions from coaches due to time constraints, 
inability to increase the number of classroom observations, and geographic distribution difficulties resulting in decreased attendance or no attendance at PLC meetings.

Most of the post-observation feedback teachers received was oral. Teachers wanted more formal, specific, and written feedback from coaches. Although the coaches wrote a Teacher Observation Report (Appendix H), they were very brief and the coaches did not share them with participants. The participants felt the quality of that feedback was poor. In addition, teachers and coaches did not have enough time to discuss feedback after observations. Finding a time to sit down and do the post observation meeting was very difficult. Furthermore, teachers would like to have more observations and PLC group meetings. Since coaches and teachers had different schedules and driving to different schools was time consuming, it was difficult to have more than one observation and PLC meeting per month.

\section{Solutions of the Problems}

To solve the problems in the coaching design, participants and coaches changed the way they communicated.

First, in response to participants’ need for receiving more feedback and having time for post-observation discussion, Lydia and her coach, Andy, conducted the postobservation discussion on Wimba. Andy observed Lydia teach but met online for the post-observation discussion. Lydia was unable to meet with Andy because she had to teach another class. Initially, they conducted the post-observation discussion by phone, however, they decided to switch to Wimba in order to include video. This enabled Lydia to review the observation notes and also reflect and complete the reflection form before their discussion. Lydia explained: 
Since we are not able to talk F2F for the debriefing after the classes, I have to include the Wimba as a F2F. By the time we are done with the classes he can watch on PF, I have to immediately start teaching in another class that is not PF. And so he is not able to stay long enough for staying after the school. And also after the school a lot of time I will have after school activity because I am a junior sponsor. So since we do use Wimba, we can talk back and forth. I think in our case, that would have to be included in the F2F visit. Because otherwise, we wouldn't be able to talk about the lesson after it happened. And then after the class, the classes he watches, he has a reflection sheet that he asks me to fill out and I email it to him and then we discuss. And he sends his observations, he emails them to me and so we talk about his observation and my reflection on Wimba.

By moving the post-observation discussion online not only finds time outside of the school day to meet, but it also provides time for Lydia and Andy to share and read each other's reflection and observation notes.

According to Lydia, they usually scheduled the post-observation discussion on the night of the observation or two or three days afterwards. In the online post-observation discussion, Lydia asked questions related to her questioning skills and strategies to keep students focused. She stated:

I can get clarification when he would write up something on his observations, he can explain things that I don't understand or I can give him more information if he did not know, like if he saw something happened and I did it for reasons, he didn't understand or he did not think of, I can clarify. He can clarify what he wrote down so if I think what did you mean by that, he can explain it on the Wimba.

I reflect and he does the observation but just those two would not be able to let us really discuss it and if he has some suggestions of the things to do, he is able to do it and I can ask questions about what he means or has he seen an example and he can tell me more about how it would work for me as opposite to - ok, this is what you should try because I may not understand if I just see it in his observation forms.

Moving post-observation discussion to Wimba provides an opportunity for Lydia to reflect and review her teaching. It also provides greater flexibility for Lydia and Andy to conduct a post-observation discussion. 
Second, in response to participants' need for PLC meeting, Lydia and her PLC group used Wimba for the PLC meetings. As mentioned earlier, Lydia was unable to join the PLC meetings due to location. Thus, they tried Wimba. However, due to technical issue, they were not able to have a good meeting. She said,

I think we just need to find a good way to do it because we've tried Wimba, we've tried chat room; So far, this year, we had three meetings and we have not yet really had a good meeting where we can all talk to one another except for maybe the last 5 minutes, if that, because we keep having technology problems.

Although the PLC meeting on Wimba was not successful because of technology issue, Lydia and her PLC group tried the online PLC meeting as an alternative to the F2F PLC meeting.

Summary. The coaches and participants encountered three problems in the coaching and PLC meeting: 1. receiving too little feedback from coaches; 2, limited number of classroom observations, and 3. limited number of F2F meetings with PLC.

In response to the coaching and PLC meeting problems, teachers moved the postobservation discussion and PLC meeting online. For example, Lydia and Andy changed the post-observation discussion from F2F to online (Wimba) so that Lydia could receive detailed feedback from Andy. They had more in-depth discussions of the classroom observations. Moreover, Lydia and her PLC met on Wimba so they did not have the added burden of driving to a central location. Except the technology problems, moving the post-observation discussion and PLC meeting online was successful and helpful in supporting her learning. Using online tool such as Wimba solved the problems associated with F2F meeting. 


\section{Limitation of the Solutions}

The problem with having online post-observation discussion and PLC meetings (rather than F2F) was the poor quality of internet communication. Without a stable Internet connection and online communication tools, this solution holds no promise. Lydia experienced several technical issues while using Wimba for coaching and during the PLC meeting. While Lydia and Andy were able to solve the technical issues associated with their online post-observation discussion, they were not successful in solving the technical issues encountered during their PLC meetings. The technical issue decreased Lydia's participation in the PLC activities and limited her opportunity to collaborate with other teachers to address the challenges of teaching PF curriculum. .

\section{Summary of Case One: Coaching}

The C1 teachers with different teaching experience and background appreciated the opportunity of receiving coaching from the PF PD program. The coaching design, as a support system, gave teachers opportunities to reflect on the implementation and their teaching practice.

Classroom observations provide opportunities for coaches to see the actual implementation. Receiving feedback from the coaches also helped teachers to improve and change their teaching practice. Most important, coaching stimulates teachers to reflect and think deeply about teaching, student learning, and ways to become better teachers. Moreover, because of F2F coaching, teachers felt more focused and accountable to what they were doing. The feedback from coaches helped teachers to adjust and modify their teaching practice. 
However, coaching has some limitations. Teachers received little feedback from coaches due to time constraints, had difficulties to have more classroom observations, and had difficulties to meet F2F with PLC as a group. To solve these problems, teachers used Wimba as a tool to have post-observation discussions and PLC meetings. Wimba worked well as an alternative mode of communication for the post observation discussion, however, technical issue prevented teachers in Lydia’s PLC to have effective PLC meetings.

Besides these limitations, mentors and teachers appreciated the classroom observations. They mentioned that the classroom observation is an essential component for effective coaching. Being able to see the actual implementation was beneficial for teachers and coaches. For teachers, they can have extra support and ask specific questions associated with the teaching. For coaches, they are able to provide specific feedback and help teachers identify their problems.

In the $\mathrm{C} 1$ case, coaches observed the actual implementation of the PF curriculum had great impact on teaching and learning. Moving the post-observation discussion to an online format gave teachers and coaches more time to reflect and more support. The combination of F2F with online coaching offered solutions to problems presented by the limitations of time and space. 


\section{Case Two: Online Mentoring}

The case study includes five teachers and two mentors who utilized online mentoring to support the implementation of the PF curriculum. First, I provide participants' demographic information. Second, I describe the online mentoring process and expectations. This includes conversations between participants and mentors before and during the mentoring and PLC meetings. Third, I discuss problems participants encountered in the mentoring and the solutions that they put into place. Fourth, I discuss the limitations posed by these solutions.

\section{Participants of the Study}

A total of five teachers - Becky, Nancy, Sarah, Andria and Ted and two mentors - Andy and Ryan, from two PLC groups, participated in the study. Becky and Nancy (participants in the same PLC) taught in different school districts (eighty minutes away from each other) and shared the same mentor, Ryan. Sarah, Andria and Ted taught in the same school district and shared the same mentor, Andy. Andria and Ted taught in the same school building, while Sara taught in a building located fifteen minutes away. Four of the participants (except Nancy) have participated in PF since 2007. The following table (Table 5) describes the teachers of the two C2 groups in case \#2. 
Table 5

Demographic data of C2 teachers

\begin{tabular}{l|l|l|l|l|l}
\hline Mentors & $\begin{array}{l}\text { Teachers } \\
\text { by PLC }\end{array}$ & $\begin{array}{l}\text { Prior PF } \\
\text { experience }\end{array}$ & $\begin{array}{l}\text { School district } \\
\text { demographic }\end{array}$ & $\begin{array}{l}\text { Years of Physics } \\
\text { teaching } \\
\text { experience }\end{array}$ & $\begin{array}{l}\text { Years of } \\
\text { teaching } \\
\text { experience }\end{array}$ \\
\hline \multirow{3}{*}{ Andy } & Becky & Y & Rural & 2.5 & 7 \\
\hline & Nancy & $\mathrm{N}$ & Rural & 1 & 5 \\
\hline & Sarah & $\mathrm{Y}$ & Urban & 6 & 20 \\
Ryan & Andria & $\mathrm{Y}$ & Urban & 4 & 16 \\
\hline
\end{tabular}

Note: Y means yes; $\mathrm{N}$ means no

The four with prior PF experience were confident in their physics content

knowledge. Furthermore, they have a good understanding and experience of teaching the

PF curriculum. Below, I provide demographic information, teaching experience, and goals for each of the five participants.

Becky has taught science subjects for seven years and is the only science teacher in her school. She is an experienced PF teacher and has a deep understanding of the PF curriculum. Her goals for participating in PF were to collaborate with colleagues and improve the implementation of 5E (Bybee, 1997) and whiteboarding. As the only science teacher in her school, communicating and collaborating with other science teachers is her priority.

Nancy has five years experience teaching high school science. She teaches in a rural area and is the only science teacher in her school. She has participated in the PF program since 2011. Due to her lack of PF experience, she has concerns about the implementation and pacing of the curriculum materials.

Sarah has been teaching science subjects for twenty years. Sarah and the other two teachers in her PLC (Andria and Ted), teach in the same urban school district. She 
has been a participant in the PF program since 2007. Thus, as an experienced teacher, she is confident in her content knowledge. One of her PF classes contains a majority of students with learning disabilities. For this reason, her primary concerns are with implementing PF for students with learning problems. These concerns include pacing, student learning, and student engagement.

Andria has been teaching science subjects for sixteen years. Like Sarah, Andria has been a participant in the PF program since 2007. Her goals are to learn new instructional strategies to help students learn physics concepts. She also focused on student learning and the modification of curriculum to satisfy learning needs.

Ted has eleven years experience of teaching science subjects. Ted has been a participant in the PF program since 2007. Therefore, he understands and is familiar with the PF curriculum. Since he has special needs students in his class, he focused on learning progress and engagement for these students.

Andy (mentor to Becky and Nancy) is a retired Physics teacher who has been a coach and mentor in the PF program since 2007. He is the same Andy who is the coach in case \#1. Ryan (mentor to Sarah, Andria and Ted) is a former high school physics teacher. He has been a coach and mentor in the PF program since 2008. He understands the PF curriculum and its implementation. Like John and Andy (Case \#1), Ryan was trained under Cognitive Coaching. (Costa \& Garmston, 2002). In cognitive coaching, mentors use questions to help mentees develop the ability to solve problems through planning, reflecting, and problem solving strategies. Ryan described how he used Cognitive Coaching strategies to help his mentees. He explained:

Cognitive Coaching is built around constructivist idea, the idea is that the coach's job is mostly to listen and to ask questions. The goal is helping participants make 
sense of what are their problems; and so a typical coaching conversation for me looks like asking the participants; I always begin with the same question -how are the things going and usually talk for couple minutes about just how life is going in general, I really try to keep it in general at first, you know, how is school, how is life, how is family and then we shift transition to talk about their lesson, whatever the lesson their reflected on, and it's a little different for my participants. So some of them want just go through the entire lesson, they follow their form and they just read, kind read down for me, and I just listen. Others, some of them just talk about the lesson in general, and then I will ask probing kind of question. I am doing that. But I am trying to ask questions, trying to find anything in the conversation where it seems like they are having a struggle or question, or problem or concern or something like that.

In this case, teachers had varied teaching experiences and focused on different areas to implement successfully the PF curriculum. Thus, the participants had different goals to improve their teaching practice. Through the online mentoring design, participants asked for different types of support for improving their teaching and student learning.

\section{Online Mentoring Process and Expectation}

In this section, I first discuss the project expectation for mentors and teachers.

Second, I present the mentoring process by describing how mentors and teachers schedule the online meetings, what mentor and teachers do during the online meeting, what they discuss, and what occurs during a typical PLC meeting. Third, I discuss problems or issues they encountered as they used online mentoring to conduct the mentoring sessions. As the five participants had similar mentoring experience, I focus on Becky’s experience, however, I also include other participants' experiences as part of the case. The reason I selected Becky is because she had more meetings with her mentor, she enjoyed reflecting on her teaching, and she expressed a strong desire to improve her teaching practice. These qualities made her an ideal informant for this investigation. 
First, the PF project has requirements for both mentors and teachers. The mentors had two primary responsibilities: monthly mentoring and monthly PLC meetings, while teachers complete a self-reflection form before meeting with mentors. The mentors prepare for the discussion by reviewing the teacher's reflection form. The mentor provides support for teachers as they implement the PF curriculum. In the monthly PLC meeting, mentors need to participate, as an observer, in the online PLC meetings with assigned teachers. The mentors are expected to conduct at least eight online mentoring sessions throughout the academic year (one/month). In the next section, I introduce the C2 case by describing Becky and Ryan’s experience of online mentoring.

Becky and Ryan scheduled the online mentoring meetings via email or Sakai private messages at the beginning of the month. All of the online meetings were based on the availability of mentor and teachers. Before the online meeting, Becky completed the teacher reflection form and emailed it to Ryan. Along with the reflection form, Becky also sent Ryan the outline of the lesson that included what happened in the classroom, how the lesson went, what she did and the tools she used. They met online using Wimba as the communication platform. Wimba is a synchronous tool that supports audio and video conferencing and also incorporates recording features. Thus, teachers and mentors can record the meeting for future review.

During the monthly online meeting, Ryan and Becky went through the reflection form and discussed the lessons or questions associated with the implementation. In addition to monthly online mentoring, Becky and Ryan met online once a week. However, other teachers did not schedule weekly meetings with Ryan. The purpose of Becky's weekly meeting was to touch base, mainly talking about what is happening in the class 
and student learning. Becky described her weekly and monthly meeting with Ryan, she stated:

My mentor and I meet once a week on Wimba and then we meet once a month, in addition to that, to discuss the reflection. And he is also available by email, via email. You know, just when things come up. But I see him often on Wimba, it is not very necessary to email. We mostly talked about the lessons. I taught either specific lessons or maybe the last few lessons and how those progress and what adjustment I have to make, um, what type of questions I ask to make those adjustments, what I have to modify, um is it, um or the students learning it faster or slower than they have when I taught it at the past.

Becky met with Ryan more than once a month on Wimba. Most of the time, they

discussed the student learning, and lesson progress, adjustment and modifications. For

example, in one of their conversation, Becky talked about her students’ difficulties

learning Newton’s law. She said:

It reminds me when you learn electricity. Individually, they are fine. For that day, the next day, when you are learning about it, they are doing a great job. The same way with the third law, the day you are learning about it, it is great. But when you go to apply it, it seems like they throw everything out the window. It just blows my mind.

Becky was concerned about her students learning the physics concepts and the ability to apply the concepts to the next lessons.

Because of her previous experience in PF, Becky had fewer questions regarding the physics content. Other than student learning, Becky also asked questions associated with curriculum and lesson modifications. She stated:

We mostly talked about the lessons. I taught either specific lessons or maybe the last few lessons and how those progress and what adjustment I have to make, um, what type of questions I ask to make those adjustments, what I have to modify, um is it, um or the students learning it faster or slower than they have when I taught it at the past. 
Becky as an experienced teacher focused on the lesson and student learning in the mentoring sessions. She met about four times a month with Ryan that was more than what the PF program asked for.

Nancy’s mentoring experience was similar to Becky’s with a few differences. Unlike Becky, this is Nancy’s first year of teaching the PF curriculum. Thus, she had different focuses for improving her teaching practice. Her main goal was to make sure that she taught the curriculum in the right way to improve student learning. Nancy's questions were associated with curriculum, student learning, classroom management and instructional strategies. She described her conversation with Ryan.

I tried to fill out the reflection form before we meet and email it to him. And then during the reflection discussion, we go down through the form and discuss what is working and how I did things and the issues that I have. And as we go, you know, areas where I have issues then we discuss some different ways to do it, he can give me some suggestions on that. Also, just having another perspective and say well, what about this, I may not have thought about that. So I find it really helpful. And then, at the end, we may talk about other things in the classroom that are going on and I'd like to get some suggestions on that also.

Having the reflection discussion with mentor was very beneficial for Nancy. She reflected on her teaching and identified issues associated with teaching. Ryan as a mentor provided his perspectives and experience to Nancy was helpful in terms of improving teaching.

Sarah focused on her class with special needs students. She focused on the same group of student because she believed that focusing on the same class would make it easier for Andy to provide assistance. She verbally described the class to Andy in order to help him understand the situation. She stated:

I have a class that has eight autistic children in it in $9^{\text {th }}$ grade and two students who are special education and the class about twenty kids which means $50 \%$ of the class is disabled in some way. So that is the class that I am focusing on with 
him. And that's why having him have a visual about how class is running; how the student is doing would be interesting for him. I haven't found a way to do that yet. But that is the class that we are talking about, so I keep reflecting on the same group of the students which allows us to sort of building a rapport about these kids with him. So, he sort of, he is following me through the lessons with these students. That's what we did and I feel great about listening to his ideas about working with these kids. Usually he would ask me questions about the seating arrangement of students or the materials that I used. Or he might asks about some questionings that I did and those are kind of things that he would ask me during the discussion.

In the mentoring discussion, Sarah often asked questions associated with pedagogy, content questions for improving her students' learning and modification of the PF materials such as lab for better teaching the content knowledge. She stated:

I provide him insight of whether white boarding, whether I am using some kind of team problem solving, whether I have an experiment or lab. So, I give him an understanding the pedagogy that I am using and we think together about the content knowledge and I tell him my goals for the content knowledge. Sometimes things work more effectively than others. So, that's really the direction of how we talk about it. I really have a good understanding of pedagogy and so I am giving him the pedagogy and he sort of reflects back on the content, ways for me to help kids, questioning strategies or the things that I can help bring into the direction that I want to go with the content objectives.

The lesson that I taught were having the students build a series circuit with two bulbs, a battery and a switch and test the current in four different positions. And I have adapted this from PF and I used a modified electricity board that I created for my students to use when I did this lesson. And so, what I was talking with about was, um, thinking about how to include parallel because I don't have time to include parallel and the value of including that content within this lesson. Um, the lesson was collaborative and it had guided discussion. So, I think the reflection piece was really focused on how to broaden the content to reach additional, to really push the students. So I think that was the big part of discussion on that reflection from.

Overall, Sarah mainly discussed pedagogy, questioning strategies and pacing of the material with Andy. Since she had special needs students in her class, she focused on student learning and the way to improve learning. 
Andria usually reflected on the lessons that she was teaching at the time of the mentoring section. In the discussion, she focused on classroom management and student learning process.

Actually lot of time we talked about the classroom management kind of things that are tied to the kind of open-endedness with PF. Well, you know, kids are developing their own thought process. And we talked about the classroom climate, the learning environment, the school environment, how all these things are tied to my teaching to PF.

Usually we are discussing the classroom and lessons we were on and just reflecting on, you know, he is asking me questions about how the lesson went and how does this different than this particular class compare to another class. This is really giving me opportunity to reflect upon what I did in the class and how I gave my students understanding.

Through the mentoring discussion with Andy, Andria thought about her students'

thinking and learning and the strategies to help her students to learn better.

Ted's questions were very similar to Andria's. Ted focused on student learning and helping student to learn physics concepts. He stated:

I would say, we spent most of the times talking about the learning that took place with the kids. What would be the evidence that I saw such as lesson, where do I see that really deep knowledge that explain to the kids, where are they developing higher order concepts as well as when they get poor score in certain areas, what would be the evidence. I am one of the few people in the academy that actually also a special education teacher. Andy often asked me questions about special education classroom, is there a difference in terms of how the instruction is, how I teach things a little different in the special education setting. So probably, that is the good quarter of it that I get questions how things are different.

Ted focused on improving student learning. As a special education teacher, he also reflected on instructional strategies to improve his teaching of physics to students with learning problems.

In the mentoring, the teachers asked various questions associated with the implementation of the PF curriculum. The summary of the questions asked by the 
teachers is presented in Table 6 below. Data from teacher interview, coach interview and coach observation notes were used to construct the table. This list was generated from the participants' responses to my interview question: what are the things you and your mentor did the most in online meeting? Due to the flexibility of the online meetings, the teachers were able to meet to discuss the lessons and teaching practice.

Table 6

Summary of the types of questions asked by C2 Participants in the online mentoring sessions

\begin{tabular}{|c|c|c|c|c|c|}
\hline & Becky & Nancy & Sarah & Andria & Ted \\
\hline $\begin{array}{l}\text { 1. Student learning - } \\
\text { difficulties, } \\
\text { misconceptions, } \\
\text { progress }\end{array}$ & 1 & 3 & 3 & 1 & 1 \\
\hline 2. Instructional strategies & 1 & 6 & 1 & 1 & 1 \\
\hline $\begin{array}{l}\text { 3. Curriculum/lesson } \\
\text { modification }\end{array}$ & 1 & 1 & 1 & & \\
\hline 4. Pedagogy & 1 & 1 & 3 & & \\
\hline $\begin{array}{l}\text { 5. Classroom learning } \\
\text { environment }\end{array}$ & & & & 2 & \\
\hline 6. Content knowledge & 1 & & 1 & 1 & \\
\hline $\begin{array}{l}\text { 7. Pacing of } \\
\text { material/lesson }\end{array}$ & 1 & 1 & 1 & & \\
\hline 8. Student engagement & & & 1 & & \\
\hline 9. Classroom management & & & 1 & 1 & 1 \\
\hline 10. Instructional planning & & & 1 & 1 & 1 \\
\hline 11. Questioning Strategies & & & & & \\
\hline 12. Sequencing & & & & & \\
\hline
\end{tabular}

According to the table, Ted asked fewer questions than other teachers and Sarah asked the most. She asked questions from all categories except (5), (11) and (12). It does not say that Sarah had less teaching experience, it is because the focuses were different. In addition, all of the participants spent the most time discussing questions associated with 
student learning and instructional strategies. The second most asked questions were about pedagogy and curriculum/lesson modification. The fewest questions were asked about student engagement. Only one participant (Sarah) asked that question. However, none of the C2 participants asked about questioning strategies (11) or sequencing (12). This may be related to the venue because the mentor did not observe the actual implementation and participants may not notice the issues related to their questioning skills or sequencing of the lesson. Furthermore, participants in the same PLC asked similar questions. For example, Becky and Nancy are in the same PLC and they asked the same type of questions with the exception of \#6. Sarah and Andria asked about the same six questions: $1,2,4,6,9, \& 10$ out of the eight questions they asked.

In addition to receiving the supports from mentors, participants addressed the importance to have opportunity to self-reflect on their teaching practice. Particularly, participants had busy schedules and many things they needed to do, finding time to reflect was difficult. Sarah thought the mentoring provided her an opportunity to reflect, she said:

I take the most effective part is having the ability to have time set aside where you can help you guide your reflection and give you feedback and ideas on how to improve your teaching and the curriculum. I found it very helpful. As I said, when you're busy, it is good to have a reason to stop and reflect because I think that improve your practice and do stuff and reflect; and have a mentor to give you set time when you gonna meet, of course you stop and reflect. Also, it is great to have a resource to help you know perspectives to give you additional ideas and additional ways to teach things to talk through how are you doing things and how to evaluate students really help you see ways to improve.

Andria also talked about the importance to reflect, particularly teachers had busy

schedule and many things to do. Andria said:

Just taking the time to reflect on particular lesson, I think that is really important. But it is something that is kind of luxury, um, teachers work really hard and they 
have a lot of things to juggle and you know, besides their own life, you know, there is a lot to do. Sometimes you don't have the opportunity to reflect on, ok, what happened today, what works well, what did work as well, how can I change for next year. You don't always have opportunity to reflect on that. But this [mentoring] certainly provides the time to do that.

Mentoring design provides opportunity for reflections. Reflection helps participants to think deeply about their teaching and the ways to improve the implementation.

\section{Professional learning community (PLC) Meeting}

As mentioned in the previous section, PF designed a professional learning community as part of the coaching and mentoring design. Thus, each PLC has its own schedule to meet and collaborate to improve the implementation of Physics First curriculum. Since Becky and Nancy are in the same PLC, they met online once a week. Ryan attended online, as well. Ryan's role was different in the two circumstances. In the mentoring session, Ryan took an active role and led the discussion. However, in the PLC meeting, he listened to the discussion and let the teachers lead the discussion. Becky and Nancy attended the PLC meetings regularly but another two teachers in the same PLC did not.

Becky and Nancy teach in rural areas and are the only science teachers to teach the PF in their respective districts. The PLC provides the only opportunity they have to collaborate with other science teachers. Nancy described the impact these meetings have on her teaching. She said,

One of the really great things for me is getting to talk to other teachers that teach PF. They teach the science like I do and get ideas and share ideas with them. Only one other science teacher [in her small school] and he teaches life science and I teach chemistry and Physics. So it is really great to have somebody to share ideas with.

As the leader of the PLC, Becky had a different perspective of those meetings. She said, 
Our mentor is there, but he is just kind of listen to it, teachers do the talking. I tend to give lots of advice to the other teachers because this is their first year teaching it. So, I remember what that feels like, so I try to help them a little bit and say you don't have to go as in-depth on that or maybe you can skip that lesson, here is where you can buy some extra equipment or something like that. We just talked about the lesson, what went well, what did not go well, where you are, what lesson you're on, just really whatever happened in your class in the last week.

Becky, as a senior teacher in teaching the PF curriculum, played leader to the group. She assisted other teachers.

Nancy described how Becky took a leadership position. She stated,

Becky has been through PF before and she has been great said Ok and no. I did not do all the activity in the acceleration unit, for example. And then she sent a message with the activity that she did. So, that helps me in my planning my acceleration because she is a little ahead of me. So most of the time, we were just discussing the curriculum, where we are, what is working and asking for, you know, ideas on things, where students are having troubles or asking ok, what did you do here or did you do all the curriculum, what things did you do or how did you get it done, how long did this take, that type of stuff.

The weekly PLC meeting offered Becky and Nancy opportunity to touch base and share their experience. Thus, being able to share the PF teaching experience also benefited their teaching practice. Since Becky is an experienced PF teacher, she led the discussion and provided support to Nancy and other teachers. Ryan also participated the weekly meeting as a facilitator. He listened to the conversation and shared his experience if necessary.

According to Ryan, he tried to let teachers lead the PLC meeting. For example, he let participants decide the meeting schedule. He said:

We met as a PLC group, and I turned it over to them actually and we designated a leader, a captain in our PLC and they decided to meet weekly; at the time work for them, it was 3:30 every Wednesday. That is what they try to stick to. So it really wasn't me at all, I said yep, it works for my calendar too. As it turns out, only really two of them meet regularly and I am always there. One of them comes once in a while and third of them have never heard of her at all. Mostly two or 
three of them but they do report the two that keep coming, report that has been helpful; especially the one who is brand new, she really just is, she is just learning a lot and finds it really helpful. Usually because the strategy, so I want the veteran teacher work with the beginning teacher; beginning teacher always asks the veteran for tips and tricks that work for them.

Becky, Nancy and Ryan met weekly as a PLC group.

Sarah, Andria and Ted in another PLC also talked about their online PLC meeting. According to Andria, they met online to share what is working and what is not working as they implemented the PF curriculum. She wanted to make sure they meet the PF requirements. Andria described what they do in the PLC meetings:

The same thing we do in person. We share where we're at and what's working, what's not working. We kind of doing nods and votes and scheduling like when are we going to meet for the following month, we schedule those meetings. We review and make sure that everybody is taking care of business for PF. Like this month, what are we responsible for, you know, because there have been some surprises, things that we did not know about until we were requested to fill them out or I didn't know about and my PLC did not seem to know about it -- Like writing up things for Share-a-thon [PD follow-up activity] and just keeping abreast on those changes.

Ted described how they helped each other through the PLC meetings. He stated:

Sometimes in Wimba, we talk about the lesson we tried, things that are upcoming, what ideas that we have, how you do the reflection. We switch ideas from each other, that is a good chunk that we talk about on Wimba. We do discuss situation in school with students, you know, the situation I have, what do you have to maybe find the solution to this. We set a teacher day, um, any paper work questions that we have. We tried to discuss surveys, um, I would say both meetings has been collaboration on lesson and how did you do it, and how are you going to do this and ideas.

The PLC design provides opportunity for teachers to discuss shared problems of practice throughout the academic year. One teacher acts as moderator of these conversations and the mentor may provide suggestions or concluding remarks, but the 
mentor does not fill a leadership role in the PLC meetings. As a result, teachers grow together professionally as a group with added support from their mentors.

Summary. Teachers benefited from mentoring and PLC meeting. They felt that mentoring supported their teaching and the implementation of the PF curriculum. Another benefit of mentoring is that it supported teachers to reflect on their teaching. The PLC meeting was helpful for the participants because they shared their experience to help others. At the same time, they also learned from others. The Wimba meetings were smooth without any technical issues. The PLC design offers opportunities to develop a learning community and enhance collaboration among teachers. Due to the online nature of mentoring, teachers save travel time and they can meet anywhere convenient. Thus, teachers and mentors met more frequently to discuss and reflect. Online meetings are a flexible method for mentoring, particularly for teachers and mentors who were separated, geographically. Online mentoring eliminates time and location constraints so that teachers and mentors can meet freely. In addition, mentoring also provides opportunities for teachers to reflect on the teaching and implementation. Because of the self-reflection form and the online discussions, teachers were motivated to reflect-on and identify problems. This self-evaluation process is important in terms of improving teaching and learning (Carroll, 1981).

\section{Problems of the Mentoring design}

In this section, I focus on the problems that participants (mentors and teachers) encountered in the mentoring process. In the Physics First project, mentoring was designed to provide teacher-participants ongoing support as they implemented the Physics First curriculum. Teachers and mentors communicated through Wimba for 
mentoring and PLC meetings. However, mentors and teachers discussed two problems they encountered in the mentoring process: 1 . the absence of classroom observations and 2. difficulties developing and sharing laboratory equipment and methods through the PLC online venue .

Without seeing the actual teaching, mentors did not know the classroom setting, the pace of the lesson or teachers' interaction with students. Mentors relied on a selfreflection form and teachers' verbal description to understand the situation or issues. Thus, it caused misunderstandings in the mentoring discussion. For example, Andy sometimes misinterpreted Sarah’s description of a classroom event. Sarah explained:

Most of the difficulty are just that my mentor does not know my classroom so he does not know how it is setup or designed. So that is the difficulty that I can't give him a more visual sense of how the classroom is running. I have to use my own descriptive narration to provide him an understanding of what is happening. And I could see that at the time, he would ask me questions and I would not be as clear or he would not, he would misinterpret what I was saying because he had not seen the classroom. So that occasionally is a problem.

Without seeing the actual implementation, mentors can only discuss what the teachers provide on the self-reflection form. Thus, mentors were only able to support teachers on things that were included in the reflection. If the teacher decided not to include something on the reflection form, the mentor had no way of knowing. As the Mentor, Ryan felt similar to Sarah. He stated:

F2F brings the strength of being able to actually watch them teach, and so right now, I have never seen any of these teachers teach. I don't know what do they look in the classroom. I don't know their interactions with their students. So there is some conversations that we can't have. I can't ask, "I notice that you were spending a lot of time here, I love the questions you asked," or "I notice you didn't ask very many questions"; I can't get that. So that is really the limitation of this. And so, I am not using the online platform right now to get any of those actual classroom practice things which I think are really important. But I have talked to my participants, I am going to talk to them again in the follow-up here this Saturday about what I would like to observe them teach through Wimba. So 
have them set up webcam at the back of the class and to watch them teach a lesson so that I can get a sense of their flavors. I think that will change some of our conversations.

The supports that Ryan can provide are limited because of not being able to see the actual implementation. Ryan proposed to use Wimba to observe teaching to overcome this issue.

Other C2 teachers mentioned the importance of having mentors observe the actual teaching practice. For instance, Becky had the experience of a coach visiting her classroom during her earlier PF experiences. She talked about the difference:

When I am teaching, I prefer somebody visits my classroom. They don't have to visit my classroom but I would like them to see me teaching. I have a little different experience because this is my second time that I participate in Physics First program. So the first time I had my coach visit my classroom. I have to say that was more useful to me at that time because I've never taught it before. So, it was really good to have someone watch my teaching. So, I don't know it's the distance or the technology; but I think it's that the difference, the biggest difference to me is now nobody watches me teach. And I'd like to have that feedback.

As an experienced teacher, she might not need as much help from coaches or mentors as a PF-novice teacher, however, she states that she still wants the feedback offered by an observer.

The second problem with the mentoring design of the PLC meetings was the difficulty associated with developing and sharing laboratory equipment and methods through the online venue. For example, Andria compared the F2F to the online venue. Based on her experience, she believed teachers could do the physical things better, such as creating lab materials, testing new equipment, and trying out new demonstrations, in a F2F environment.

Well, I think, in general, a F2F meeting you are just able to share more, this is the paper, everything is right there in front of you. But my PLC meets online part of 
the time, as well; and we get a lot out of those meetings, as well. We can't do the physical things, you know, like creating lab equipment, you know, there is lots of things for PF for lab that we made like my PLC this year has made a hovercraft to use in the force unit, force and newton's law unit.

In short, Andria felt that meeting online was effective but cannot do physical things such as developing lab material. The PLC felt that F2F meetings overcome the limitations of meeting online.

Summary. There were two major problems with the mentoring design and both were associated with the quality of communication. The first problem was the absence of classroom observations from the mentoring design and the second problem was the difficulty to develop and share laboratory equipment and methods through the online PLC venue. The absence of classroom observations limited the information that mentors could use to support mentees. In the mentoring process, teachers provided written and descriptive information for mentors. Therefore, teachers shared only part of their classroom experience and the incomplete picture shared by the reflective writing. The first problem meant that mentors received a filtered version of the classroom experience, making it difficult to have a meaningful discussions about practice. The feedback participants received from mentors was superficial or worse, misunderstood the problem altogether. Unfortunately, the mentors could not provide the kind of support participants needed for questions about student engagement, questioning strategies and sequencing. Thus, participants asked for classroom visits to improve the quality of the mentoring sessions and with it improve the quality of their teaching practice.

The second problem was that the online PLC meetings did not support the level of communication required to develop and share laboratory equipment and methods. The purpose of the PLC is to create a collaborative environment for teachers to learn and 
grow as a group. However, the online form of communication only partially supported the PLC meetings. It was not able to provide an environment where teachers can physically develop materials to share and improve their teaching.

\section{Solutions of the Problems}

In response to their need for classroom visits, several C2 teachers thought about using Wimba or videotaping their teaching practice for mentors. For instance, Becky thought about using Wimba for Ryan to see her teaching. She stated:

When I am teaching, yes [I prefer somebody visits my classroom]. They don't have to visit my classroom but I would like them to see me teaching. One thing Ryan and I talked about was could we do that through Wimba. You know, could he watch my lesson through Wimba?

To overcome this issue, Ryan and Becky set up a Wimba meeting for the purpose of observing Becky’s teaching practice. The session went well and gave Ryan an opportunity to see the classroom. He stated:

I felt that it went well. It was nice to be able to see Becky's classroom. In fact, it worked a bit better than I thought it would. I felt that I had a good sense for what was going on in her class and it gave us some things to talk about after the lesson. It is definitely limited because you can only see a fixed field of view, and are unable to see student work, hear conversations, ask questions, etc. But, it was better than NOT seeing the class.

Nancy also addressed the same concern. When asked about requesting additional help from mentors, she suggested videotaping her teaching so that Ryan could provide additional support for improving her teaching. She stated:

I think it might be helpful if maybe mentor could observe me teaching; um, or maybe I can video tape or have somebody video tape me teaching and have mentor look at that and give me some suggestion based on that. 
If Ryan could observe her teaching, Nancy could learn other things that she did not notice in her teaching practice. Although Nancy mentioned to videotape her teaching and send it to Ryan, it did not happen during the data collection period.

In response to the mentoring problems, teachers asked for classroom visits from mentors. Teachers clearly stated that classroom observations would help them improve instruction.

Second, in response to the limitation of having PLC meeting online, some C2 teachers decided to meet F2F, as well. Sarah, Andria and Ted taught in the same school district, therefore, they decided to meet in-person. Andria talked about the flexibility to meet in both environments. She stated:

We thought that we benefit more from F2F meeting. We all live in the same city which probably is not what the other groups have. The other groups probably have to travel. So I can understand that. But I am telling you that we get a lot out of that F2F times but we also having the flexibility to meet online or meet in person whatever meets our needs. So like this month, we are meeting online every week but in previous month, we meet one week on one school, one week on another school, one week online and then take one week off. So I would say that having the flexibility to online or in person is a real benefit.

Sarah, Andria and Ted met more than once each month. Since they can meet on both online and F2F, they utilized the two venues to fit their schedule and needs.

When they met on the F2F environment, they met at each other's classroom. By doing so, they can see the classroom setting and see how and what materials and equipment were used in supporting the implementation. They agree to these meetings even though they require more time for travel.

Traveling to each other's classroom also made it possible for them to borrow equipment and materials from each other. Andria stated: 
The other thing is nice about F2F is that we take turn meeting in different people's classroom. When I am in Sarah's classroom, I can look around the room and I can see the different things that she's going on, and she starts sharing with us the equipment and some really neat things that happens from these things, like, for instance, we tried out the equipment in each other's room, try out the things that works. Sarah, when we were doing electricity, she is always using Van de Graaff Generator, we don't have one of those in our school, so we started playing around with it and she explains how she used it in static electricity. And I borrowed it from her and used it in my classroom. So those kind of things, that's what I am saying, we were after school, we go to each other's classroom whenever we meet and we get ideas about instruction just by seeing what's different at that school.

C2 teachers changed the PLC meeting from online to F2F to address their need to develop material for learning and teaching. In addition to that, they met in each other's classrooms to see how other teachers arranged the equipment and the setting to teach PF curriculum.

\section{Limitation of the Solutions}

The limitations of having F2F PLC meeting are the same as having F2F classroom visit. The limitations are the location and time constraints. First, participants are geographically apart; it takes time to drive to having PLC meeting and it costs money to transport people. Therefore, this solution may only work for teachers who work near one another. Sarah, Andria and Ted were able to meet F2F because they taught in the same school district. It took less than fifteen minutes of driving for them to meet at each other’s classroom. If they had been further apart, Sarah believed they might not have met F2F.

Another limitation, at least in this project, was that the mentor did not travel to take part in the F2F meetings. This meant the meeting was absent the expertise of their assigned mentor, While the mentor could have taken part via Wimba, this did not occur. Since Sarah, Andria and Ted met F2F and online alternately, without joining the F2F meeting, 
Andy fell out of communication with what that group was doing. Thus, he did not mentor the F2F PLC meeting and did not provide support for those teachers.

\section{Summary of Case two: Mentoring}

The C2 teachers with different teaching experience and background appreciated the opportunity of receiving mentoring from the PD. The mentoring design, as a support system, gave teachers opportunities to reflect on the implementation and teaching practice. Teachers and mentors were able to meet without time and location constraints. Therefore, both teachers and mentor can better utilize time to meet. The frequent meetings also helped to build a relationship between teachers and mentor. The strong rapport between mentor and mentees is essential for creating trust and developing a comfortable mentoring environment. Additionally, mentoring provides opportunity for teachers to step out from teaching to reflect and think deeply on the teaching, student learning and the way to become better teachers. The self-evaluation/reflection process associated with the online mentoring helped teachers to examine and identify problems on specific lessons or teaching practices. The mentoring design provided on-going supports for C2 teachers.

However, the participants felt the mentoring design had two limitations. Limitation 1: The mentor was expected to provide in-depth feedback about the teachers practice. However, the absence of classroom observations restricted the ability of the mentor to provide meaningful feedback. Without seeing the actual teaching implementation, mentors were not able to ask questions about classroom management or student interactions. Additionally, mentors could not observe problems or issues teachers experienced. Although mentors could use synchronous tool to observe the teaching, the 
field of view was restricted. So, mentor could not observe a full view of the classroom. He could only see what the camera pointed at.

Limitation 2: The purpose of the PLC is for teachers to collaborate and to share and solve problems of practice. The online mode of communication made it difficult for teachers to develop and share laboratory equipment and methods. Not being able to have classroom visits to see the actual implementation is a setback to the quality of the mentoring experience. In response to these two limitations, teachers and mentors changed the design of the online mentoring program in two ways: they considered using Wimba for classroom observation and they met F2F for some of their PLC meetings.

These two solutions were not perfect. F2F PLC meetings use precious time for travel to and from the meeting location. Teachers had to drive, spending more time than they would use meeting online. Moreover, mentors’ participation in the PLC meeting decreased because there was not money in the project budget to support these extra trips. The classroom observation using Wimba also cannot support mentoring. Mentor cannot see all of the classroom interactions. That said, the teachers wanted to make the changes to F2F classroom observations and F2F PLC meetings because they needed feedback based on the actual implementation and physically develop material for teaching.

Besides these limitations, mentors and teachers appreciated the flexibility of meeting online. Meeting online eliminated the physical and monetary limitations of traveling to a rural school. Because of frequent meetings, mentors were able to build trust and develop a comfortable relationship with teachers. The good relationship improved the effectiveness of mentoring because teachers were more willing to share their experience. 


\section{CHAPTER FIVE: ASSERTIONS, IMPLICATIONS AND CONCLUSIONS}

The purpose of this study was to investigate how F2F coaching and online mentoring influence teacher professional development and learning. The overarching question guiding this study is: What affordances do face-to-face and online venues provide to a professional development project in terms of mentoring? This question is supported by the following sub-questions.

1. How do the types of questions asked face-to-face by teachers compare to the types of questions asked online by teachers?

a. What types of questions are asked in face-to-face meetings by teachers?

b. What types of questions are asked in online meetings by teachers?

2. How do coaches, mentors, and teachers utilize different venues to support their responsibilities?

a. In what ways did C1 participants and coaches change the face-to-face design of their coaching sessions to better accommodate their needs?

b. In what ways did the C2 participants and mentors change the online design of their mentoring sessions to better accommodate their needs?

In this chapter, I present assertions based on the two case profiles in Chapter Four. The assertions describe major themes observed across the cases and are organized around the sub-research questions which guided this study. This chapter includes the following sections: a summary of the findings, a discussion of the findings in relation to the research literature discussed in Chapter Two, assertions, a discussion about of how this study contributes to hybrid PD design, implications for hybrid PD, and recommendations for future research. 


\section{Assertions}

Assertion \#1: The types of questions that were asked in face-to-face and online postobservation discussion were very similar. The quality of those discussions is influenced by the venue and the context.

The first research question: How do the types of questions asked F2F by teachers compare to the types of questions asked online by teachers? was to know whether the types of questions asked F2F and the types of questions asked online were different. To understand the types of questions that were asked in F2F and online is important for designing a PD to support learning and teaching. As stated in chapter one, the effective PD should provide on-going support and learning opportunities for teachers. In this study, the PF project utilized F2F and online environments to provide support for teachers. Hence, it is critical to learn whether the venues can support participants' learning and teaching.

In this section, I will discuss similarities and differences between the questions asked by C1 and C2 participants. Second, I will discuss in what way the venues or the context influence participants in asking questions associated with teaching practice.

First, C1 and C2 participants asked similar questions. As stated in Chapter four, a total of twelve types of questions emerged from the data (Table 7). 
Table 7

Summary of the types of questions asked by C1 and C2 Participants

Types of questions asked

2. Student learning -difficulties, misconceptions, progress

3. Instructional strategies

4. Curriculum/lesson modification

5. Pedagogy

6. Classroom learning environment

7. Content knowledge

8. Pacing of material/lesson

9. Student engagement

10. Classroom management

11. Instructional planning

12. Questioning Strategies

13. Sequencing

The most asked questions in C1 were associated with student learning -difficulties, misconceptions and progress, instructional strategies and pedagogy. The least asked questions in C1 were content knowledge and sequencing. Additionally, none of the C1 participants asked classroom learning environment questions (Table 8). 
Table 8

Summary of the types of questions asked by C1 teachers in the F2F coaching sessions

\begin{tabular}{|c|c|c|c|c|}
\hline & Henry & Bella & Jason & Lydia \\
\hline $\begin{array}{l}\text { 1. Student learning - } \\
\text { difficulties, misconceptions, } \\
\text { progress }\end{array}$ & 1 & 1 & 1 & 1 \\
\hline 2. Instructional strategies & 1 & 3 & & 1 \\
\hline $\begin{array}{l}\text { 3. Curriculum/lesson } \\
\text { modification }\end{array}$ & & 2 & 1 & \\
\hline 4. Pedagogy & 1 & & & \\
\hline $\begin{array}{l}\text { 5. Classroom learning } \\
\text { environment }\end{array}$ & & & & \\
\hline 6. Content knowledge & 1 & & & \\
\hline 7. Pacing of material/lesson & 1 & & & \\
\hline 8. Student engagement & & 1 & & 1 \\
\hline 9. Classroom management & & 1 & & 1 \\
\hline 10. Instructional planning & 1 & 1 & & \\
\hline 11. Questioning Strategies & & & 1 & 1 \\
\hline 12. Sequencing & & 1 & & \\
\hline
\end{tabular}

On the other hand, the most asked questions in C2 were associated with student learning -difficulties, misconceptions and progress and instructional strategies. The least asked question in C2 was student engagement. However, none of the C2 participants asked questioning strategies and sequencing questions (Table 9). 
Table 9

Summary of the types of questions asked by C2 Participants in the online mentoring sessions

\begin{tabular}{|c|c|c|c|c|c|}
\hline & Becky & Nancy & Sarah & Andria & Ted \\
\hline $\begin{array}{l}\text { 1. Student learning - } \\
\text { difficulties, } \\
\text { misconceptions, } \\
\text { progress }\end{array}$ & 1 & 3 & 3 & 1 & 1 \\
\hline 2. Instructional strategies & 1 & 6 & 1 & 1 & 1 \\
\hline $\begin{array}{l}\text { 3. Curriculum/lesson } \\
\text { modification }\end{array}$ & 1 & 1 & 1 & & \\
\hline 4. Pedagogy & 1 & 1 & 3 & & \\
\hline $\begin{array}{l}\text { 5. Classroom learning } \\
\text { environment }\end{array}$ & & & & 2 & \\
\hline 6. Content knowledge & 1 & & 1 & 1 & \\
\hline $\begin{array}{l}\text { 7. Pacing of } \\
\text { material/lesson }\end{array}$ & 1 & 1 & 1 & & \\
\hline 8. Student engagement & & & 1 & & \\
\hline 9. Classroom management & & & 1 & 1 & 1 \\
\hline 10. Instructional planning & & & 1 & 1 & 1 \\
\hline \multicolumn{6}{|l|}{ 11. Questioning Strategies } \\
\hline 12. Sequencing & & & & & \\
\hline
\end{tabular}

When comparing the questions that C1 and C2 participants asked in coaching and mentoring, similarity was found in both cohorts. For instance, participants all focused on student learning and instructional strategies. This indicates that F2F and online venues can support teachers in these two areas.

However, no C2 participants asked about questioning strategies or sequencing and only one C2 participant asked student engagement questions. As stated in chapter four, Jason who focused on his questioning strategies, stated he could not do it without classroom observation. According to Jason, how to ask questions, how much time to give students to answer questions in important in terms of student learning. He often worried 
that he might not give enough time for his students and that may have negative impact on his students.

Additionally, as a novice physics teacher, Bella had trouble with sequencing instruction. However, she did not notice this issue until John pointed it out to her following a classroom observation. Moreover, none of the C2 participants asked classroom learning environment questions and Sarah was the only C2 participant who asked student engagement questions.

The two examples suggested that F2F classroom observation is necessary if classroom instruction is to be improved. Also, without classroom observation (F2F), mentors were able to support teachers in the areas they described in their Teacher Reflection Reports and unable to support teachers with problems they did not describe. Because the content of teachers' reflections was self-selected, discussions with mentors tended to focus only on those areas teachers recognized they needed assistance, unlike in the case of coaching, in which a coach might notice something problematic that was not evident to the teacher about his/her practice. As stated in chapter three, intersubjectivity is the mutual understanding that people share through meaningful interaction. C1 participants and coaches had opportunity to share experience (classroom observation) but had limited opportunity to interact (post-observation discussion). On the other hand, C2 participants and mentors had limited opportunity to share experience (no classroom observation).

Second, the venues influence participants asking questions. Referring to a C1 case, Henry and Jason had limited time after the observation to ask questions. Hence, they tended to focus on the most critical questions and due to the busy schedules of classroom 
teachers during the workday, they spent very little time discussing them. Bella, on the other hand, asked questions from nearly all twelve of the categories listed in Table 4. Perhaps she asked these questions because the class she taught contained a high number of special needs students.

On the other hand, C2 participants had longer reflection discussion time with mentors. On average, they asked more questions than C1 participants.

Based on the data, the questions asked by participants in the F2F and online venues were similar. This suggests that F2F and online venues can equally support mentoring the teaching practice. However, there were limitations of mentoring (online). Some of the questions asked by C2 participants could not be discussed unless the mentor observed the classroom. In the PF online design, the mentor did not observe any of the lessons being taught. Without observing the teaching practice, issues may not be noticed by mentors or mentees. Therefore, if the goal is to improve instruction, then F2F observation is essential. 
Assertion \#2: Classroom observation is an essential component for coaching and mentoring designs.

The goal of coaching and mentoring in the PF project is to support teachers' implementation of the PF curriculum. Classroom observation is an important component for mentoring design because it provides an opportunity for coaches to observe implementation of program goals, enactment of teaching behaviors, student interactions, and the classroom setting. The lack of classroom observations means the coach will not have a firsthand knowledge of how the project is being implemented, how the teacher organizes and manages the classroom, how students respond, the availability of materials, and how the classroom is structured for learning and teaching. What the coach sees of the classroom is actually filtered through the perception of the teacher (written reflection). Teacher and observer my construct different interpretations of events they both observe in the classroom; however, this is not possible when the mentor is unable to observe those experiences. Therefore, due to the absence of a shared experience (described as intersubjectivity by Vygotsky) teachers in C2 received limited support from their Mentor. Four themes emerged from the data suggested the benefits of classroom observation. The benefits of classroom observation are: 1) having an expert in the classroom helps teachers identify teaching problems, 2) making participants focus and take responsibility on practice, 3) helping participants to reflect on teaching, and 4) receiving accurate feedback, free of misunderstandings.

The C1 coaching did include classroom observation. Participants were able to communicate with the coach prior to the observation as to what the lesson entailed and what things he/she wanted the coach to observe. Information gained from these observations benefit coaches and participants in the post-observation discussion because 
the coach and participant had a shared experience. Both were able to pinpoint specific events that support or contradict best practice for program implementation.

The C2 mentoring did not include classroom observation. Participants complained that much of the time spent in discussing teaching problems with their mentor was wasted in an attempt to describe classroom events in sufficient detail to have a meaningful discussion about them.

First, having an expert in the classroom observing teaching helps teachers identify teaching problems. As stated in chapter four, Jason, Lydia and Bella asked coaches to help them identify problems with sequencing instruction and ways to improve questioning strategies. Jason (C1 participant) appreciated the classroom observation and specifically addressed that he cannot improve his teaching without a coach's observation. In support of Jason, C2 teachers wanted mentors to observe them teaching and provide feedback based on those observations. Becky (C2 participant), who had been observed during her initial PF experience (2007-2010), wanted those observations to continue. As stated in chapter four, Becky wanted feedback based on her teaching. Nancy (C2 Participant) also addressed this concern. Both wanted mentors' feedback based on their teaching practice. Nancy desired the feedback afforded by classroom observations. Recall she suggested the mentor observe her by videotape.

Having feedback on teaching is viewed as an important element to improving teaching practice. Both C1 and C2 participants addressed that having an expert in the classroom is important in terms of improving teaching practice.

Second, classroom observation helps the teacher maintain a tight focus on their teaching practice. For example, Henry felt the classroom observation made him focus 
more on his teaching because he was being observed. It also impacted his teaching practice. Henry explained:

I think, to be honest, it is just like any observation, you know teachers undergo observation by their administrators and this is exactly the same, but it's having a professional in your room that is observing what you do. I think that holds you a little more accountable and makes you, you know, kind of want to do your best for that person, so I think that probably makes me, I don't know, maybe focus, I don't know if it changes what I do whole lot.

Henry felt the coach's classroom observations did not change his routines. Instead, it made him take responsibility for his teaching. This is important because the PF project goals want teachers to adopt the PF pedagogy and curriculum and continue implementing them. Therefore, having teachers take responsibility and be accountable to what they are doing, is critical.

Third, classroom observation helps participants to reflect on teaching. Knowing they are going to be observed, teachers become more aware of how and what is being taught. Jason thought that classroom observation helped him to reflect about his teaching practice. He stated:

The biggest thing is made, forces me to reflect and think about how I am going to do it. If I am not going to be watched, if I am not going to get feedback, probably won't think twice about it at all, I am just going to this. But if I am going to be watched, it makes me reflect before I have to do the lesson.

Classroom observation made Jason more aware of how he was teaching the PF lessons.

Fourth, classroom observation enhances the accuracy of the feedback -- free of misunderstandings. Coach as an expert to observe teacher's teaching firsthand and provide feedback based on the teaching, was viewed as desirable and necessary to improve practice. The $\mathrm{C} 1$ participants often pinpointed specific aspects of their teaching and asked for feedback from coaches. For instance, Jason and Lydia wanted to improve 
their questioning skills. They asked their coach to pay attention to the questions they asked.

In addition to requesting feedback based on her teaching practice, Sarah was also concerned about the misunderstandings created when she attempted to discuss classroom events that her mentor had not observed. Sarah (C2 participant) mentioned the absence of classroom observation is a problem of the mentoring design. Without observing the actual classroom teaching, Sarah spent a great amount of time helping her mentor to understand the classroom setting and what was happening in the classroom. It was difficult for Andy to understand Sarah’s classroom setting, situation or student interactions without being present to observe Sarah teach. Discussions of her teaching were fraught with misunderstandings. These misunderstandings frustrated both sides and limited the level of discussion

Becky and Sarah (C2 participants) suggested to Andy and Ryan (mentors) that they use Wimba to observe their teaching. This arrangement was enacted by Becky and Ryan and they agreed it was superior to the original online design (without classroom visit). According to Ryan, the observation through Wimba went well and provided them a context for future discussions.

Overall, in the coaching design, C1 participants received F2F classroom observations from coaches; but C2 participants did not. All of the C1 and C2 participants agreed that classroom observations are important and benefit their practice. All the participants viewed the observations positively because 1) having an expert in the classroom helped teachers identify teaching problems, 2) making participants focus and take responsibility 
on practice, 3) helping participants to reflect on teaching, and 4) accuracy of the feedback and free of misunderstandings. 
Assertion \#3: Effective coaching or mentoring includes time for meaningful postobservation discussions.

Learning is a type of social interaction (Vygotsky, 1978). Thus, for learning to occur, mentors and teachers must have opportunities to interact. The design of postobservation discussion and mentoring discussion offer a platform for coaches, mentors and teachers to interact. The post-observation and reflection discussion provided opportunity for coaches and participants to discuss the observations and problems, share ideas and clarify the observations. Thus, the benefit of the post-observation discussion and reflection is to 1) make time for coaches/mentors to provide meaningful feedback, 2) support teachers to think deeply about their teaching.

First, through post-observation discussion, teachers can have in-depth discussion and receive feedback from coaches. C1 coaches and participants had limited time after the classroom observation. Due to the hectic schedules of schools, during the school day, teachers rarely have more than 5 minutes for discussions about practice. Five minutes is too brief for thoughtful or reflective thinking to occur. The quality of these postobservation discussions suffered because teachers seldom have time to stop and reflect during the school day. For instance, Henry and Jason complained that they did not receive enough feedback from John (their coach). Lydia and Andy solved this problem by holding online post-observation discussions. Lydia preferred F2F, but due to time and space and financial constraints, they agreed to hold online discussions. The quality of these post-observation discussions improved due to this change of venue. Sharing observation notes supported the clear communication and promoted deeper reflection by the participants. For instance, recall that Lydia was able to see Andy’s observation notes and how that helped her clarify Andy’s questions. 
Second, with teachers knowing they will have a post-observation discussion with their mentor, motivated them to think deeply about their teaching. In the case of mentoring, participants had the opportunity to self-reflect on their teaching practice. However, participants who had busy schedules found it hard to find time to reflect. With help from the guided Teacher Reflection Forms (Appendix I), participants were able to reflect more deeply about teaching and the implementation of PF curriculum. Nancy found the reflection discussion was helpful in terms of improving her teaching practice. She stated:

I think the most effective part is having the ability to have time set aside where he can help guide your reflection and give you feedback and ideas on how to improve your teaching and the curriculum. I found it very helpful. As I said, when you're busy, it is good to have a reason to stop and reflect because I think that improves your practice and do stuff and reflect; and have a mentor to give you a set time when you gonna meet, of course you stop and reflect. Also, it is great to have a resource to help you know perspectives to give you additional ideas and additional ways to teach things to talk through how are you doing things and how to evaluate students really help you see ways to improve.

The C2 participants found that online meetings are a flexible way to mentor, particularly for teachers and mentors who are widely separated, geographically. Online mentoring eliminates time and location constraints so that teachers and mentors can meet, freely. In addition, mentoring also provides opportunities for teachers to reflect on the teaching and implementation because teachers can step out from teaching and reflect and identify problems. C2 teachers felt that the self-evaluation process associated with the reflection form is important in terms of improving teaching and learning.

In summary, without in-depth discussion of the observations, coaching is making a little impact on the instruction or the improvement of the implementation. The $\mathrm{C} 1$ participants were dis-satisfied with the brief, superficial, and low quality post-observation 
discussions (due to time constraints in participants' or coach's schedules). On the other hand, C2 participants had more reflection discussion than C1 group, but the quality of their discussion was limited by the absence of classroom observations.

C1 and C2 participants recognized the need for and benefits from reflecting on teaching practice. The post-observation and reflection discussion is critical to promote indepth reflection and support implementation of the PF curriculum. Mentoring design eliminates time and location constraints, thus, teachers and mentors met more frequently to discuss and reflect. Also, the self-reflection form and mentoring gave teachers some time to reflect on their classroom and what was going on in their teaching and find ways to improve. 


\section{Summary of Findings}

In this section, I present the summary of finding for each research questions.

The first research question: How do the types of questions asked F2F by teachers compare to the types of questions asked online by teachers? focused on the types of questions asked in F2F and online venues. I thought that online and F2F venues have different attributes. Therefore, I expected that the questions asked by teachers would have some similarities and differences. Based on the data, most of the participants were able to receive support on questions associated with implementation of the PF curriculum. C1 and C2 participants asked similar questions except in two areas - questioning strategies and sequencing. For the mentor to provide support for these two types of questions, coaches need to be present in the classroom to observer teaching practice. Additionally, the types of questions discussed by participants or mentors depend on the context and venue. In the F2F venue, the coach can observe the verbal and non-verbal interactions between the teachers and the students. Thus, because the coach is able to observe the classroom, he/she has more information about the teaching practice and provides better support because it is based on observation. However, the mentor relied on the teacher's Self-Reflection Form and the teachers' verbal descriptions to understand the situation or issues. Thus, the support that mentors can provide is limited by the observations of the teacher.

The second question (How do coaches, mentors, and teachers utilize different venues to support their responsibilities?) addresses the way that coaches, mentors, and participants utilize different venues to support their responsibilities. I have learned that F2F and online venues have limitations in terms of providing support for mentoring. 
Therefore, I expected coaches, mentors and participants would use venues in different ways to support learning and mentoring. For C1, coaches used F2F classroom observation to see verbal and non-verbal interactions in the classroom. C1 participants used F2F to share challenges and success with coaches and other PLC teachers. For C2, mentors and participants had frequent and in-depth online discussion with mentors and other PLC teachers.

However, strict adherence to one or the other designs had some setbacks that decreased the effectiveness of coaching and mentoring. Because participants had no opportunity to have in-depth post-observation discussion with coaches and received little feedback, Lydia (C1) and her coach moved F2F post-observation discussion to online. This decision, paired with continued F2F classroom observations, enhanced the quality of coaching. On the other hand, C1 participants had difficulty meeting with PLC teachers due to time, space, and distance constraints. Post-observation discussions were cut short and PLC meetings were canceled. As a result, participants collaborated less frequently with others. In response, Lydia and her PLC teachers replaced F2F PLC meetings with online PLC meetings. This decision was an attempt to remove travel time as a constraint. However, due to technical difficulties with Wimba, this avenue was unsuccessful.

For both C1 and C2 participants, F2F classroom observation is an essential component for coaching and mentoring. C2 participants asked for classroom observation because they desired meaningful post-observation feedback. To overcome the limitation, Becky and Ryan used Wimba for classroom observation. Although online observation still had limitations, such as limited viewing of the classroom, Ryan was able to have more in-depth discussions with Becky. 
Online PLC meeting was effective in terms of sharing lesson plans and discussing teaching practice. However, participants cannot develop material for teaching the lesson or demonstration. Hence, three participants planned both F2F and online PLC meetings. Choice of venue was based on the perceived purpose of the meeting. If the meeting was aimed at developing instructional materials, they met F2F and if the purpose of the meeting was to share reflections about teaching specific lessons, they met online.

In summary, the findings from this study present a new perspective on using F2F, online and hybrid venues to support mentoring and teacher learning and teaching. Participants in this study changed the coaching or mentoring process to support their learning and teaching needs. This also suggests that using a single venue is a limited approach to mentoring and the support of teaching and learning. Hybrid PD Design uses time more efficiently and provides more frequent opportunities for learning and mentoring than a single venue platform.

\section{Discussion}

The purpose of this section is to understand how the findings help to fill gaps in the literature, support the current literature, and provide an alternative perspective. In this section, I revisit the literature review in Chapter Two, the case profiles in Chapter Four, and the assertions.

As stated in chapter two, researchers have limited understanding of hybrid professional development. For example, we do not understand how F2F and online support one another, we do not know what level of F2F and online combination can best support PD, we do not know what kinds of support teachers feel comfortable getting online, and we don’t know whether that kind of support is possible to provide. Moreover, 
the research of hybrid PD adopted hybrid-learning design for designing a PD. However, hybrid learning designs are developed for learners in general and are not specifically developed for teacher.

\section{Hybrid design and social constructivism}

In social constructivism, learning occurs through discourse and social interaction with more experienced others (Vygotsky, 1978). The idea of zone of proximal development (ZPD) explains the process of how individual becomes more experienced through the support of a context or peers (Vygotsky, 1978). Vygotsky (1978) defines that "the distance between the actual developmental level as determined by independent problem solving and the level of potential development as determined through problem solving under adult guidance, or in collaboration with more capable peers “(p. 86). From a social constructivist perspective, intersubjectivity is the mutual understanding that people share through meaningful interaction and communication (Gauvain, 2001; Woo \& Reeves, 2007). Mentoring is a type of social interaction that "creates intersubjectivity among the participants, thus transmitting meaning, values, affect, motivation, and indeed the planes of consciousness of mentors and entire cultures” (Gallimore, John-Steiner \& Tharp, 1992).

As stated in the assertion one and two, classroom observation and reflection discussion are essential components for an effective PD design. The two components aim at providing social interaction, discourse, and collaboration opportunities for mentors and mentees. Thus, hybrid PD create a environment for ZPD to develop and mentors and mentees share the intersubjectivity. 


\section{Hybrid Design supports effective mentoring}

Coaching and mentoring designs in this study had some setbacks that decrease the effectiveness of mentoring. Therefore, coaches, mentors and participants hybridized venues to meet their needs. Their decisions to go against the communication design of the PF PD project suggests that hybrid design offers improved support of mentoring. Initially, the professional developers expressed concerns when they became aware that participants were using alternative means to address their needs (not adhering to 'experimental' conditions); this was exacerbated by the original external evaluation team, whose perspective was to avoid "contamination"- even to the extent of expecting teachers in different cohorts at the same school not to interact with one another. The naturalistic paradigm under which the research team operated, however, did not preclude this phenomena, and allowing teachers and mentors/coaches to seek out their own solutions to what they identified as barriers to working together effectively was consistent with this paradigm. This finding also matches other research suggests the essential elements for effective mentoring. The effective mentoring should help mentee to be able to reflect (Rudney \& Guillaume, 2003). For example, C1 and C2 participants all addressed that coaching and mentoring provided opportunity for teachers to step out from teaching to reflect and think deeply on the teaching. Second, receiving feedback (Donnelly \& McSweeney, 2011) is critical for improving teaching. All of the participants in this study valued the feedback form coaches and mentors. For example, Jason mentioned that if he did not have feedback from Andy, he will not be reflecting on his teaching. Third, the PLC design provides an environment for sharing experience/understanding (Jaffe, Moir, Swanson, \& Wheeler, 2006). For example, Becky, as a leader in her PLC group, shared 
her experience with Becky and helped Nancy to improve her teaching. Fourth, mentoring made teachers to take accountability and responsibility of learning (Rikard \& Banville, 2010; Abell, Dillon, Hopkins, Mclnerey, \& O'Brien, 1995). Henry and Jason mentioned that coaching helped develop a greater sense of responsibility for learning.

Hybrid design is an integration of online and F2F, it delivers a more flexible learning environment and enhances interaction and collaboration opportunities for teachers. This finding aligns with the work by Vaughan and Garrison (2006) which suggested the hybrid learning approach "will create a flexible and accessible environment for faculty to engage in sustained critical reflection and discourse about their teaching practice” (p. 150). Most importantly, hybrid design increases the collegiately because teachers can meet freely in either environment, depending on their learning needs.

An effective PD design should meet participants’ learning needs, have skilled facilitators or moderators, connect with teachers’ practice, create a learning community, and develop mechanisms for reflection (Loucks-Horsley, Love, Stiles, Mundry, and Hewson, 2003). In this study, F2F and online designs cannot meet the requirements of effective PD. It is the hybrid design that supports each components of effective PD. Moreover, teaching is a social activity that can also be very isolating (National Academy of Sciences, 2007). On-going support is critical for effective professional development programs. Lack of on-going support and opportunities to interact often cause the failure of teacher professional development.

This study also provides an alternative view on teachers' ability to use technology for their learning. Researches have focused on teachers' comfort with technology as a possible barrier to their participation and learning in online and hybrid PD (Sujo de 
Montes \& Gonzales, 2000; Al-Senaidi, Lin, \& Poirot, 2009). In this study, participants did not demonstrate reluctance to use technology for learning. Instead, participants were observed to seek out and/or embrace certain technologies in light of their efficacy in serving different purposes related to their professional development need. This study fills the gaps in the research literature. First, in this study provides insight of how PD participants utilize F2F, online, and hybrid environments for learning. For instance, Lydia and Andy hybridized coaching process so that Andy can observe the teaching and Lydia can have reflection discussion with Andy. Second, this study provides better understanding on how a hybrid environment supports PD, learning and improve teaching. For instance, hybrid provides more flexibility to schedule PLC meetings dependent on the purpose of the PLC meeting.

Regardless which delivery model was used for mentoring, they all need to provide teacher an opportunity to step back from being in the moment of teaching and reflect on practice and forces them to make this a part of their learning. It is easy to adopt hybrid but might be difficult to implement it in the right way. PD designers and teacher educators need to consider the objectives of the PD to utilize hybrid design.

\section{Implication}

In this section I provide the implications of my research. In the following, I explain implications for professional development designer/ organizer.

One of the implications for this study relates to the design of hybrid professional development. The finding of this study suggests that using hybrid design supports learning and teaching. The study would inform a professional development designer and 
teacher educator as they design hybrid PD programs. Thus, based on my assertions, I propose a hybrid PD design (mixed venue).

In this section, I proposed a hybrid mentoring design for statewide PD. This hybrid design is appropriate for statewide PD and extends beyond single building PD or any PD where travel is involved. However, this hybrid design may not be applicable for national or international PD projects because travel time and distance are too great, making it impossible to offer classroom observation to participants.

In the perfect world, with unlimited funding and time, F2F would be the best venue for mentoring. However, we do not live in a perfect world. F2F communication loses its efficacy as the geographic area of the professional development project increases.

Online communication becomes useful and necessary when participants are beyond walking distance and where time and travel become issues for F2F meetings. The attributes of online communication offer flexibility without transportation expenses. Because participants are able to communicate from the comfort and privacy of an empty classroom, office, or one’s home, they encourage reflection and collaboration.

Based on the findings and my assertions, I propose a hybrid design for individual mentoring and PLC meetings. The ideal mentoring design for hybrid PD should include (1) online pre-observation report, (2) F2F classroom observation, (3) online postobservation discussion/reflection (Figure 7) and (4) F2F and online PLC design. 


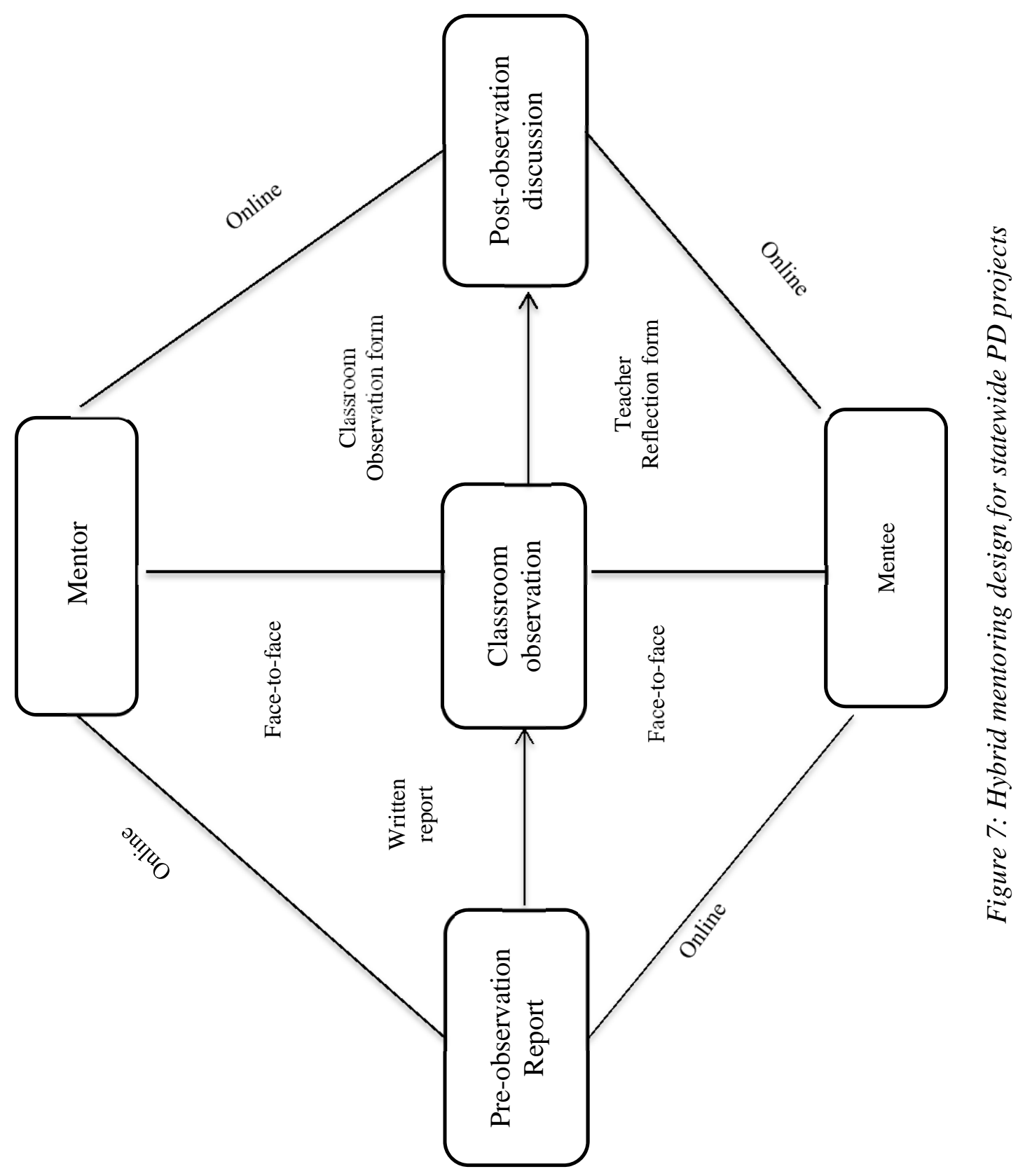


First, the pre-observation report should be conducted online. The purpose of the pre-observation report is to deliver information from the mentee to the mentor about a specific lesson. The report consists of a written description of the lesson plan and a written description of concerns or problems about the lesson. While this could lead to questions asked by the mentor, the intent of the message is to help the mentor prepare for what is going to be observed in the classroom. This information could be delivered F2F (in the 5 minutes preceding class), but online provides a more efficient use of time.

As stated in the chapter four, C1 participants and coaches did not have time for F2F pre-observation discussions. Thus, coaches would not know the nature of the lesson he/she was to observe, and the coach would not know if the teacher had concerns about the lesson. Therefore, in the hybrid design, the teacher sends an online pre-observation report to the mentor that includes: the lesson plan, teaching progress and concerns/problems about the lesson, one day in advance of the lesson.

Second, in keeping with Assertion \#1 coaches should conduct F2F classroom observations. The purpose of the classroom observation is to provide an opportunity for mentors to observe an actual implementation of a specific lesson. It also provides an opportunity for the mentor to observe verbal and non-verbal interactions in the classroom. The verbal communication, such as students' responses to questions and teacher's questioning strategy, and the non-verbal communication, such as body language, provide an unfiltered experience of the classroom culture. According to Kellogg and Lawson (1993), 82\% of teachers' communication in the classroom is nonverbal. The classroom observation could be delivered online, but this filtered experience cannot capture all of the non-verbal communication. 
These observations are essential if mentors are to understand what is happening in the teacher's classroom and assist the teacher with concerns or solving problems. As we learned from Henry and Jason, teachers are more accountable and focus on the teaching practice more carefully when they are observed. Teachers who are more thoughtful make it possible for mentors and mentees to have more in-depth post-observation discussions. In addition to observing teaching, notes taken by the mentor serve to document what is happening in the classroom and can help guide the post-observation discussion. Mentors will share observation notes with mentee and discuss those notes in the postobservation discussion. Mentee will complete a self-reflection form and share with mentors. The Teacher Reflection Form should include 1) details of a lesson s/he has implemented by responding to several self-evaluation questions and 2) additional comments about the lesson.

While F2F classroom observation provides the richest experience of the classroom environment, online classroom observation can be used if the PD project has limited funding to support travel expenses. The time and expense of driving to a school for F2F observation may be too high. However, as stated above, online classroom observation does not provide an equal level of communication to F2F observations. Recall that Ryan and Becky used Wimba for classroom observation. Ryan’s experience with online classroom observation was positive, but the observation provided a limited experience of the classroom culture.

Third, mentors and mentees should have online post-observation discussions. These discussions provide opportunities for teachers to reflect on teaching and the implementation of the PF curriculum. The power of the post-observation discussion 
rests on the common understandings that result from the shared experience of the classroom culture. The online discussion works better than the F2F meeting because mentor and mentee can have more time for discussion, more privacy, and more flexibility in terms of scheduling the discussion. The obvious problem with the F2F meeting is the difficulty of meeting immediately after the observation, or the difficulty of waiting until the teacher is free in that same day for a later meeting with the mentor. These meetings are always rushed and the teacher is pre-occupied with minute-to-minute demands of the job. An answer to this problem is that the mentor could return another day to conduct a F2F discussion. The problem with this is the added expense of travel. Delaying the postobservation discussion provides time for the teacher to reflect and to write and share his/her reflections with the mentor.

In the coaching design, Henry and Jason complained about too little time for the post- observation discussion with their coaches. Brief post-observation discussions did not provide enough time for Henry and Jason to discuss their teaching actions at a meaningful level. Without the post-observation discussion, participants do not reflect. The benefits of reflecting on the lesson with an expert observer are lost. The quality of the lesson, enthusiasm, concerns, reactions, and plans are not discussed. The teacher has lost an opportunity to improve. Too little time also limits interactions between teachers and coaches resulting in decreased rapport.

In order to have a reflective post-observation discussion, mentees need to complete a self-reflection form and send it to mentors before the discussion. In addition, mentors should share his/her observation notes with mentees. By doing so, mentors and mentees can understand and appreciate each other's perspectives. As stated in chapter 
four, most of the C2 participants appreciated the opportunity to reflect. Knowing that they would discuss a lesson with his/her mentor motivated the teachers to think more deeply about the lesson.

Fourth, mentors and mentees can meet online or F2F for PLC meetings, depending on the location of the teachers and the reason for the meeting. The purpose of the PLC design is to develop a collaborative learning environment, develop a greater sense of responsibility for learning, and to reduce the isolation of teachers. When the PLC agenda focused on completing PF requirements, online meetings provide an adequate venue for communication. This kind of information is easy to share online. When the PLC agenda shifted to developing activities, assessments, and labs, the online venue was limiting and the team moved away from the online to a F2F venue. An added benefit was teachers got to see one another's classrooms and the actual equipment they used. This did not happen with the online venue. If the purpose of the PD is for teachers to work together to produce activities or equipment, then the best venue for communication is F2F. If the purpose is to communicate information, then online will do.

The hybrid PLC design (Figure 8) can enhance the flexibility and provide more collaborative opportunities for teachers. The hybrid PLC design addresses the limitations mentioned in chapter four. The limitations are: (1) for C1 PLC, participants were not able to meet F2F due to distance and schedule and (2) for C2 PLC, participants need hands-on opportunities to develop material for teaching. The choice of venue is dependent on the purpose of the PLC meeting. Online PLC supports a limited type of communication.

First, meeting F2F, for some PLCs, works, but for others the F2F requires too much time. As stated in C1 case, Henry was able to meet with two PLC teachers because 
they worked at the same building. However, he was not able to meet with his PLC member who taught in different school district. Lydia had similar problems in participating PLC meeting. In order to solve this problem, Lydia and her PLC tried Wimba to replace F2F PLC meeting. If mentees are geographically apart, online PLC is a solution as long as the purpose of the meeting fits the scope of the venue.

Second, participants cannot physically develop material for teaching online. In the C2 PLC meeting, Sarah, Andria and Ted taught in the same district and two of them (Andria and Ted) taught in the same building. When they began PF all their PLC meetings were held online. While this venue supported discussions about similar experiences of teaching physics, it did not support the development of lessons or the production of demonstrations or laboratory activities. For this reason, they decided to hold some meetings F2F. While this change worked well for teachers in the same school building or district, when greater distances are involved, meeting F2F may not be possible. A possible solution is to allow time for PLC meetings during the quarterly follow-up meetings. 


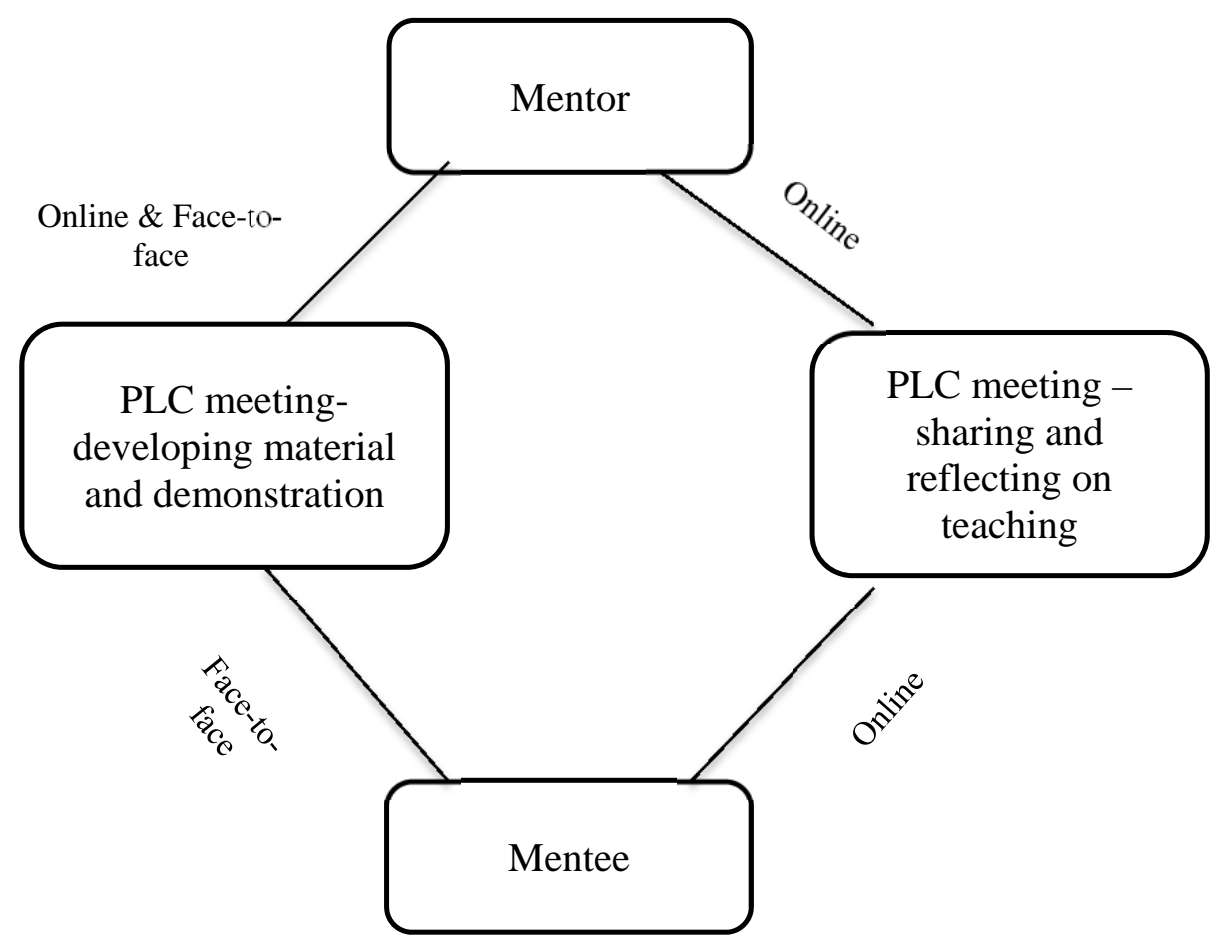

Figure 8. Hybrid PLC design

\section{Summary of Hybrid Design}

The hybrid mentoring and PLC design should include: (1) online pre-observation report, (2) F2F classroom observation and online as a second option (3) online postobservation discussion with Observation Form and the Teacher Reflection Form, and (4) online PLC meeting with periodic F2F meetings.

In the study, teachers from C1 and C2 had concerns with the online and F2F venues. For instance, C1 participants had only short periods of time to discuss the classroom observations before and after the lesson and the feedback they received was limited. C2 participants were not observed by a mentor. Instead, teachers reflected on a lesson, shared that written reflection with a mentor, and held an online discussion about 
the reflection. However, discussion proved difficult because of the absence of a shared experience to serve as the basis of the discussion. For mentors, questions they can ask in the mentoring sessions were limited. Mentors did not observe the actual implementation of a lesson, thus, they did not have a clear understanding of what was happening in the classroom. Also, teachers filtered the lesson experience. They did not share every concern or problem encountered in the lesson. Therefore, these issues were not topics of the discussion. Thus, being able to use hybrid for different purposes provides teachers more learning opportunities. Although teachers may need to spend time driving to different locations or find extra time to meet on Wimba.

Andy provided a window into working within both F2F and online environments. Andy was in the unique position of serving as mentor and coach in F2F and online environments. Andy and Lydia agreed that a F2F classroom observation plus an online post-observation discussion support deep thinking and reflection about teaching. Through the discussion, mentees self-evaluate the implementation and identify problems. For example, Lydia was allowed to read Andy’s observation notes, and she completed the Teacher Reflection Form prior to her online discussion with Andy. The writing and sharing of these notes improved the quality of the post-observation discussion. However, in his coaching experience, it was difficult to find a time to discuss with teachers immediately after the observation. The coaching was not as effective as mentoring because it required more time for traveling to schools. Sometime, it took eight hours to complete a single observation. On the other hand, mentoring is less time consuming and is more flexible. But, without the classroom observation, mentors found it difficult to understand the problems and provide appropriate support. 
As mentioned earlier, C2 participants, Sarah, Andria, and Ted, utilized both F2F and online venues for PLC meetings. In the online PLC meetings, they discuss the success and challenges they encountered in the teaching practice such as lesson progress, student learning, and instructional strategies. When meeting F2F, they shared their classroom setting and material organization, and most importantly, the three teachers developed materials for teaching the PF curriculum. By meeting on both venues, Sarah, Andria and Ted had more flexibility to schedule PLC meetings and accomplish meeting goals.

For hybrid PLC design, travel expense and time are the big concerns for F2F meetings. Online can provide a collaborative opportunity for PLC meetings. However, using the hybrid design depends on what the PLC intends to share. If it is about sharing teaching practice, then online appears to work. If it is about creating instructional materials, then meeting online is a problem.

Meeting on F2F and online brings different benefits and limitations. Thus, in order to provide collaborative PLC learning, the hybrid PLC should include a required F2F PLC meeting for their quarterly meetings on campus. This would not get them into each other's classrooms, but they could design activities together.

Hybrid as the combination of F2F and online communication is the best solution for coaching and mentoring. It overcomes the limitations of coaching and mentoring. Evidence from the data suggests that hybrid design provides the flexibility and opportunities to optimize high quality professional development.

In summary, hybrid design has three major benefits in terms of supporting PD. First, the financial aspect is important for designing a PD project. Many PD projects 
receive less funding for state or federal government. F2F meeting requires more resources and financial support. It is costly to provide mentoring support such as classroom observation or F2F meetings for teachers. Online meeting could save money and eliminate time and location constraint. But it limits mentors’ ability to support mentees, especially when it is poorly applied. Thus, the hybrid design can decrease expenditures for renting meeting spaces, teacher time, substitute pay, and travel expenses.

Second, hybrid designs improve the quality of teaching and learning. As stated in the chapter four, participants who used hybrid environments had opportunities to have indepth online discussions with coaches and increased collaborative opportunities with other teachers. This is also enhancing mentors' ability to use Cognitive Coaching (Costa \& Garmston, 2002) strategy to support mentoring. For example, by changing postobservation discussion to online venue, Andy was able to use CC strategy to help Lydia to identify teaching problems and reflect her teaching practice. This also suggests that hybrid design provides more flexibility for learning than F2F or online venue alone.

Third, the hybrid design also enhances mentor's ability to support mentees. In this study, coaches and mentors were also influenced by venues in terms of supporting teachers. For instance, if mentors observed classroom practices they could provide more support and help the teacher improve practices such as student engagement. Thus, the quality of coaching and mentoring can be improved if mentors or coaches had flexibility to use hybrid environment. 


\section{Conclusion}

The overarching research question of this study is: what affordances do F2F and online venues provide to a professional development project in terms of mentoring? Based on the findings from this study, coaches, mentors and teachers benefited from using F2F or online venues. From teachers' perspective, the benefits of coaching includes: 1) having an expert in the classroom helps the teacher identify teaching problems, 2) helping participants to reflect on teaching, and 3) accuracy of the feedback and free of misunderstandings. F2F venues give coach an opportunity to be present in the classroom and observe verbal and nonverbal interactions in the classroom. On the other hand, eliminates time and location constraints so that teacher and mentors can meet freely. "Reforming science education requires substantive changes in how science is taught, which requires equally substantive change in professional development practices at all levels” (National Research Council, 1996, p. 5). The effective teacher professional development is expected to provide opportunities for in-depth learning and improving teaching. Face to face and online venues all have advantages and disadvantages in promoting learning and teaching. The combinations of these two venues maximize the potentials of effective PD. However, it is easy to adopt technology but difficult to implement it in the right way. PD designers or project leaders need to have sound understanding of technology and how to use that technology. By doing so, the PD is more effective and could satisfy the needs for improving quality teaching and learning.

This study provides an alternative view of the flexibility of learning environments. The original design of coaching (F2F) and mentoring (online) did not include hybrid communication. But in the study, teachers managed their way to utilize F2F and online 
venues to accomplish their needs. This also means that neither F2F nor online can satisfy teachers in terms of their learning and teaching needs - it takes both. This is different than other studies where participants were assigned to use hybrid as learning or communication methods. The teacher-participants in our study made their own decisions to hybridized. When considering learning needs or improving teaching practice, teachers did not always pick the easiest or most convenient venue. However, the teachers changed the stiff choice of venue in order to better meet their needs for improved mentoring. The all-online venue was corrupted to include some F2F and the all-F2F was corrupted to include some online. When the teachers and their coach/mentors felt a need to change venue, they did so.

The single drawback to teachers deciding, in all cases, which venue to use is the budget. When PD designers ask for financial support, they must provide a budget to the funding agency. Leaving venue decisions to the mentors and teachers involves different levels of funding. A better way to proceed is for the PD designers to know the kinds of communication that will be involved and to choose the best venue, accordingly. This study is a first step in that direction.

\section{Future research}

Based on findings and discussion of this study, I suggest the following recommendations for future research in the fields of mentoring and hybrid professional development design.

First, in this study, a mentor and a teacher used webcam for classroom observation. However, it was not as effective as F2F classroom observation. A limitation of online classroom observation is the stationary webcam located in the classroom. The 
ability of a mentor to understand the context of the classroom is limited by what the camera can experience. What benefit would result if the mentor had robotic control of the camera's position, zoom lens, and audio during classroom observations? To what extent would drone surveillance interfere with instruction?

Second, in this study, participants, mentors and coaches hybridized venues to support learning, teaching, and mentoring. The findings suggest that hybrid design is better than F2F and online venue. Additionally, this study provided some evidence on the types of questions that can be asked F2F and online. However, that data is limited. It is important to know the affordance of venues in supporting learning and teaching. Future research should seek to find out if there are other benefits associated with venue that this study did not detect. However, more research should be done in the future. This is important because it can help PD designer or educator to better utilize hybrid environment to support learning and improve teaching.

Third, the mentors and coaches in this study were trained under a Cognitive Coaching framework (Costa \& Garmston, 2002). The ability of a mentor to provide support is limited by his/her expertise. Does an expert teacher or an expert observer or an expert at Cognitive Coaching make the best mentor? What type of expertise makes the best mentor?

Moreover, research of hybrid mentoring in teacher education is limited. More research is needed on what pedagogical challenges are best addressed through hybrid mentoring and how mentor and mentee construct knowledge through hybrid mentoring. 


\section{REFERENCES}

Abell, S. K., Dillon, D. R., Hopkins, C. J., McInerney, W. D., \& O’Brien, D. G. (1995). Somebody to count on: Mentor/intern relationships in a beginning teacher internship program. Teacher and Teacher Education, 11(2), 173-188.

Al-Senaidi, S., Lin, L. \& Poirot, J. (2009). Barriers to adopting technology for teaching and learning in Oman. Computers \& Education, 53(3), 575-590.

Ball, D. L., Hill, H. C., \& Bass, H. (2005). Knowing mathematics for teaching: Who knows mathematics well enough to teach third grade, and how can we decide? American Educator, 29(1), 14-22.

Barnett, M., Keating, T., Harwood, W., \& Saam, J. (2002). Using Emerging Technologies to Help Bridge the Gap Between University Theory and Classroom Practice: Challenges and Successes. School Science \& Mathematics, 102(6), 299314.

Bonk, C. J., \& Graham, C. R. (2006). The handbook of blended learning: Global perspectives, local designs. San Francisco, CA: Pfeiffer Publishing.

Brady, L., \& Schuck, S. (2005). Online mentoring for the induction of beginning teachers. Journal of Educational Enquiry, 6(1), 65-75.

Brown, A. L., Ash, D., Rutherford, M., Nakagawa, K., Gordon A., \&.Campione, J.C. (1993). Distributed expertise in the classroom. In G. Salomon, (Ed.), Distributed Cognitions, New York: Cambridge University Press. 
Campbell, M., W. Gibson, A. Hall, D. Richards, and P. Callery. 2008. Online vs. face-toFace discussion in a Web-based research methods course for postgraduate nursing students: A quasi-experimental study. International Journal of Nursing Studies 45 (5), 750-59.

Carroll, J. (1981). Faculty self evaluation. In J. Millman (Ed.), Handbook of teacher evaluation (pp. 180-200). Beverly Hills, CA: Sage.

Cole, M., \& Styron, R. A. (2006). Traditional or online methods of professional development: A comparative study of K-12 teacher preferences. Journal of Research for Educational Leaders, 3(2), 24-38.

Costa, A., \& Garmston, R. (2002). Cognitive coaching: A foundation for Renaissance schools (2nd ed.). Norwood, MA: Christopher-Gordon.

Donnelly, R. and McSweeney, F. 2011. From humble beginnings: Evolving mentoring within professional development for academic staff. Professional Development in Education, 37, 259-274.

DuBois, K. A., Aruguete, M. S., \& Muhlig, J. (2004). Are Computer-Assisted Teaching Methods Effective? Teaching of Psychology, 31(1), 65-68.

Denzin, N. K., \& Lincoln, Y. S. (Eds.). (2000). Handbook of qualitative research $\left(2^{\text {nd }}\right.$ ed.).Thousand Oaks, CA: Sage Publications.

Diem, R. A. (2000). Can it make a difference? Technology and the social studies. Theory and Research in Social Education, 28, 493-501.

Driscoll, M. (2002). Blended learning: Let’s get beyond the hype. E-Learning, 3(3), 5456. 
Fredrickson, S. (1999). Behind the curve in teacher preparation. How schools and colleges of education should be preparing their pre-service teachers to using instructional technology. Journal of Information Technology Impact, 1 (2), 73- 80.

Fusco, J., Gehlbach, H., \& Schlager, M. (2000). Assessing the impact of a large-scale online teacher professional development community. In J. Willis (Ed.), Proceedings of the 11th International Conference of the Society for Information Technology and Teacher Education (pp. 2178-2183). Charlottesville, VA: Association for the Advancement of Computing in Education.

Gauvain, M. (2001). The social context of cognitive development. New York: Guilford.

Gallimore, R., John-Steiner, V. P., \& Tharp, R. G. (1992). The developmental and psychologicalfoundations ofmentoring. New York: Institute for Urban and Minority Education, Teachers College, Columbia University.

Guskey, T. (1999). Apply time with wisdom. Journal of Staff Development, 20(2), 10-14.

Gutke, H. J., \& Albion, P. R. (2008). Exploring the Worth of Online Communities and e-Mentoring Programs for Beginning Teachers. In K. McFerrin, R. Weber, R. Carlsen \& D. A. Willis (Eds.), Proceedings of the 19th International Conference of the Society for Information Technology \& Teacher Education (pp. 1416-1423). Las Vegas, NV.

Habanek, D. (2006). Issues: Blending online and face-to-face teaching. Academic Exchange Quarterly,10(3), 71-74.

Hawkes, M., and A. Romiszowski (2001). Examining the Reflective Outcomes of Asynchronous Computer-Mediated Communication on Inservice Teacher Development. Journal of Technology and Teacher Education, 9(2), 285-308 
Hatch, J. A. (2002). Doing qualitative research in education settings. New York: State University of New York Press.

Huling, L., \& Resta, V. (2001). Teacher mentoring as professional development. (ERIC Digest ED460125). From http://www.ericdigests.org/2002-3/mentoring.htm Habanek, D. (2006). Issues: Blending online and face-to-face teaching. Academic Exchange Quarterly,10(3), 71-74.

Israel, M., Pattison, J., Moshirnia, A. \& Newton, J. (2008). Supporting Novice Special Educators through E-Mentoring. In K. McFerrin et al. (Eds.), Proceedings of Society for Information Technology \& Teacher Education International Conference 2008 (pp. 5101-5108). Chesapeake, VA: AACE.

Jaffe, R., Moir, E., Swanson, E. \& Wheeler, G. (2006). E-mentoring for student success: Online mentoring and professional development for new science teachers. In C.Dede (Ed.), Online professional development for teachers: Emerging models and methods, pp. 89-116. Cambridge, MA: Harvard Education Press.

Jaworski, B. (1994). Investigating mathematics teaching: A constructivist inquiry. London: Falmer Press.

Kellogg, P., \& Lawson, B. (1993). Envoy: your personal guide to classroom management. Battle Ground: Michael Grinder.

King, K. P., \& Dunham, M. D. (2005). Finding Our Way: Better Understanding the Needs and Motivations of Teachers in Online Learning. International Journal of Instructional Technology and Distance Learning, 2(1), 11-26

Kirk, J. J., \& Olinger, J. (2003). From traditional to virtual mentoring. Washington, DC: ERIC. 
Kottak, C. P. (2007). Window on Humanity: A Concise Introduction to Anthropology. Boston: McGraw- Hill Higher Education.

Knowles, M. (1975). Self-directed learning: A guide for learners and teachers. Chicago, IL: Follet.

Lee, D. (2003).New Technologies in the Politics Classroom: Using Internet Classrooms to Support Teaching and Learning. Politics, 23(1), 66-73.

Levin, J., \& Waugh, M. (1998). Teaching teleapprenticeships: Electronic network-based educational frameworks for improving teacher education. Interactive Learning Environments, 6 (1-2), 39-58.

Lincoln, Y. S., \& Guba, E. G. (1985). Naturalistic inquiry. Beverly Hills, CA: Sage.

Liu, W., Carr, R., \& Strobel, J. (2009). Extending teacher professional development through an online learning community: A case study. Journal of Educational Technology Development and Exchange, 2(1), 99-112.

Loucks-Horsley, S., Stiles, S., \& Hewson, P. (1996). Principles of effective professional development for mathematics and science education: A synthesis of standards. NISE Brief, I (1).

Loucks-Horsley, S., Hewson, P.W., Love, N., \& Stiles, K.E. (1998). Designing professional development for teachers of science and mathematics education. Thousand Oaks, CA.: Corwin.

Loucks-Horsley, S., Love, N., Stiles, K.E., Mundry, S., \& Hewson, P.W. (2003). Designing professional development for teachers of science and mathematics education (2nd ed.). Thousand Oaks, CA.: Corwin. 
McAllister, N.C., \& McAllister, D.F. (1996). Providing education electronically to nontraditional sites: New delivery to a new audience. Proceedings of the 14th Annual Int'l Conference on Marshaling New Technological Forces: Building a Corporate, Academic, and User-Oriented Triangle, 187-193.

National Academy of Sciences (2007). Enhancing professional development for teachers: Potential uses of information technology. Washington, DC: The National Academies Press.

National Research Council. (1996). National Science Education Standards. Washington, DC: The National Academies Press.

National Science Teachers Association (NSTA) (2006). NSTA Position Statement: Professional Development in Science Education. http://www.nsta.org/about/positions/profdev.aspx

Ocker, R., \& Yaverbaum, G. (1999). Asynchronous computer-mediated communication versus face-to-face collaboration: Results on student learning, quality, and satisfaction. Group Decision and Negotiation, 8, 427-440.

Office of Technology Assessment (1995). Teachers and technology: Making the connection. U.S. Congress, Government Printing Office, Washington, DC.

Olson, S., \& Loucks-Horsley, S. (2000). Inquiry and the national science education standards: A guide for teaching and learning. Washington, District Columbia: National Academy Press.

Osguthorpe, R. T. \& Graham, C. R. (2003). Blended learning environments: definitions And directions. Quarterly Review of Distance Education, 4(3), 227-233. 
Patton, M. Q. (2002). Qualitative research \& evaluation methods. Thousand Oaks, CA: Sage Publications.

Rikard, G.L., \& Banville, D. (2010). Effective Mentoring: Critical to the Professional Development of First Year Physical Educators. Journal of Teaching in Physical Education, (29), 245-261.

Rodes, P., Knapczyk, D., Chapman, C., \& Chung, H. (2000). Involving teachers in web-based professional development. T H E Journal, 27(10), 94-99.

Roddy, M. (1999). Using the Internet to Unite Student Teaching and Teacher Education. Journal of Technology and Teacher Education, 7(3), 257-67.

Rogoff, B. (1990). Apprenticeship in thinking: cognitive development in social context. New York, NY: Oxford University Press.

Rudney, G. L., \& Guillaume, A. M. (2003). Maximum mentoring: An action guide for teacher trainers and cooperating teachers. Thousand Oaks, CA, USA: Corwin.

Schneider, R. (2008). Mentoring new mentors: Learning to mentor preservice teachers. Journal of Science Teacher Education, 19, 113-116.

Shulman L. S. (1986). Those who understand: Knowledge growth in teaching. Educational Researcher, 15(2), 4-14

Shulman, L. S. (1987). Knowledge and teaching: Foundations of the new reform. Harvard Educational Review, 57(1), 1-22.

Single, P. B. and Muller, C. B. (1999). Electronic mentoring: Issues to advance research and practice. Atlanta, GA: International Mentoring Association Annual Meeting Proceedings (pp. 234-250). 
Spradley, J.P. (1980). Doing participant observation. In J.P. Spradley, Participant observation (pp. 53-84). New York: Holt, Reinehart \& Winston.

Stake, R. E. (1998) Case Studies. IN Denzin, N. K. \& Lincoln, Y. S. (Eds.) Strategies of Qualitative Inquiry. Thousand Oaks, SAGE Publications.

Stephens, A., \& Hartmann, C. (2004). A successful professional development project's failure to promote online discussion about teaching mathematics with technology. Journal of Technology and Teacher Education, 12, 57-73.

Sujo de Montes L.E.\&Gonzales C.L. (2000) Been there, done that: reaching teachers through distance education. Journal of Technology and Teacher Education, 8, 351371.

Sun, P.C., Tsai, R.J., Finger, G., Chen, Y.Y., \& Yeh, D. (2008). What drives a successful elearning? An empirical investigation of the critical factors influencing learner satisfaction. Computers \& Education, 50(4), 1183-1202.

Treacy, B., Kleiman, G. \& Peterson, K. (2002). Successful online professional development. Learning \& Leading with Technology, 30(1), 42-47.

Trilling, B., \& Fadel, C. (2009). 21st century skills: Learning for life in our times. New York, NY: John Wiley.

Utts, J., Sommer, B., Acredolo, C., Maher, M.W and Matthews, H.M. (2003). A study comparing traditional and hybrid Internet-based instruction in introductory statistics classes. Journal of Statistics Education, 11. Retrieved from http://www.amstat.org/publications/jse/v11n3/utts.html

Vrasidas, C., \& Zembylas, M. (2004). Online professional development lessons from the field. Education and Training, 46, 326-334. 
Vygotsky, L. S. (1978). Mind in society. Cambridge, MA: Harvard University Press.

Woo, Y., \& Reeves, T. (2007). Meaningful interaction in web-based learning: A social constructivist interpretation. The Internet and Higher Education, 10(1), 15-25.

Yin, R. K. (2002). Case study research: Design and methods ( $3^{\text {rd }}$ ed.). Thousand Oaks: Sage Publications.

Zang, D., \& Nunamaker, J. F. (2003). Powering e-learning in the new millennium: An overview of elearning and enabling technology. Information Systems Frontiers, 5 (2), 207. 
Appendix A

Data Collection Matrix

Research Question: What affordances do face-to-face and online venues provide to a professional development project in terms of mentoring?

\begin{tabular}{|c|c|c|c|c|c|c|}
\hline Sub-Questions & $\begin{array}{l}\text { Teacher } \\
\text { Interviews }\end{array}$ & $\begin{array}{l}\text { Coach } \\
\text { \&Mentor } \\
\text { Interviews }\end{array}$ & $\begin{array}{l}\text { Field } \\
\text { Notes }\end{array}$ & $\begin{array}{c}\text { Classroom } \\
\text { Visit/Wim } \\
\text { ba }\end{array}$ & Artifacts & $\begin{array}{l}\text { Coach } \\
\text { \&Mentor } \\
\text { Monthly } \\
\text { Log }\end{array}$ \\
\hline $\begin{array}{l}\text { 1. How do the types of } \\
\text { questions asked face-to- } \\
\text { face by teachers compare } \\
\text { to the types of questions } \\
\text { asked online by } \\
\text { teachers? }\end{array}$ & & & & & & \\
\hline $\begin{array}{l}\text { a) What types of questions are } \\
\text { asked in f2f meetings? }\end{array}$ & $\mathrm{P}$ & & & S & & S \\
\hline $\begin{array}{l}\text { b) What types of questions are } \\
\text { asked in online meetings? }\end{array}$ & $P$ & & & S & $P$ & S \\
\hline
\end{tabular}

14. How do coaches, mentors, and

participants utilize different venues to support their responsibilities?

a) In what ways did C1 participants and coaches change the face-to-face design of their coaching S $\mathrm{P}$ S S sessions to better accommodate their needs?

b) In what ways did the C2 participants and mentors change the online design of their mentoring sessions to S $\mathrm{P}$ S $\mathrm{P}$ better accommodate their needs? 


\author{
Appendix B \\ Informed consent form
}

\author{
MU Science Education Center \\ Ya-Wen Cheng, Doctoral Candidate
}

321-O Townsend Hall

Columbia, MO 65211-2400

VOICE (573) 529-046

University of Missouri
Email: yck86@mizzou.edu

You are invited to participate in a research study that examines two different venues (hybrid and online) as part of professional development program. The purpose of the study is to investigate the benefits and barriers of using two different venues to support teacher professional development. The results of this study will inform the design of teacher professional development programs and enhance teacher learning.

\section{INFORMATION}

Your participation in this study is voluntary; you may choose not to participate and there will be no penalty or consequence. If you decide to participate, you may withdraw from the study at any time without penalty. Your participation in the A TIME for Physics First program will not be affected by your decision to participate or to decline participation in the study.

\section{PARTICIPATION}

If you agree to participate in the study, you are agreeing to be interviewed by the researcher. In addition, you are agreeing to let the researchers use interview data, audio data, and all the information you post on the online components of the A TIME for Physics First program as part of the research study. In reporting the research findings, your name and school will be removed and replaced with pseudonyms.

\section{BENEFITS}

Your participation in this research study will improve the design of A TIME for Physics First program and provide insight into the factors influencing coaching and mentoring as part of professional development program. The information gained in this study may be published and be useful to science teacher educators and professional developers at other universities and colleges. 


\section{CONFIDENTIALITY}

Your responses to interview questions will be kept strictly confidential. If you agree to let us record your interview, the recordings will be kept on file for four years. In all reporting of the data and analyses, the researchers will remove your name and replace it with a pseudonym. You may choose to end your participation at any time during the study, and your data will be destroyed.

\section{RISKS}

This project does not involve any risks greater than those encountered in everyday life. If you feel any discomfort with a question you are asked during the interview, you may choose not to respond.

This project has been reviewed and approved by the University of Missouri Human Subject Review Board. The Board believes the research procedures adequately safeguard your privacy, welfare, civil liberties, and rights. For additional information regarding human subject participation in this research, please contact the University of MissouriColumbia IRB officer at (573) 882-9585.

If you have questions or concerns about this evaluation project or our interviews, you may contact the principal investigator or investigator.

\section{Investigator}

Ya-Wen Cheng, Doctoral student of Science Education

321 O Townsend Hall

University of Missouri

Columbia, Missouri 65211

(573) 529-0466

yck86@mizzou.edu

\section{CONSENT}

I have read and understand the above information, and I have received a copy of this form. I understand that my participation is voluntary and that I may withdraw at any time without consequences to me. By signing below, I indicate my willingness to participate in the study. 


\section{Appendix C}

Coach Interview

Participant's Name:

Interviewer:

Date:

Please describe a typical coaching session in online and face-to-face venue.

Have you had any difficulties in the coaching process? If so, what are the difficulties?

\section{Face-to-Face}

What are the purposes of visiting your PLC members?

How did you schedule a visit?

Describe what happened in your most recent observation

- What problems did you observe?

- How do you help the teachers with these problems?

- What questions did the teacher ask?

- Were these questions difficult to answer? Easy to answer?

- What kind of help do most teachers seek from you during F2F meetings?

- How often do you contact any given teacher between face-to-face contacts?

- What kinds of things get talked about during these contacts?

- What type of feedback did you provide to your PLC members following the visits?

\section{$\underline{\text { Online }}$}

What are the purposes of these online meetings?

How did you schedule an online meeting?

- What problems did you observe?

- How do you help the teachers with these problems?

- What questions did the teacher ask?

- Were these questions difficult to answer? Easy to answer?

- What kind of help do most teachers seek from you during online meetings?

- How often do you contact any given teacher between online contacts? 
- What kinds of things get talked about during these contacts?

- What type of feedback did you provide to your PLC members following the online meeting?

\section{Venues}

What support did you provide the most in face-to-face coaching environment?

In what ways does face-to-face environment support coaching?

What is the least effective part of face-to-face coaching?

What support did you provide the most in online coaching environment?

In what ways does online environment support coaching?

What is the least effective part of online coaching?

How do you utilize hybrid environment to support coaching?

What is the most effective part of hybrid coaching?

What is the least effective part of hybrid coaching?

In this project, you are trained under cognitive coaching model. Thus, please describe how you use cognitive coaching in face-to-face and online environment.

Please give an example of how you used cognitive coaching model in F2F and online session with a participant. 
Appendix D

Mentor Interview

Participant's Name:

Interviewer:

Date:

Please describe a typical coaching session in online venue.

Have you had any difficulties in the coaching process? If so, what are the difficulties?

\section{Online}

What are the purposes of these online meetings?

How did you schedule an online meeting?

- What problems did you observe?

- How do you help the teachers with these problems?

- What questions did the teacher ask?

- Were these questions difficult to answer? Easy to answer?

- What kind of help do most teachers seek from you during online meetings?

- How often do you contact any given teacher between online contacts?

- What kinds of things get talked about during these contacts?

- What type of feedback did you provide to your PLC members following the online meeting?

\section{Venues}

What are the things you did the most in online mentoring environment?

In what ways does online environment support mentoring?

How do you utilize online environment to support mentoring?

What is the most effective part of online mentoring?

What is the least effective part of online mentoring?

In this project, you are trained under cognitive coaching model. Thus, please describe how you use cognitive coaching in online environment.

Please give an example of how you used cognitive coaching model in an online session with a participant. 
Appendix E

Teacher Interview (Cohort 1)

Participant's Name:

Interviewer:

Date:

Please describe your experience in receiving coaching form Physics First program

Have you had any difficulties in the coaching process? If so, what are the difficulties?

How do you plan a visit with your coach?

What happened during coach’s visit to your classroom?

Why did you focus on the things you mentioned above during the classroom visits?

In what ways does coaching support your professional growth?

How do you use face-to-face coaching to support your learning and teaching?

How do you use online coaching to support your learning and teaching?

How does coaching impact your learning and your students' learning?

What are the things you and your coach did the most in face-to-face meeting?

What are the things you and your coach did the most in online meeting?

What is the most effective part of coaching?

What is the least effective part of coaching?

What would you change to make it more effective and fit your teaching and learning needs?

What are the things that you enjoy or benefit the most in participating Physics Frist Program?

How does it impact your teaching practice? 
What is the most difficult part of the Physics First Program?

How does your coach help you address these difficulties? 
Appendix F

Teacher Interview (Cohort 2)

Participant's Name:

Interviewer:

Date:

Please describe your experience in receiving mentoring form Physics First program

Have you had any difficulties in the mentoring process? If so, what are the difficulties?

In what ways does mentoring support your professional growth?

How do you use mentoring to support your learning and teaching?

How does mentoring impact your learning and your students’ learning?

What are the things you and your mentor did the most in online meeting?

What is the most effective part of mentoring?

What is the least effective part of mentoring?

What would you change to make it more effective and fit your teaching and learning needs?

What are the things that you enjoy or benefit the most in participating Physics Frist Program?

How does it impact your teaching practice?

What is the most difficult part of the Physics First Program?

How does your coach help you address these difficulties? 
Appendix G

Observation Protocol

\section{Event information}

Date:

Number of participants:

Name of the participants:

Length of the meeting:

Where does the event take place?

\section{Activities Observed}

What are the focuses of the conversation?

_ Instructional Strategies

_ Content knowledge

_ Implementation of Physics First curriculum

_ Leadership role, skills

_ Classroom management

_ Individual Student Concerns

_ Other

General observations about the conversation (interactions, activities, materials)

Outcomes of the conversation

Note 


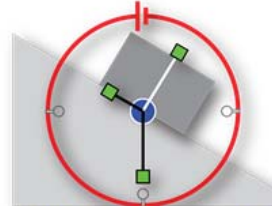

A TIME for PHYSICS FIRST

\section{A TIME FOR PHYSICS FIRST Classroom Observation Form}

\begin{tabular}{|c|c|c|c|c|c|c|c|c|c|c|}
\hline \multicolumn{7}{|c|}{$\begin{array}{l}\text { Mark "E" for extensive, "M" for moderate, or "S" for } \\
\text { slight }\end{array}$} & \multirow{2}{*}{\multicolumn{4}{|c|}{$\begin{array}{l}\text { Use the scale 1-3 to rate the environment } \mathbf{1} \text { - Low (not } \\
\text { conducive to learning); } 3 \text {-High (exceptionally conducive to } \\
\text { learning) }\end{array}$}} \\
\hline \multicolumn{4}{|c|}{$\begin{array}{l}\text { Instructional Delivery } \\
\text { Method Observed (time) }\end{array}$} & \multicolumn{3}{|c|}{$\begin{array}{l}\text { Student } \\
\text { Engagement }\end{array}$} & & & & \\
\hline & $\mathrm{E}$ & $M$ & $\mathrm{~S}$ & $E$ & $M$ & $S$ & \multirow{9}{*}{\multicolumn{4}{|c|}{$\begin{array}{l}\text { Classroom Learning Environment: The Physical climate is: } \\
\square 1 \square 2 \square 3 \text { Classroom Arrangement (eg. conducive to } \\
\text { moving around, gathering equipment, working in groups) } \\
\square 1 \square 2 \square 3 \text { Attractiveness (eg. student work displayed, } \\
\text { lighting,) } \\
\square 1 \square 2 \square 3 \text { Free of external disruptions (eg weather) } \\
\square 1 \square 2 \square 3 \text { Cleanliness (eg. floors, tables, stacks of paper) } \\
\square 1 \square 2 \square 3 \text { Temperature (too cold/hot) } \\
\square 1 \square 2 \square 3 \text { Other } \\
\text { Classroom Learning Environment: The Instructional climate } \\
\text { is: } \\
\square 1 \square 2 \square 3 \text { Student behavior } \\
\square 1 \square 2 \square 3 \text { Student engagement (eg. on or off tasks, } \\
\text { students asking questions) } \\
\square 1 \square 2 \square 3 \text { Lesson organization } \\
\square 1 \square 2 \square 3 \text { Materials prepared } \\
\square 1 \square 2 \square 3 \text { Class tone (eg. respectful, cheerful, tired, } \\
\text { hungry) } \\
\square 1 \square 2 \square 3 \text { Free of Internal disruptions (eg. housekeeping } \\
\text { activities, buddy room, student coming in to take tests) } \\
\square 1 \square 2 \square 3 \text { Other }\end{array}$}} \\
\hline $\begin{array}{l}\text { Class } \\
\text { discussion/ } \\
\text { Guided } \\
\text { discussion }\end{array}$ & $\square$ & $\square$ & $\square$ & $\square$ & $\square$ & $\square$ & & & & \\
\hline $\begin{array}{l}\text { Collaborativ } \\
\text { e learning }\end{array}$ & $\square$ & $\square$ & $\square$ & $\square$ & $\square$ & $\square$ & & & & \\
\hline $\begin{array}{l}\text { Guided } \\
\text { practice }\end{array}$ & $\square$ & $\square$ & $\square$ & $\square$ & $\square$ & $\square$ & & & & \\
\hline $\begin{array}{l}\text { Hands-on } \\
\text { experiments } \\
\text { /laboratory } \\
\text { work }\end{array}$ & $\square$ & $\square$ & $\square$ & $\square$ & $\square$ & $\square$ & & & & \\
\hline Stations & $\square$ & $\square$ & $\square$ & $\square$ & $\square$ & $\square$ & & & & \\
\hline Lecture & $\square$ & $\square$ & $\square$ & $\square$ & $\square$ & $\square$ & & & & \\
\hline $\begin{array}{l}\text { Student } \\
\text { presentation } \\
\text { S (eg. } \\
\text { Power } \\
\text { point) }\end{array}$ & $\square$ & $\square$ & $\square$ & $\square$ & $\square$ & $\square$ & & & & \\
\hline $\begin{array}{l}\text { Question } \\
\text { and answer } \\
\text { (Students) }\end{array}$ & $\square$ & $\square$ & $\square$ & $\square$ & $\square$ & $\square$ & & & & \\
\hline $\begin{array}{l}\text { Seat work } \\
\text { (e.g., } \\
\text { worksheets, } \\
\text { textbook } \\
\text { readings) }\end{array}$ & $\square$ & $\square$ & $\square$ & $\square$ & $\square$ & $\square$ & & & & \\
\hline $\begin{array}{l}\text { Whiteboardi } \\
\text { ng }\end{array}$ & $\square$ & $\square$ & $\square$ & $\square$ & $\square$ & $\square$ & & & & \\
\hline $\begin{array}{l}\text { Socratic } \\
\text { Dialogue }\end{array}$ & $\square$ & $\square$ & $\square$ & $\square$ & $\square$ & $\square$ & & & & \\
\hline $\begin{array}{l}\text { Demonstrati } \\
\text { on }\end{array}$ & $\square$ & $\square$ & $\square$ & $\square$ & $\square$ & $\square$ & & & & \\
\hline $\begin{array}{l}\text { Other (eg. } \\
\text { Notebookin } \\
\text { g) } \\
\text { Specify }\end{array}$ & $\square$ & $\square$ & $\square$ & $\square$ & $\square$ & $\square$ & & & & \\
\hline \multirow{5}{*}{\multicolumn{7}{|c|}{$\begin{array}{l}\text { Did students work in: } \square \text { Whole Class } \\
\square \text { Independent Work } \\
\text { What evidence of modeling was seen? }\end{array}$}} & & & & \\
\hline & & & & & & & DOK Level & DOK Description & Prevailing & $\begin{array}{l}\text { Highest } \\
\text { Reached }\end{array}$ \\
\hline & & & & & & & Level 1 & Recall & $\square$ & $\square$ \\
\hline & & & & & & & Level 2 & Skill/Concept & $\square$ & $\square$ \\
\hline & & & & & & & Level 3 & Strategic Thinking & $\square$ & $\square$ \\
\hline
\end{tabular}




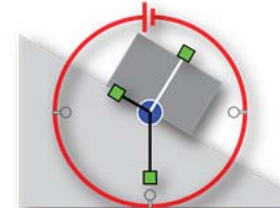

A TIME for PHYSICS FIRST

Appendix $\mathrm{H}$

\title{
A TIME FOR PHYSICS FIRST
} Classroom Observation Form

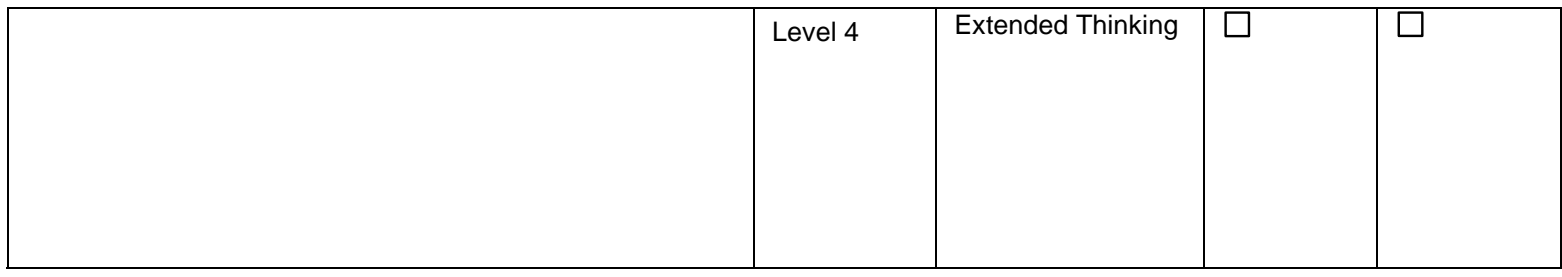
Teacher
Building
Room\#
Course
Date
Time
Grade Level
No. of Students
$\square$ Regular $\square$ Honors
Co-teaching/Class within a class
Special Education self-contained
Coach/Mentor Name
What Physics First unit is being taught?

What lesson is being taught?

Learning Objectives:
Were learning objectives for the lesson clearly identifiable? $\square$ Yes $\square$ No
Did the students appear to understand the learning objective? $\square$ Yes $\square$ No
Was the instructional activity aligned to the learning objective(s)? $\square$ Yes $\square$ No
Were students focused on the learning objectives? $\square$ Yes $\square$ No
Was there closure to the learning objective/lesson? $\square$ Yes $\square$ No

\begin{abstract}
Was differentiated instruction observed? $\square$ Yes $\square$ No
Was the teacher engaged in the

learning activity? $\square$ Yes $\square$ No

Did feedback elicit respectful communication in the classroom? $\square$ Yes $\square$ No Did feedback drive instruction in the classroom? $\square$ Yes $\square$ No

Did the teacher use teacher use technology during class? $\square$ Yes $\square$ No

Did students use technology during classroom? $\square$ Yes $\square$ No

If yes, what was used and how?
\end{abstract}

How much time was lost due to housekeeping activities?

Is the Physics First Curriculum being implemented? $\square$ Yes $\square$ No

Special considerations (e.g. class period is $\mathbf{5 0}$ minutes and lesson is 2 days, fire drill, etc.)

In your opinion, what level of effectiveness was the teaching of the Physics First Curriculum: : $\square 1 \quad \square 2 \quad \square 3 \quad \square 4 \quad \square 5$

(1 being novice; 5 being expert)

Evidence of leadership

\section{Script of Class}


Appendix I

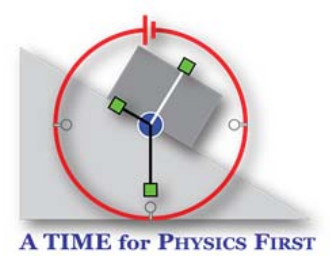

\section{A TIME FOR PHYSICS FIRST Mentee Self Reflection Form}

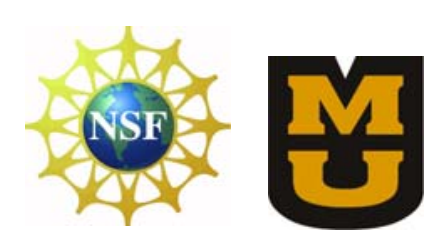

Please save this document titled with your name and date of lesson. Send the document to your mentor as an attachment in an e-mail through Sakai Private Messages (Sakai e-mail) as soon as possible or within 48 hours of the lesson. In the email, please indicate the best time(s) to have a post conversation. Plan to have a post lesson conversation as soon as possible or within 48 hours following the email.

Teacher Building Room\# Course Mentor Name Length of Class

Date $\quad$ Time $\quad$ No. of Students $\quad \square$ Regular $\square$ Honors $\square$ Co-teaching/Class within a class

Special Education self-contained

1. What Physics First unit is being taught?

2. What lesson (title) is being taught?

3. Brief description of lesson

4. Did you make any modifications of the worksheets as they were presented in the program? $\square$ Yes

$\square$ No

If so, explain or attach the document

5. Learning Objectives for the lesson:

6. Did the students appear to understand the learning objective? $\square$ Yes $\square$ No

7. Check the instructional method(s) used?

\begin{tabular}{|l|l|l|l|}
\hline$\square$ & Class discussion/Guided discussion & $\square$ & Collaborative learning \\
\hline$\square$ & Student presentations (eg. Power point) & $\square$ & Guided practice \\
\hline$\square$ & Question and answer (Students) & $\square$ & Hands-on experiments/laboratory work \\
\hline$\square$ & Seat work (e.g., worksheets, textbook readings) & $\square$ & Stations \\
\hline$\square$ & Whiteboarding & $\square$ & Socratic Dialogue \\
\hline$\square$ & Demonstration & $\square$ & Other (eg. Notebooking) Specify \\
\hline
\end{tabular}

8. What evidence(s) of modeling was(were) used?

9. How was technology used in the classroom? $\square$ By the teacher $\square$ By the students $\square$ Not used in this lesson If yes, what was used?

10. How much time was used for housekeeping activities (e.g. roll call, fire drill, etc.)

11. Notes/Comments about the class/lesson

Classroom Learning Environment: The Physical climate is:

(1 being not conducive to learning(low) to 3 being exceptionally conducive to learning (high))

12. $\square 1 \square 2 \square 3$ Classroom Arrangement (conducive to moving around, gathering equipment, working in groups, etc.)

13. $\square 1 \square 2 \square 3$ Attractiveness (student work displayed, lighting, etc.)

14. $\square 1 \square 2 \square 3$ Free of External disruptions (weather, announcements, etc)

15. $\square 1 \square 2 \square 3$ Cleanliness (floors, tables, stacks of paper, etc.)

16. $\square 1 \square 2 \square 3$ Temperature (too cold/hot)

17. $\square 1 \square 2 \square 3$ Other

Classroom Learning Environment: The Instructional climate is:

( 1 being not conducive to learning to 3 being exceptionally conducive to learning)

18. $\square 1 \square 2 \square 3$ Student behavior

19. $\square 1 \square 2 \square 3$ Student engagement (on or off tasks, students asking questions, etc) 
20. $\square 1 \square 2 \square 3$ Lesson organization

21. $\square 1 \square 2 \square 3$ Materials prepared

22. $\square 1 \square 2 \square 3$ Class tone (respectful, cheerful, tired, hungry, etc.)

23. $\square 1 \square 2 \square 3$ Free of Internal disruptions (housekeeping activities, buddy room, student coming in to take tests, etc.)

24. $\square 1 \square 2 \square 3$ Other

Using the rubric below, check the column that you feel best describes the lesson 


\begin{tabular}{|c|c|c|c|c|}
\hline & 1 & 2 & 3 & 4 \\
\hline $\begin{array}{l}\text { 25. High Order } \\
\text { Thinking } \\
\text { (HOT) (what } \\
\text { the teacher is } \\
\text { asking the } \\
\text { students to } \\
\text { do) }\end{array}$ & $\begin{array}{l}\text { Students are } \\
\text { primarily engaged } \\
\text { in lower order } \\
\text { thinking (LOT) } \\
\text { (i.e., they either } \\
\text { receive or recite, } \\
\text { or participate in } \\
\text { routine practice) }\end{array}$ & $\begin{array}{l}\square \text { Students are } \\
\text { primarily engaged in } \\
\text { routine LOT } \\
\text { operations a good } \\
\text { share of the lesson. } \\
\text { There is at least } \\
\text { ONE significant } \\
\text { question or activity } \\
\text { in which some } \\
\text { students perform } \\
\text { some HOT } \\
\text { operations }\end{array}$ & $\begin{array}{l}\text { Students are engaged } \\
\text { in at least one major } \\
\text { activity during the lesson in } \\
\text { which they perform HOT } \\
\text { operations. This activity } \\
\text { occupies a substantial } \\
\text { portion of the lesson and } \\
\text { many student are } \\
\text { performing HOT } \\
\text { operations. }\end{array}$ & $\begin{array}{l}\text { Almost all students, } \\
\text { almost all of the time, are } \\
\text { performing HOT. This } \\
\text { occurs when students } \\
\text { combine facts and ideas in } \\
\text { order to synthesize, } \\
\text { generalize, explain, } \\
\text { hypothesize or arrive at } \\
\text { some conclusion or } \\
\text { interpretation. } \\
\text { Manipulating information } \\
\text { through these processes } \\
\text { allows students to solve } \\
\text { problems and discover } \\
\text { new meanings and } \\
\text { understandings }\end{array}$ \\
\hline $\begin{array}{l}\text { 26. Deep } \\
\text { Knowledge } \\
\text { (what the } \\
\text { students are } \\
\text { actually doing } \\
\text { with the } \\
\text { knowledge) }\end{array}$ & $\begin{array}{l}\text { Knowledge } \\
\text { remains } \\
\text { superficial and } \\
\text { fragmented; the } \\
\text { teacher and } \\
\text { students are } \\
\text { involved in the } \\
\text { coverage of } \\
\text { simple information } \\
\text { which they are to } \\
\text { remember }\end{array}$ & $\begin{array}{l}\text { Knowledge is } \\
\text { treated unevenly } \\
\text { during instruction } \\
\text { (i.e. deep } \\
\text { understanding of } \\
\text { something is } \\
\text { countered by } \\
\text { superficial } \\
\text { understanding of } \\
\text { other ideas). Focus } \\
\text { is not sustained. }\end{array}$ & $\begin{array}{l}\square \text { Knowledge is } \\
\text { relatively deep because } \\
\text { either the teacher or the } \\
\text { students provide } \\
\text { information, arguments or } \\
\text { reasoning that } \\
\text { demonstrate the } \\
\text { complexity of an important } \\
\text { idea. During the lesson } \\
\text { many students do at least } \\
\text { one of the following: } \\
\text { a)Sustain a focus on a } \\
\text { significant topic for a } \\
\text { period of time; or b) } \\
\text { Demonstrate their } \\
\text { understanding of the } \\
\text { problematic nature of } \\
\text { information and/or ideas; } \\
\text { or c) Demonstrate } \\
\text { understanding by arriving } \\
\text { at a reasoned, supported } \\
\text { conclusion; or d) Explain } \\
\text { how they solved a } \\
\text { relatively complex } \\
\text { problem. }\end{array}$ & $\begin{array}{l}\text { Knowledge is very } \\
\text { deep because during the } \\
\text { lesson almost all students } \\
\text { do at least one of the } \\
\text { following: a)Sustain a } \\
\text { focus on a significant topic } \\
\text { for a period of time; or b) } \\
\text { Demonstrate their } \\
\text { understanding of the } \\
\text { problematic nature of } \\
\text { information and/or ideas; } \\
\text { or c) Demonstrate } \\
\text { understanding by arriving } \\
\text { at a reasoned, supported } \\
\text { conclusion; or d) Explain } \\
\text { how they solved a } \\
\text { relatively complex } \\
\text { problem. In general, } \\
\text { students' reasoning, } \\
\text { explanations and } \\
\text { arguments demonstrate } \\
\text { fullness and complexity of } \\
\text { understanding }\end{array}$ \\
\hline
\end{tabular}




\begin{tabular}{|c|c|c|c|c|}
\hline $\begin{array}{l}27 . \\
\text { Substantive } \\
\text { Conversation* }\end{array}$ & $\begin{array}{l}\square \text { Virtually no } \\
\text { features of } \\
\text { substantive } \\
\text { conversation } \\
\text { occur during the } \\
\text { lesson }\end{array}$ & $\begin{array}{l}\text { Feature \#2 } \\
\text { (sharing) and/or \#3 } \\
\text { (coherence) occur } \\
\text { and involve at least } \\
\text { one example of } \\
\text { sustained } \\
\text { conversation (i.e. at } \\
\text { least } 3 \text { consecutive } \\
\text { interchanges) }\end{array}$ & $\begin{array}{l}\square \text { All } 3 \text { features of } \\
\text { substantive conversation } \\
\text { occur, with at least one } \\
\text { example of sustained } \\
\text { conversation, and many } \\
\text { students participate }\end{array}$ & $\begin{array}{l}\square \text { All } 3 \text { features of } \\
\text { substantive conversation } \\
\text { occur, which at least one } \\
\text { example of sustained } \\
\text { conversation, and almost } \\
\text { all students participate }\end{array}$ \\
\hline \multicolumn{5}{|c|}{$\begin{array}{l}\text { *Substantive Conversation has } 3 \text { features } \\
\text { 1. The talk is focused on the subject matter in the discipline and includes higher order thinking, such as making } \\
\text { distinctions, applying ideas, forming generalizations, or raising questions; not just reporting of experiences, facts, } \\
\text { definitions, or procedures } \\
\text { 2. The conversation involves sharing of ideas and is not completely scripted or controlled by one party (as in teacher led } \\
\text { recitation). Sharing is best illustrated when participants explain themselves or ask questions in complete sentences, } \\
\text { and when they respond directly to comments of previous speakers. } \\
\text { 3. The dialogue builds coherently on participants' ideas to promote improved collective understanding of a theme or } \\
\text { topic (which does not necessarily require an explicit summary statement) }\end{array}$} \\
\hline
\end{tabular}

28. Any other comments/questions you would like to share at this time: 


\section{VITA}

Ya-Wen Cheng was born and raised in Taipei, Taiwan. She received a Bachelors of Business Management from Aletheia University in Tamsui, Taiwan. After graduated from college, Ya-Wen attended the English Language Institute of the University of Alabama for six months before moved to Columbia, Missouri. In 2007, Ya-Wen earned a Master’s Degree with an emphasis on Educational technology from University of Missouri- Columbia.

In the last two years of her undergraduate studies, Ya-Wen designed and participated in a computer-based learning system, which focused on elementary science. It was a turning point when she decided to change her major from business to education. Her research focuses on the hybrid (combination of Online and Face-to-face environment) to support teacher education. She also focuses on applying educational technology in science education to help teachers to learn and teach science more effectively.

Ya-Wen earned her doctoral degree in the Fall of 2013 with Dr. Mark J. Volkmann as her dissertation advisor. During her doctoral program, she worked as a graduate research assistant (GRA) for several state-funded and National Science foundation (NSF) funded projects. Ya-Wen’s assistantship included Improving Teacher Quality Grant from Missouri Department of Higher Education and A Time for Physics First, and Quality Elementary Science Teaching from NSF. 